University of Redlands

\title{
Lighting Balloon Suitability Analysis: Singapore Grand Prix Case Study
}

A Major Individual Project submitted in partial satisfaction of the requirements

for the degree of Master of Science in Geographic Information Systems

by

He Shimei (Michelle)

Dr. Douglas M. Flewelling, Ph.D., Committee Chair

Dr Mark Kumler, Ph.D.

December 2010 
Lighting Balloon Suitability Analysis: Singapore Grand Prix Case Study

Copyright (C) 2010

by

He Shimei (Michelle) 
The report of He Shimei (Michelle) is approved.
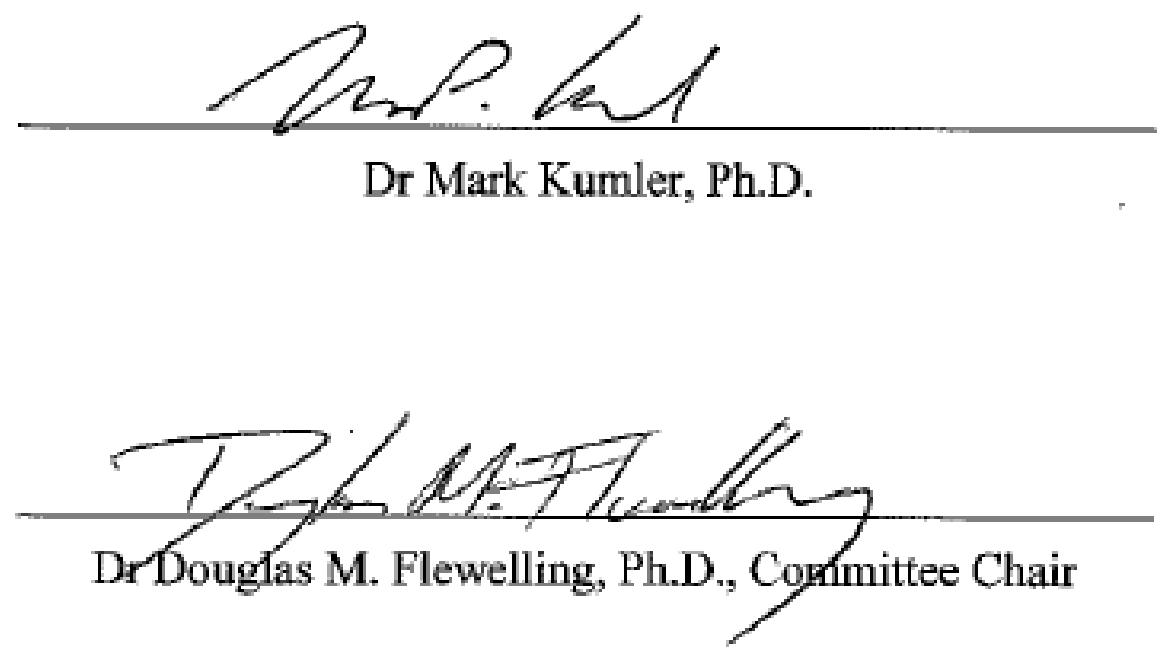

December 2010 



\section{Acknowledgements}

I would like to thank my family for the support they provided during my year here.

Special thanks to Dr Douglas Flewelling for bringing me through the project from the early days when I requested to meet with him even before individual meetings started. His guidance, ideas, and advice helped me tremendously in completing the project. Thanks also to Dr Mark Kumler for his interest in my project and as my second reader. I would also like to thank Partex International for giving me this interesting project to work on. It was really eye opening!

I would also like to thank the people who have assisted me in many ways on my project. Ruben Ortiz for IT support. Mohammed Alsharif for IT support, ideas and the encouraging words. Noor Yusuf for the discussions, teaching me scripting/coding concepts. Nathan Strout for helping so much with the project's scripting. And finally Bjorn Svensson for all the help with the web application.

In addition, I would like to thank Debra Riley for always being there when we needed her. Without fail. As an international student, I would like to specially thank people from IFC and Serene Ong for looking out for me and making this year a memorable one. To all my fellow Cohort members and the MSGIS faculty for making this a great GIS learning experience.

Most importantly, thanks to God for the provision in so many different ways. 



\author{
Abstract \\ Lighting Balloon Suitability Analysis: Singapore Grand Prix Case Study \\ by \\ He Shimei (Michelle)
}

Lighting balloons are increasingly being used to light up night activities, while providing a better aesthetic environment. Partex International in Singapore is the sole distributor of one such lighting balloon brand, called Airstar. Airstar lighting balloons have been used extensively for night related activities like events, construction work, rescue and movie sets. Partex was contracted to light up the circuit park of the Singapore Grand Prix F1 racing event with the Airstar lighting balloons. Due to the extent of coverage and lack of site information, Partex faced difficulty in finding the best positions to place their lighting balloons for optimum coverage. Hence, this project focused on creating GIS analyses tool that provide better placement solution for Partex. The two analyses covered in this project included: (1) a tool to find lighting priority zones based on Partex's requirements; and (2) a tool that calculates total lighting coverage based on lux values of lighting balloons input by user. The end-product of the project included a web application with compiled tools and maps created by the project team for Partex's easy access. 



\section{Table of Contents}

Chapter 1 - Introduction .................................................................................................... 1

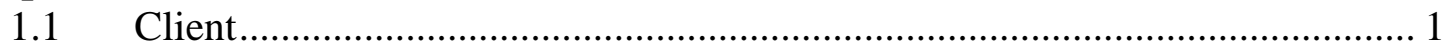

$1.2 \quad$ Problem Statement ............................................................................... 2

$1.3 \quad$ Proposed Solution ................................................................................ 3

1.3.1 Goals and Objectives ............................................................................... 3

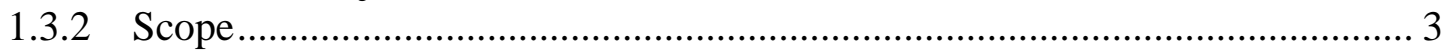

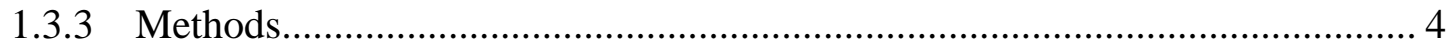

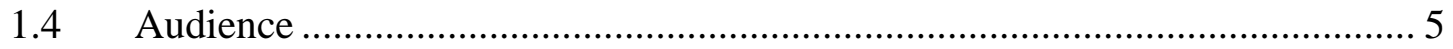

1.5 Overview of the Rest of this Report ............................................................. 5

Chapter 2 - Background and Literature Review ............................................................ 7

$2.1 \quad$ Visibility Analysis .................................................................................. 7

$2.2 \quad$ Lighting Arrangements ............................................................................ 8

2.3 Web Application for GIS .................................................................. 12

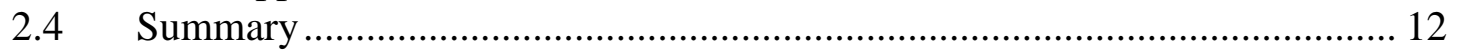

Chapter 3 - Systems Analysis and Design....................................................................... 15

3.1 Problem Statement ................................................................................... 15

3.2 Requirements Analysis ............................................................................. 16

3.2.1 Functional Requirements .......................................................................... 17

3.2.2 Technical Requirements (Non-Functional)...................................................... 18

3.2.3 Operational Requirements (Non-Functional) ……………………………….. 19

3.2.4 Transitional Requirements (Non-Functional) ................................................. 19

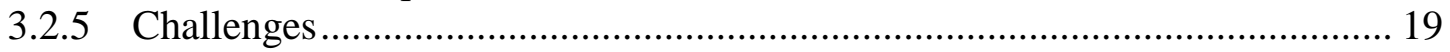

3.3 System Design ....................................................................................... 20

3.3.1 Map Design ............................................................................................... 20

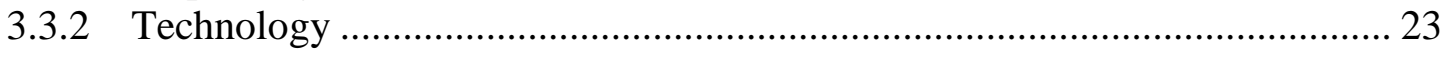

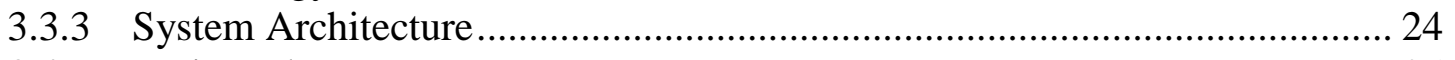

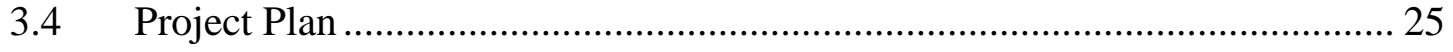

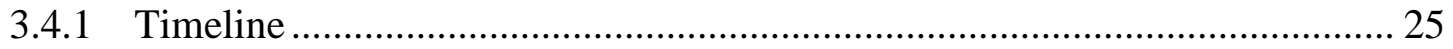

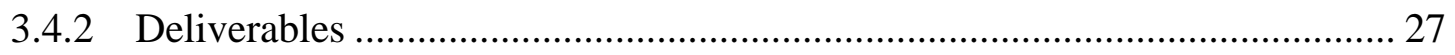

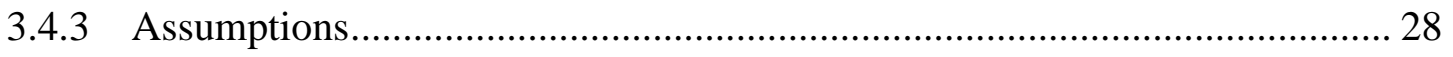

3.4.4 Critical Success Factor......................................................................... 28

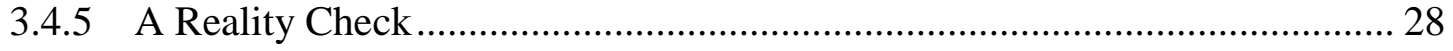

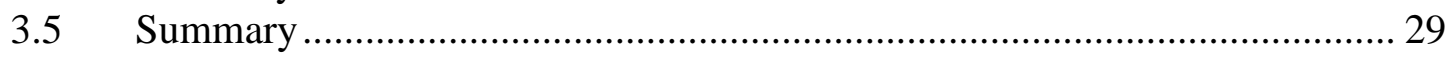

Chapter 4 - Database Design.............................................................................................. 31

$4.1 \quad$ Conceptual Data Model ........................................................................... 31

$4.2 \quad$ Logical Data Model ................................................................................... 33

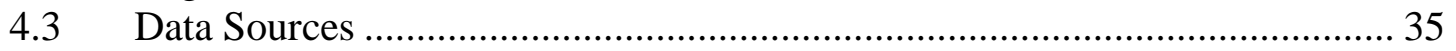

4.4 Data Scrubbing and Loading ………………….......................................... 37

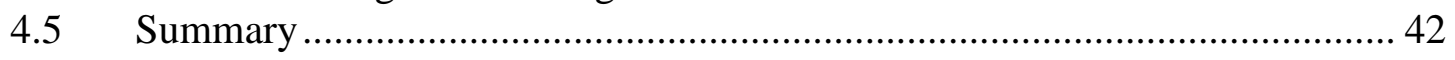

Chapter 5 - Implementation.................................................................................. 43

$5.1 \quad$ First Analysis - Lighting Zones..................................................................... 43

5.1.1 Factors required for analysis........................................................................ 44 


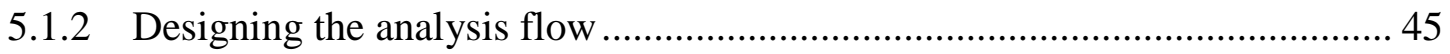

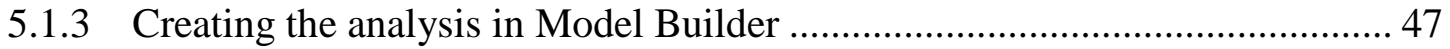

5.1.4 Model Builder to Python Scripting ............................................................... 50

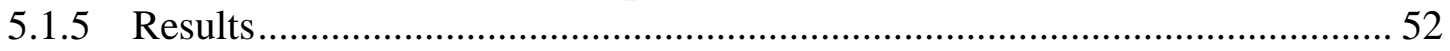

5.2 Second Analysis - Light Coverage ............................................................. 53

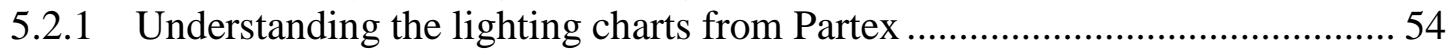

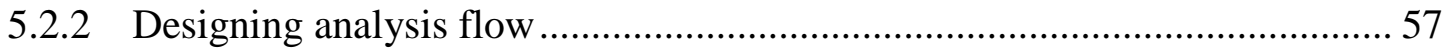

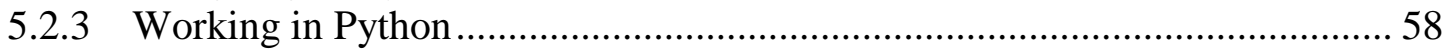

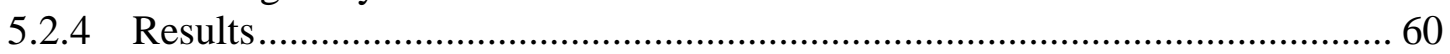

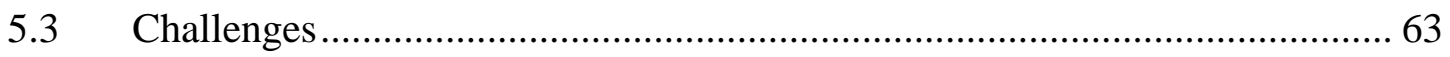

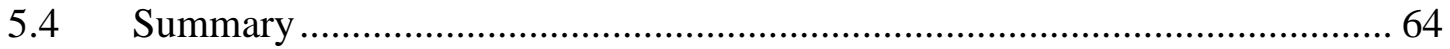

Chapter 6 - Web Application............................................................................................... 65

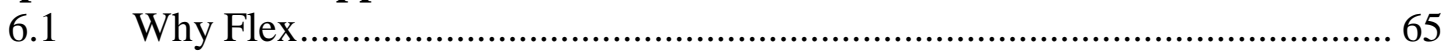

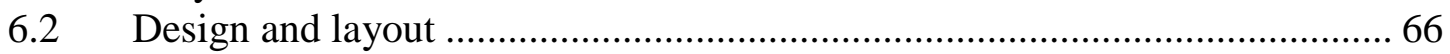

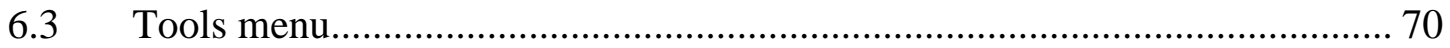

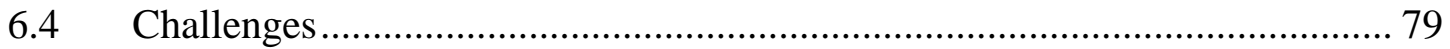

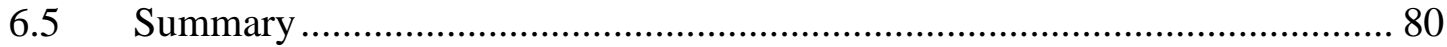

Chapter 7 - Conclusions and Future Work .............................................................81 81

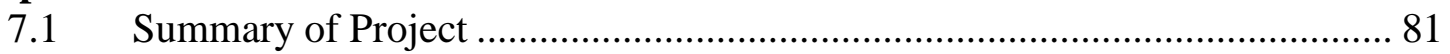

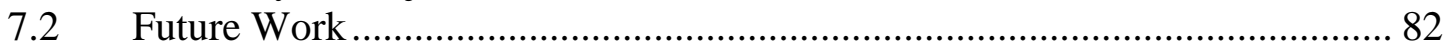

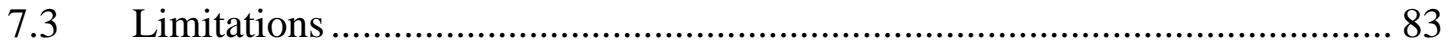

Works Cited 85

Appendix A. Data Scrubbing documentation ........................................................ 87

Appendix B. Lighting Priority Analysis Model Builder ....................................... 94 


\section{Table of Figures}

Figure 1-1: 2010 Singapore Grand Prix Circuit, http://www.singaporegp.sg ........1

Figure 1-2: $\quad$ Logo of client, Partex International and the brand of lighting balloon

that they carry (Airstar Space Lighting) ............................................ 2

Figure 2-1: The coding scheme of variants of the viewshed. ............................... 8

Figure 2-2: $\quad$ One light spacing arrangements method......................................... 9

Figure 2-3: A simple complex $\mathrm{K}$ with a configuration $\mathrm{P}$ of circles in a specific

pattern of tangency.................................................................... 10

Figure 2-4a: Constraints in the packing algorithm where circles cannot be outside the rectangle or overlap each other. .................................................. 10

Figure 2-4b: Interim steps of consideration for placement of circle c3 in order to get optimal result shown in (c)....................................................11

Figure 2-4c: Final packing result using one of the algorithm..............................11

Figure 3-1: $\quad$ Representation of study area at full extent.....................................21

Figure 3-2a: Representation of study area at 1:10,000 ....................................22

Figure 3-2b: Close up on study areas: Padang and Esplanade Zones at 1:3,624.... 22

Figure 3-3: $\quad$ Prototype of the final web application ......................................... 23

Figure 3-4: $\quad$ Recommended system architecture for Partex.................................24

Figure 3-5: Initial timeline for the project plan .............................................26

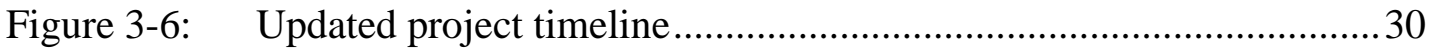

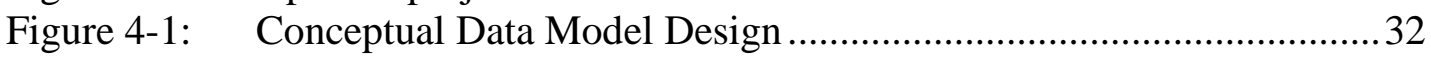

Figure 4-2: $\quad$ Layers from the final geodatabase ............................................... 34

Figure 4-3: The Operational Zones of the SGP Event.......................................35

Figure 4-4a: Photometric Specifications of Sirocco Lighting Balloons..................36

Figure 4-4b: Photometric Specifications of Crystal Lighting Balloons. .................37

Figure 4-5: CAD layer 1 with layers in circuit park not related to racing.............39

Figure 4-6: CAD layer 2 with layers pertaining specifically to racing................. 40

Figure 4-7: $\quad$ CAD layer 3 with permanent features in the circuit park................. 41

Figure 5-1: Workflow for creating first GIS analysis ........................................4 44

Figure 5-2: $\quad$ Analysis flow to find areas where lighting balloons can be placed...47

Figure 5-3a: Analysis flow captured in model builder for each required feature... 48

Figure 5-3b: Entire flow in model builder for all features in analysis...................48

Figure 5-4: $\quad$ Merging buffered layer and combining them into final output..........49

Figure 5-5: $\quad$ Model builder workflow for raster output. .....................................5 50

Figure 5-6: Drop down bar for Partex to select zone of interest..........................51

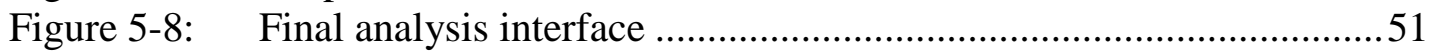

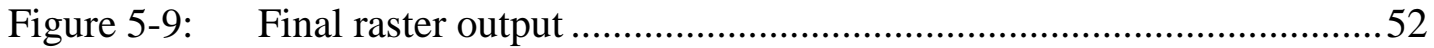

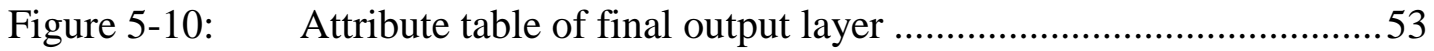

Figure 5-11: $\quad$ Process for building the second analysis. ....................................53

Figure 5-12a: Photometric specifications for the crystal lighting ........................54

Figure 5-12b: Photometric specifications for the crystal lighting ........................55

Figure 5-13: $\quad$ Generic analysis flow for calculating light coverage.....................57

Figure 5-14: $\quad$ Result output for merge, append and union tools. ........................59

Figure 5-15: $\quad$ User interface for calculating lighting coverage analysis..............60 
Figure 5-16: Interactive selection of points using feature set function.............. 61

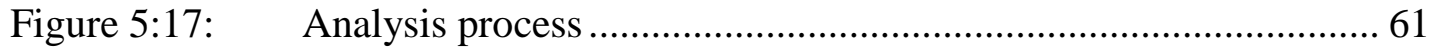

Figure 5-18: $\quad$ Lighting raster with lux value for one lighting balloon point. ...... 62

Figure 5-19: $\quad$ Lighting coverage for all lighting balloons indicated in analysis. 63

Figure 6-1: Header design of the web application .......................................... 66

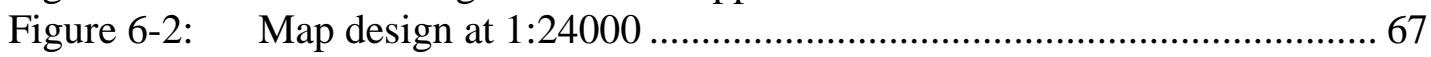

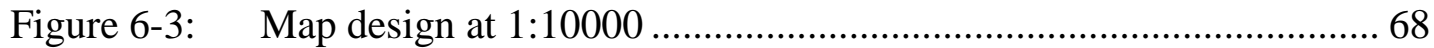

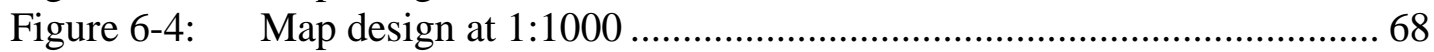

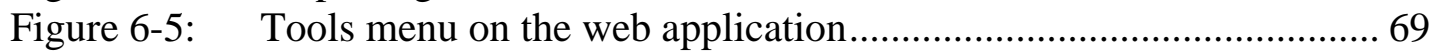

Figure 6-6: $\quad$ Pop up window from one of the tool menu button........................... 69

Figure 6-7: $\quad$ Final web application design and layout ........................................ 70

Figure 6-8: $\quad$ Company profile of Partex International ........................................... 71

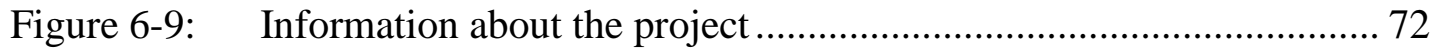

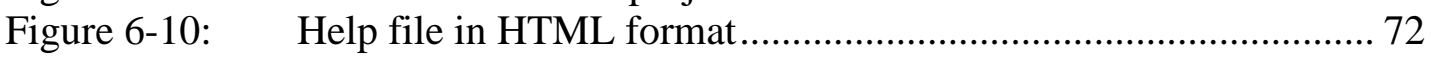

Figure 6-11: $\quad$ Table of Contents Pop Up Window ........................................ 73

Figure 6-12: $\quad$ Map Legend Pop Up Window .................................................... 74

Figure 6-13: $\quad$ Line and Area Measured Using the Measure Tool........................ 74

Figure 6-14: $\quad$ Lighting Zone Analysis Tool Interface ....................................... 75

Figure 6-15: $\quad$ Lighting Zone Tool with the Output Result ................................. 76

Figure 6-16: $\quad$ Lighting Coverage Analysis Tool Interface ................................ 77

Figure 6-17: $\quad$ Geoprocessing for one of the Lighting Balloon Type................... 78

Figure 6-18: $\quad$ Result of the lighting coverage analysis..................................... 79 


\section{List of Tables}

Table 1. Functional and non-functional requirements based on use cases and information product description......................................................... 16

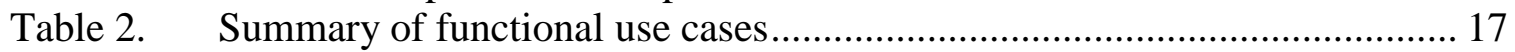

Table 3. Details of functions and steps by workflow ............................................ 18

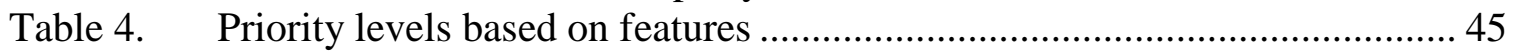

Table 5. Summary of lighting balloons used in analysis ....................................... 55

Table 6. Derived lux values of crystal lighting balloons at various distances ............ 57 



\section{List of Acronyms and Definitions}

$\begin{array}{ll}\text { SGP } & \text { Singapore Grand Prix } \\ \text { GIS } & \text { Geographic Information System } \\ \text { F1 } & \text { Formulae 1 } \\ \text { COTs } & \text { Commercial off The Shelf } \\ \text { DEM } & \text { Digital Elevation Model } \\ \text { DOT } & \text { Department of Transportation } \\ \text { MOT } & \text { Ministry of Transportation } \\ \text { OGC } & \text { Open Geospatial Consortium } \\ \text { ESRI } & \text { Environmental Systems Research Institue } \\ \text { SAFMU } & \text { Singapore Armed Forces Mapping Unit } \\ \text { CAD } & \text { Computer-Aided Design } \\ \text { REST } & \text { Representational State Transfer } \\ \text { API } & \text { Application Programming Interface } \\ \text { UML } & \text { Unified Modeling Language } \\ \text { LAN } & \text { Local area network } \\ \text { HMI } & \text { Hydrargyrum Medium-Arc Iodide } \\ \text { WPF } & \text { Windows Presentation Foundation } \\ \text { OS } & \text { Operating System } \\ \text { VB } & \text { Visual Basic } \\ \text { CSS } & \text { Cascading Style Sheets }\end{array}$





\section{Chapter 1 - Introduction}

In any night-themed event, it is important to ensure adequate lighting at the event site for both visual and aesthetic reasons. Lighted balloons often serve this purpose adequately and event organizers need to know the most suitable location for each lighting balloon to ensure sufficient coverage of key areas within the event site. This project will seek to exploit geographic information systems (GIS) capabilities to assist in planning for the lighting balloon locations. This project's client is Partex International, a company that provides lighting balloons for various night events. This project focused on building a 2and 3- dimensional visual simulation for better lighting balloon placement for the Singapore Grand Prix (SGP). The Grand Prix is a Formula 1 (F1) racing event held yearly across 19 different countries and Singapore is the first and only night race held in the history of F1 racing (See Figure 1-1) (Formula One Adminstration Ltd., 2010).

As this is a less common GIS application, there were no examples of projects or research done at the exact same scale. However, it was possible to draw from concepts

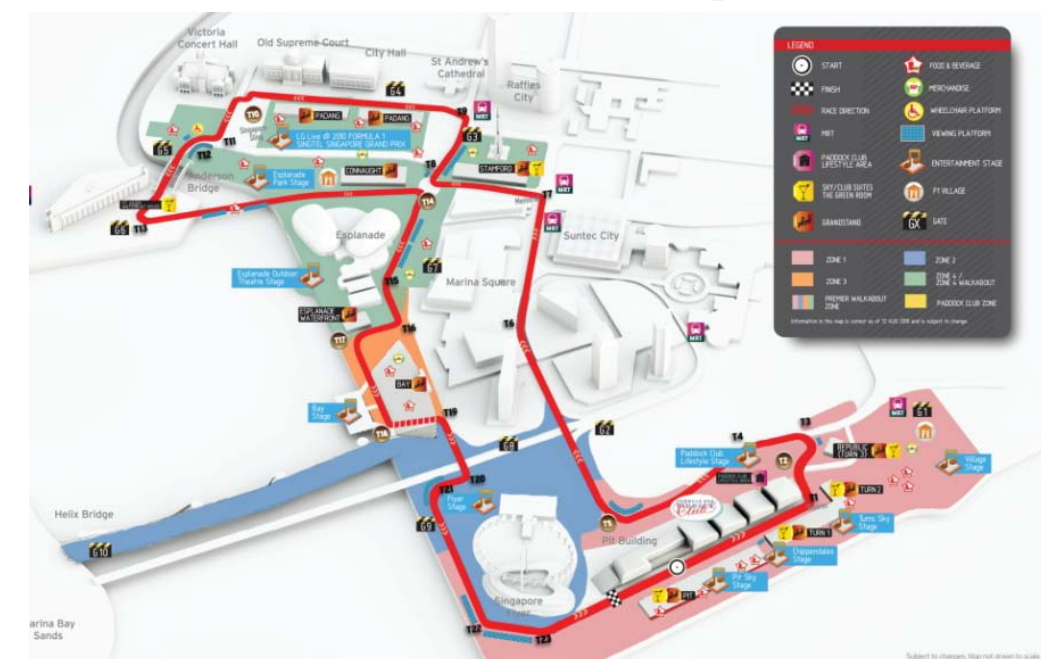

Figure 1-1: 2010 Singapore Grand Prix Circuit, http://www.singaporegp.sg

with related topics to address this project. Among many identified concepts, the closest example was a research on the use of lighting for nighttime construction, albeit done without GIS.

\subsection{Client}

The client is Partex International (Figure 1.2), a Singapore-based balloon lighting company that has the sole distributorship of lighting balloons from Airstar Space Lighting (Figure 1-2). Airstar has been providing lighting services internationally to various settings from movie sets (Titanic) to 911 Ground Zero rescue. Partex International has been a major part of Airstar's venture into the Asian market and projects they have worked on include movie sets, the Hong Kong handover, and the Beijing $50^{\text {th }}$ Anniversary celebration. Partex currently has several major contracts for night events held annually in Singapore, which includes the SGP, the study area of this project. 


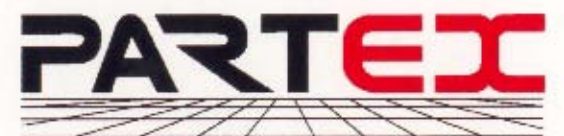

INTERNATIONAL

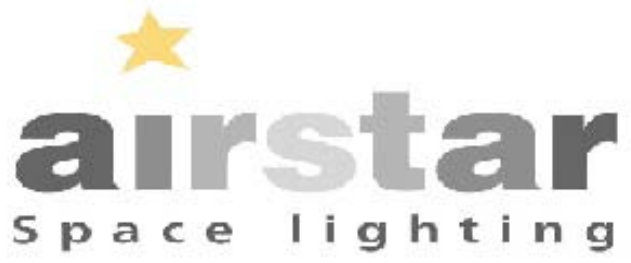

Figure 1-2: Logo of client, Partex International and the brand of lighting balloon that they carry (Airstar Space Lighting)

As part of this project, Partex will be providing vital information about the racetrack, race zones and circuit park using scanned CAD drawings of the event site. They will also provide detailed information and specifications of the lighting balloons used for the event and the location of lighting balloons in past years' event. They will also specify general considerations taken when deciding placement of each lighting balloon.

\subsection{Problem Statement}

For the SGP, Partex needs to provide optimal lighting coverage of the event site for three purposes: safety, aesthetics, and directional signage, which includes first aid, information booths, and gates.

In context of SGP, the event coordinators neither indicate the preference of balloon location nor provide detailed site information to Partex International. Despite several onsite reconnaissance visits prior to the event, the lack of situational awareness on the actual look and feel of the event was a handicap for planning the suitable location for each lighting balloon, and laying of cables. The key factors that influence lighting balloon placement for safety purposes include lighting balloon height, lighting balloon dimensions and wattage, the dark areas within the circuit park, and anticipated high activity areas. Under the requirements for directional signage location, Partex needed to know where would be a good spot to place the lighting balloon around a specific booth. Human estimate is the current method used for balloon placement decisions, without any visualization tools. This method often results in some shadowed or over-lit zones.

A visualization tool would help the client understand the circuit park coverage, have an overview of best location for a lighting balloon used for directional signage, and ensure adequate lighting for each zone in the circuit park. Because this event covers a significant downtown area, it increases the need to for a suitable placement plan. However, security restrictions and the limited time-span from set-up to start of the event made it difficult for the client to evaluate the event setting spatially. With a better visual knowledge of the event site and effects of the balloons, Partex International would be in a better position to plan for their balloon placement and help the event organizers to better facilitate the event.

The factors described above are the key considerations that Partex International highlighted as areas where they need more information and a way of better planning, and the focus of this project for a best-fit solution. 


\subsection{Proposed Solution}

Based on the requirements outlined by Partex International, the project will create a visualization tool, a web application, which will address the difficulties that they are current facing.

\subsubsection{Goals and Objectives}

The goal of this project is to provide a tool to assist Partex in lighting balloon placement for the SGP. As the client has very basic knowledge of GIS, the solutions will need to be easy to learn and user friendly. The tool will provide site knowledge of the SGP circuit park and recommend the optimal lighting balloon placement solution (for directional signage and safety purposes). Based on the above mentioned, building a web application was the most suitable delivery method that fit Partex's requirements and level of GIS knowledge. The applications should be able to provide three levels of functions for Partex: a static 2D map of the event area, for situational awareness; an analysis of zone(s) to provide lighting placement recommendations based on criteria set out by the event organizers; and a lighting coverage that shows the total amount of lighting for different placement around each zone of interest.

\subsubsection{Scope}

Based on the nature of this project, the recommendation is to build a prototype. Before elaborating on the scope of the project, it is noteworthy to state some assumptions that will not be within this scope. Firstly, it will not consider the effect of weather on the lighting balloons models. Secondly, the project will focus on the Padang and Esplanade zones within the circuit park as these zones best represent and address Partex's problems.

During the implementation of this project, it involved applying knowledge from four fields of study.

First, there is visibility analysis. In order to ensure maximum range of visibility of the directional lighting balloons for pedestrians in the circuit park, the lighting balloons need to be at the best-fit positions. Current ArcGIS software has the capabilities to perform such viewshed analyses. Hence, this portion of the project utilized commercialoff-the-shelf solutions.

The second field is on the lighting industry. Lighting charts and technical data of each lighting balloon provided by Partex were sufficient for the proceeding of this project. They provided information like the height range, illuminated area, wattage, type of bulb and even noise levels. With such information, the project only needed additional knowledge of industrial standards of lighting; for example, how luminance works, the change of luminance over distance and standards of minimum luminance set by Singapore. Using all the information, the project was in good position for the required analysis, which was unique and hence mostly scripted.

The third component of this project is creating a web application for GIS and integrating 3D GIS objects onto the web interface. Bing Maps from Microsoft has recently made this possible (Bing Maps, 2009). Bing Maps has worked with ESRI on several projects for clients and they offer a wide range of functions in their browser (Bing Customer Gallery, 2009). However, because Bing Maps comes with a licensing cost, the 
project would only use it as a benchmark to the final delivery. With an integrative 2D and 3D web platform, it would be much easier for the client to utilize the tool in future.

The final field of study for this project will be 3D creation and integration into GIS, in particular within the ArcGIS environment. In representing the final analysis results, the 2D interface provides basic, first-tier visualization for understanding the event site and a 3D simulation would provide a better visual experience for the client, especially since they have very little GIS knowledge.

To ensure the success of this project, Partex worked closely with the project team to monitor progress and quality of the final product. Most importantly, Partex provided the data and criteria instrumental to the analyses. Over the course of the project, the project team provided updates to Partex bi-monthly. The project team also discussed and explained ideas behind each interim product and Partex provided quick feedbacks on its effectiveness and even suggested improvements within the scope of the project. Partex also provided updates on changes related to the event and noted the important changes that will affect the project. Examples are the changes in the set-up arrangements, number of balloons assigned to the entire event or even the event site area.

Based on the project plan, there were to be four deliverables for this project. However, the project decided that two deliverables were sufficient. The project plan in Chapter 4 provides more details of the decision. The first delivery will be a simple 2D web application map of the event site. The second deliverable will bring in the required analysis results onto the 2D web GIS platform for Partex. It will integrate the lighting priority zones and lighting coverage analysis into the web application. This is the core delivery for this project.

\subsubsection{Methods}

This project aimed to create a web application Partex. Hence, it was broken up into three broad phases that coincided with the three functions of the project. It adopted the staged methodology because more functions were added to the deliverables as it moved through each phrase. First phase concentrated on designing a database that best fits the needs of the client. Second phase included the lighting priority zone and lighting coverage analyses for lighting balloons placement. The last phase included the creation of the web application for Partex. The following paragraphs provide more description about each phase.

The first phase is designing a geodatabase to capture the necessary information for use in the subsequent phases. This phase is important, as the foundation of the final application hinges on the design of the geodatabase. A best-fit database structure is essential to ensure least data redundancy. The specifications of the lighting balloons provided by Partex enabled decision on representing the lighting balloons optimally as a feature class. Features and entities around the circuit park that are crucial to the analysis also have to be in place with the appropriate attributes. However, the determination of appropriateness and importance needs to be an outcome of a well-thought-through process that the geodatabase design would seek to capture.

Once the necessary data were in the required condition as articulated in the first phase, the next phase was to create and test the two analyses. This analysis required the use of ArcGIS's model builder and Python scripting to integrate relevant tools for the analysis. The project drafted the logical flow of entire analysis, and subsequently selected 
available tools in ArcToolbox to create the analysis flow in model builder. The first analysis categorized the features based on priority levels set by Partex. The areas where the most lighting is required received the highest priority rating. This analysis provided Partex with recommended areas for lighting balloon placements. With this, Partex can indicate the locations where they would like to place the lighting balloons. After that, they can run the second analysis, which evaluated the placement for each lighting balloon and provided recommendations for improvements to the placement. As both analyses required many GIS tools, the analyses were created in the model builder and Python scripting environment. Using the model builder enabled modifications of the analysis tool for future work as well. Once the second phase was successful, it would have been beneficial to share the results of the analysis with the client, for their feedback and verification during the 2010 SGP to test the quality of analysis results. The 2010 SGP will run from the 24-26 September 2010.

After this phase, the design of the web application began. Here, the project team started to design the packaging of the deliverable for the client's consumption. This referred to the design of the web application, synchronizing the web design with map cartography, and finally implementation of the analysis results into a 2D web GIS application using Flex. This interactive web analysis application made it possible for Parte to have similar analyses for other events in Singapore.

\subsection{Audience}

This project report aimed to address two main categories of people. First was the client, Partex International, who are not extensive GIS users and professionals, who would be one of the main readers of this report. Second, they were the GIS professionals and academics who evaluated this project.

\subsection{Overview of the Rest of this Report}

This one-year project had both professional and academic parts to it. Being firstly a Master's level project, it has to fulfill requirements of the academic nature in terms of reports and literature review. At the same time, the problems and requirements of the client did not fall within the student's scope of knowledge. Hence, a thorough literature review was the first step to understanding and gaining knowledge on topic areas related to the project. Chapter 2 highlighted the key topic areas in academic research and studies, which are relevant to the project and shared on how the applications discussed in the researches could be used for the project's GIS analysis.

Following the literature review, the next few chapters focused on professional project management components that articulated the progress and process of this project. Chapter 3 focused on system analysis and design of the project in conjunction with Partex's requirements and their current system configuration. This chapter also captured the project plan over the one-year period. Chapter 4 then focused on the data aspects for the project. It discussed subject areas from the acquisition, to the conceptual and logical design of the geodatabase.

Finally, Chapter 5 and 6 highlighted the details of GIS analysis implementation. It covered important information on the approach, process and result of the analyses. 
At the end of the project, it shared the lessons learnt over the process of executing the project, possible future work, and recommendations for Partex. 


\section{Chapter 2 - Background and Literature Review}

This project dealt with a unique study in the field of GIS, hence the literature review focused on key concepts required in the analysis and the web application.

First, the project needed to determine the visibility of lighting balloons located near information and first aid booth locations. The project chose to use the concept of line of sight (viewshed) to determine best position for the lighting balloon at each booth location.

The second analysis focused on a particular zone of interest within the FI circuit park and a criterion set by Partex. The project utilized ArcGIS python scripting capabilities to identify areas within the zone of interest where lighting balloons can be located. The third analysis worked on the range of light emitted by each lighting balloon and ran a script that computes the amount of lighting coverage from a set of user-defined lighting balloons locations. These two analyses combined information and knowledge from various fields of study. The project selected two main topics that fit the nature and requirements of this analysis: nighttime lighting for construction, and packing algorithms.

Finally, preliminary research to understand developments and status of 2D and 3D Web GIS enabled the project to determine a reasonable extent of development required.

\subsection{Visibility Analysis}

Visibility analysis is a commonly used GIS analysis tool. It has been widely used in urban, archeological, geography, and architecture studies (LLOBERA, 2003). Fisher (1996) noted that there is a difference between an area visible from a viewing location, and areas where the viewing location can be seen. This was significant as the analyses yielded different results and were meant for different types of analysis. The former would refer to a scenario like a fire lookout, while the latter would be better applied in urban analysis where developers are interested to know the areas where a new building can be seen by pedestrians. In addition, Fisher (1996) provided three alternative viewsheds to the standard used in most GIS: horizons, local offset, and global offset. The horizons viewshed breaks down visibility of a landscape into four larger categories that provide better understanding of the landscape than a binary viewshed would. The local and global offsets label visibility from target to local/global horizons with positive and negative values. For these two viewsheds, any target on the horizon will have a 0-value. Figure 2-1 provides a visual explanation of four types of viewshed articulated by Fisher. The three lines originating from the view in Figure 2-1 are lines of sights to the three horizons in the profile. The vertical lines represented mid-points of pixels in the DEM for which visibility was determined, each aligning to the columns in the table below with three subdivisions. Each section denotes the difference in height from either the previous line of sight or the ground. 


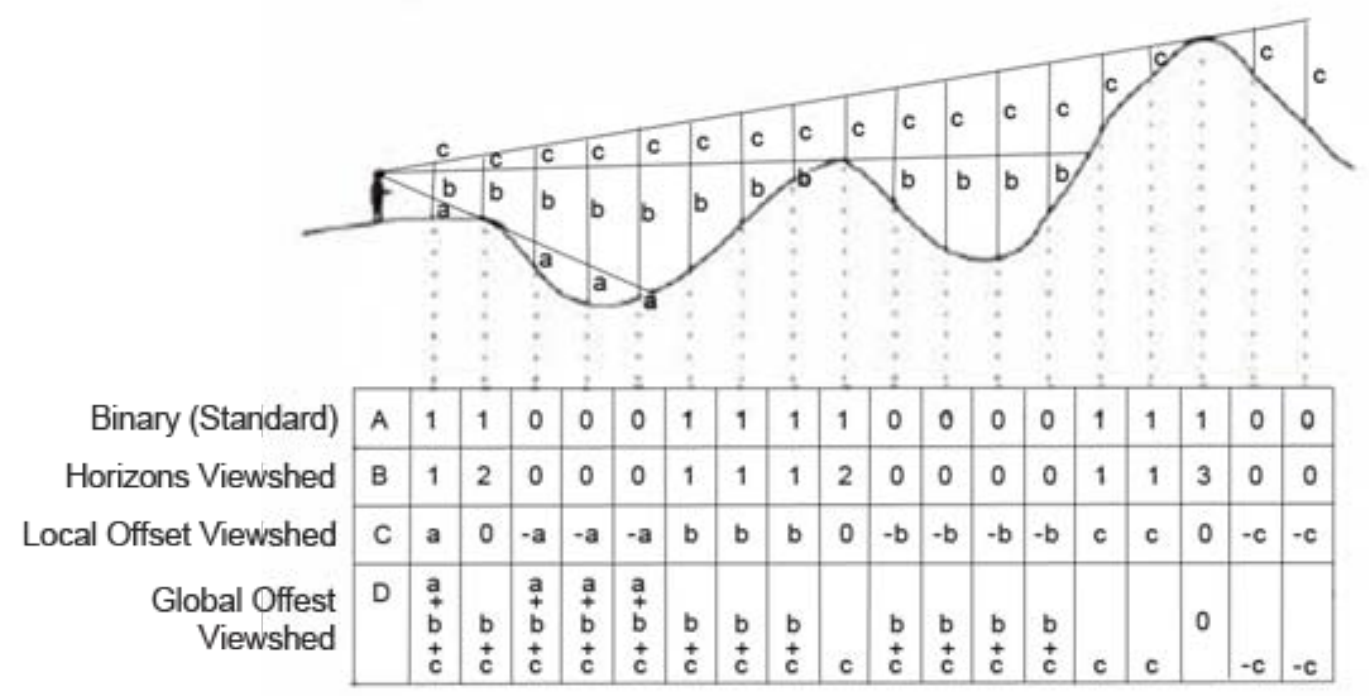

Figure 2-1: The coding scheme of variants of the viewshed. (Fisher, 1996)

LLOBERA's (2003) report, on the other hand, provided additional issues associated with finding a viewshed that went beyond the GIS software. The article introduced the notion of visualscape, which provided a more in depth understanding of viewshed analysis as compared to the tools provided in ArcGIS. This report defined a visualscape as "spatial representation of any visual property generated by, or associated with, a spatial configuration” (LLOBERA, 2003, p. 30). This spatial representation goes beyond representation in GIS to incorporate human physiology or ergonomics. The spatial configuration refers to the scope, scale, and purpose of the analysis. For each visualscape, the spatial configuration changes as the factors that influence it are varied. At different points in time of analysis, the relevance of surrounding features also change based on changes on the landscape, and the purpose of the current analysis. This was relevant to the project as the settings of each event evolve over time and slight changes in target positions and their related features impacted the overall viewshed analysis results.

The viewshed analysis for this project focused on information and first aid booths within the SGP circuit park. The analysis generated viewsheds for several locations identified around each booth, which identified areas that could see the lighting balloon. The comparison of viewsheds generated ultimately identified the best location to place the lighting balloon. The best location had the largest area for which pedestrians could locate the booths. The project also kept in mind the different approach to visibility provided by LLOBERA (2003) that went beyond what the GIS software provides.

\subsection{Lighting Arrangements}

In researching for methods and approaches for the lighting balloon arrangement, two topics were most relevant to this project. The first is lighting for nighttime construction. The second is the circle packing problem algorithm.

The nighttime construction lighting project considered many more factors in the analysis than this project could, but it provided an excellent benchmark and initial guideline for it. The ideas and recommendations were also very useful for starting platforms for this project. There has been substantial research and evaluation done on 
lighting arrangements for night construction. El-Rayes, et al. (2003) conducted extensive research into the conditions of construction site, shadows cast by various types of equipment, the key considerations in lighting (i.e., luminance, illumination, glare, height of mount, visibility), and current practices in lighting. Figure 2-2 illustrates one of the methods used to calculate lighting spacing. The research also covered other important factors required to solve the optimal placement problem.

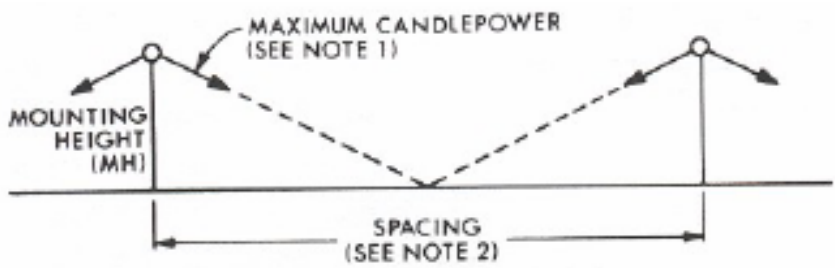

Note 1: Maximum candlepower beams from adjacent luminaires should at least meet on the road surface.

Note 2. Maximum luminaire spacing generally is less than:

'A "-Short Distribution-4.5 $\mathrm{MH}$; B'-Medium Distribution-7.5 $\mathrm{MH}_{\text {; }}$ and

'C' - Long Distribution-12.0 MH

Figure 2-2: One light spacing arrangements method (El-Rayes, et al., 2003).

It was also interesting to note that there were standards of night lighting set by the Department of Transportation (DOT) from various US states, as well as professional organizations. Based on discussions with client and based on the street lighting, the confirmation was that there is a minimum of 30 lux required for pedestrian and vehicle safety. However, the project was not able to find out if Singapore's Ministry of Transport (MOT) had more information on these standards. In an attempt to provide a tool for operational planning of lighting arrangements, an "automated Decision Support System (DSS)” using a multi objective evolutionary algorithm (NSGA-II) was built (El-Rayes \& Hyari, 2003, p. 2). The NSGA-II is a tool that incorporates multiple factors into optimization of a problem solution using pareto-optimal concepts as one major consideration (Deb, Pratap, Agarwal, \& Meyarivan, 2002). This was a conceptual framework or platform that the project used for initial study of the implementation. However, due to its complexity and the capabilities within the GIS software, an alternative solution was studied.

This project then explored the circle packing problem algorithm. In 1970, Adre'ev and Thurston separately published findings and theorems on circle packing that were a aligned to each other, as well as with Koebe's theorm. However, in the history of circle packing studies, Koebe (1936) was the first person to define the circle packing problem:

"Every triangulation of a disk produces a circle packing of the unit disk in C, a pattern of circles within the unit disk, each corresponding to a vertex of the triangulation, with circles tangent when the corresponding vertices are adjacent, and boundary circles internally tangent to the boundary of the unit disk. Moreover, this pattern is unique up to Möbius transformations of the disk or, what is the same, up to isometries of the disk realized as a model of the hyperbolic geometry of Lobachevski and Bolyai.” (Kenneth, 2009, p. 514) 
The circle packing problem has been categorized by several academics as an NPhard combinatorial optimization problem. It uses a series of mathematical formulas to prove that there is tangency between circles in a plane whose interiors are disjointed (Figure 2-3). Several authors have used the circle packing theorm to study the packing of
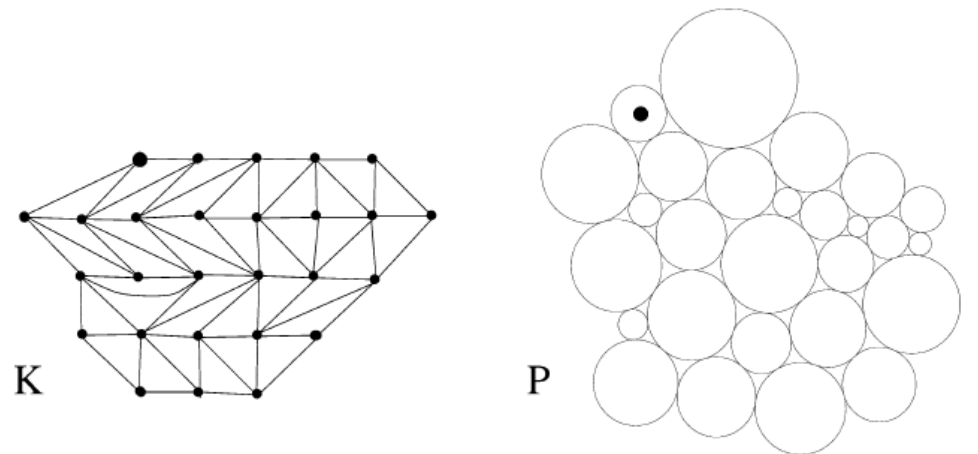

Figure 2-3: A simple complex $K$ with a configuration $P$ of circles in a specific pattern of tangency. (Collins \& Stephenson, 2003)

circles within a larger circle (Wang, Huang, Zhang, \& Xu, 2002) as well as within a larger rectangular container (Huang, Li, Akeb, \& Li, 2005). Figure 2-4 shows the constraints and considerations that goes into the algorithm that makes the final decision of circle placements(Huang, Li, Akeb, \& Li 2005).

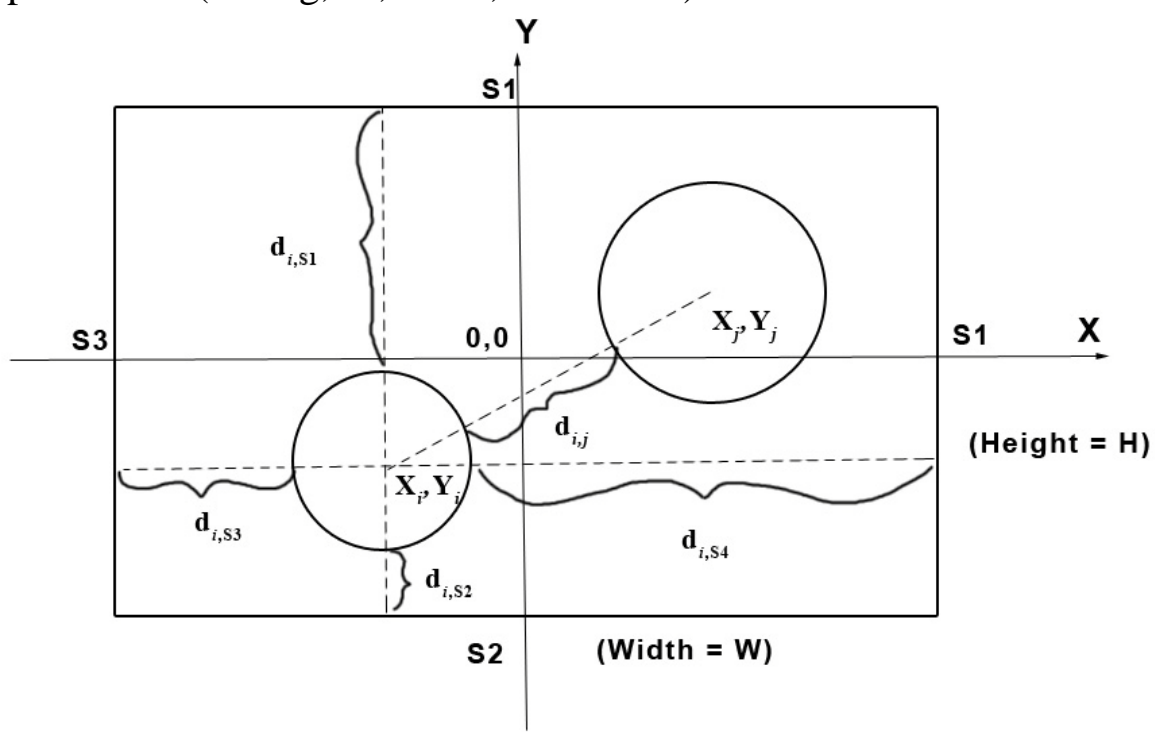

Figure 2-4a: Constraints in the packing algorithm where circles cannot be outside the rectangle or overlap each other. (Huang, Li, Akeb, \& Li, 2005) 


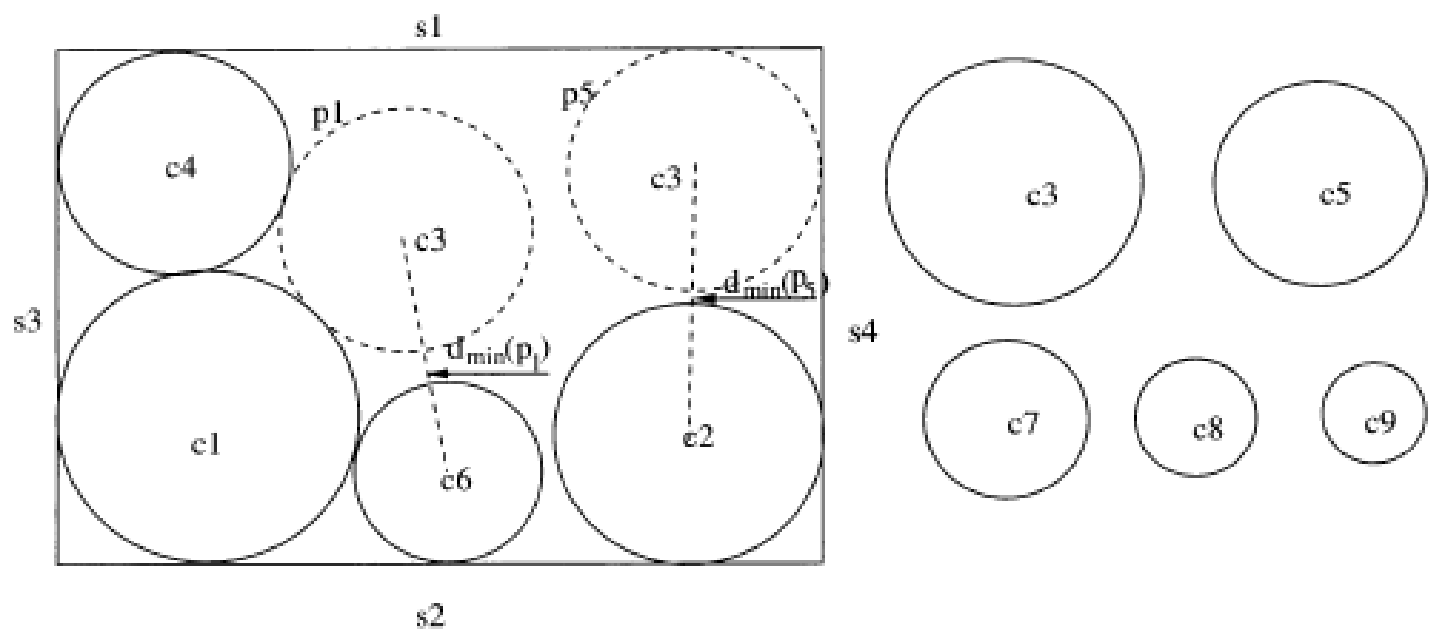

Figure 2-4b: Interim steps of consideration for placement of circle c3 in order to get optimal result shown in (c). (Huang, Li, Akeb, \& Li, 2005)

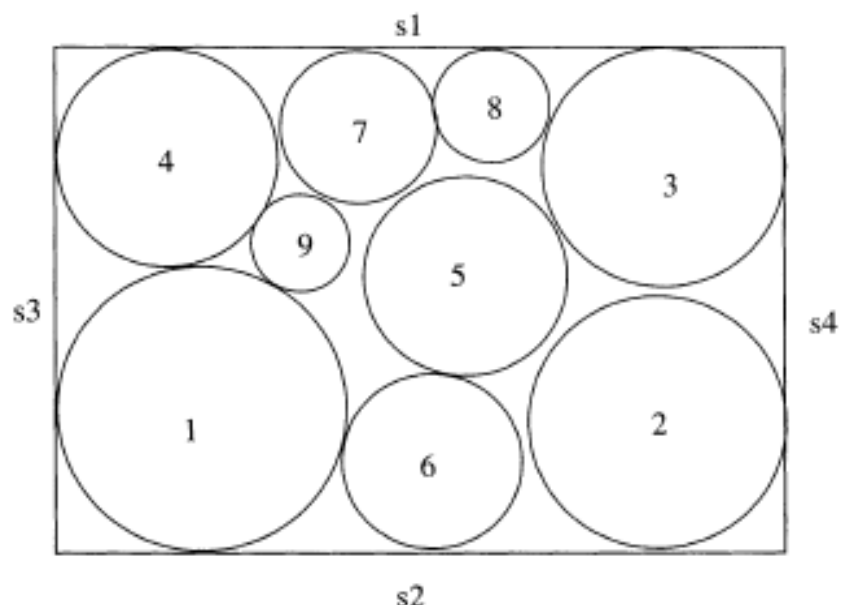

Figure 2-4c: Final packing result using one of the algorithm. (Huang, Li, Akeb, \& Li, 2005)

A noteworthy point is that most authors approached the circle packing problem from the standpoint that there should be no overlaps among the circles. Thurston was the first to discuss the probablility of circle packing with overlaps. This is related to the project as it needs a method to pack the lighting balloons within a zone with an amount of overlap, as the amount of light decreases as the distance from centre of lighting balloon increases. In order for the lighting at the entire zone to be sufficient, the lighting balloon's area of illumination (i.e., the circle) will have overlaps. However, as GIS software does not have the capability to integrate the overlapping circle packing algorithm suggested by Thurton, discussed in Collins \& Stephenson (2003), the project adopted a reverse calculation approach which allowed Partex to indicate the lighting balloon locations and a script 
evaluated how well the overlapping of the lighting spheres fit with each other. This allowed for recommendations to readjust or add lighting to areas of concern.

\subsection{Web Application for GIS}

Two-D and 3D visualization is a subject that has been receiving increasing attention due to the availability of COTs solutions and its support of web interfaces like Google and Bing maps. It also provides added situational knowledge of an area of interest without having to be on-site. While the creation of a 3D environment is very labor intensive, it would definitely be beneficial for the project to have included a GIS visualization tool to enhance Partex's planning process. With ESRI's recent release of ArcGIS 10, the support for 3D analysis has increased tremendously, as it geared the development towards handling 3D information and analysis.

A review of academic articles on the development of 3D and web GIS showed that early research on 3D GIS covered mostly basic spatial structure of a 3D GIS and how different software managed the (Basanow et al. 2008) m. However, research has progressed to a level where the authors have attempted to provide a spatial data infrastructure to create baselines for presentation and management of 3D data (Basanow, Neis, Neubauer, Schilling, \& Zipf, 2008). The authors also mentioned commonly used standards within the 3D, GIS, and Web communities, as well as those recognized formally by the Open Geospatial Consortium (OGC). These formats and standards provided good base knowledge for the project and adequate support is available in most COTs software. As the project progressed, it identified a best-fit 3D web service from the list of format options for implementation. Recent COTS developments and improvements augment the ability to provide a 3D web-based visualization tool (ESRI ArcNews Online, 2009/2010).

\subsection{Summary}

This chapter highlights the important and relevant work done in other fields of studies for this project. They are viewshed analysis, lighting arrangements for nighttime construction, circle packing problems, and 2D/3D web GIS. The viewshed analysis literature highlighted different methods of approaching a line of sight analysis based on the specific purpose of the viewshed analysis. Mach of this literature noted that most GIS software algorithms focus on standard viewshed analysis; which is the profile of terrain that can be seen from the target point. For this project, the key was to find the reverse of the standard viewshed; to find areas surrounding the booth the where the lighting balloon can be seen. The next topic of relevance was lighting during nighttime construction. This study highlighted the aspects of lighting used in the calculation of lighting placement during nighttime construction. It took into consideration many details of lighting, as the amount of lighting affects the work effectiveness on the construction site. The study provided much information and knowledge about lighting for deciding which factors are relevant within the project. However, since the use of NSGA-II pareto algorithm to solve the problem was not suitable for the project, the project looked into the circle-packing algorithm. The circle-packing algorithm provided solutions for packing a group of circles into a larger container. It was an excellent reference for this project in defining the approach for the analysis in GIS. Although the software was not designed to process 
these algorithms, it provided analysis for positions indicated by Partex. Hence, a suitable approach was to run reverse packing, which this project implemented. The final topic refers to 2D and 3D web applications for GIS. Two-D web applications are an ideal means of communications for users who do not need to know the intricacies behind the technology other than that it solves their problems. Hence, this project created a 2D web application for Partex's planning process.

In summary, the various topics identified in literature review helped shape the approach and solutions delivered for the project. The topics provided theoretical concepts and practical applications that are relevant for the project focus. Following the literature review, the project was able to ask questions that are more specific about the problems and scope required by Partex and ensured that the project delivered a best-fit solution. The next chapter attempts to articulate and formulate a design and a plan, based on the information gathered from the in-depth study of the problems faced by Partex. 



\section{Chapter 3 - Systems Analysis and Design}

The dictionary defines "analysis" as "the separating of any material or abstract entity into its constituent elements" and "design" as "the combination of details or features." Once the project team defined its scope and literature reviews were completed, the project moved into the system analysis and design process. As the definitions indicate, the analysis stage dissected requirements to understand the project and the client thoroughly. Thereafter, the project team put together the important information and details that provided a solution for the client. Conscientious analysis and design of the project helped fulfill Partex's requirements using the most efficient methods. This chapter starts by reiterating the problem statement from Partex. Next, it discusses and highlights the findings from the requirements analysis of the needs of this project. From the requirements, the project team put together a system design that fulfilled the requirements. Finally, the chapter closes with a project plan that puts the components of the system design into a timeline, which also includes shortfalls of the plan.

\subsection{Problem Statement}

Partex needed to provide optimal lighting coverage of the SGP circuit park for three purposes: safety, aesthetics, and directional signage, which includes first aid, information booths, and gates.

Because the event coordinators neither indicated the preference of balloon location nor provided detailed information of the circuit park to Partex, on site reconnaissance was required of the staff. Despite several on-site reconnaissance visits prior to the event, the lack of situational awareness caused many lighting balloons to be ill-placed. Hence, Partex needed a map that provided situational awareness and calculated lighting coverage within a zone. Partex also needed to know which part of the information and first aid booths would be the best to locate a lighting balloon for maximum view area by pedestrians. The key factors that influence lighting balloon placement include lighting balloon height, dimensions, wattage, dark areas within the circuit park, and high activity areas. These are factors gathered based on research and Partex's experience. Human estimate was the method used for balloon placement decisions in SGP and it often resulted in overlooking crucial dark areas or over lighting other areas.

Because this event covered a significant downtown area, it increased the need to for a suitable placement plan. However, security restrictions and the limited time-span from set-up to start of the event made it difficult for Partex to evaluate the event setting spatially. With a better visual knowledge of the event site and effect of the balloons, Partex International would have been in a better position to plan for their balloon placement and help the event organizers to better facilitate the event.

The factors described above were the key considerations that Partex International highlighted as areas where they needed more information and a better of way planning. A visualization tool was the first suggested solution. To give Partex a better understanding of the circuit park coverage, an overview of best location for a lighting balloon used for directional signage, and to ensure adequate lighting for each zone in the circuit park. 


\subsection{Requirements Analysis}

Reviewing the problem statement set the project up for this next step. This was a very crucial step for the project and it was imperative that much forethought go into identifying the requirements. These are the requirements that brought the project from implementation to deployment and finally to the taking over of the project by Partex.

There were two main components in the requirements analysis: functional and nonfunctional. Functional requirement referred to the physical requirements like the user interface, and products/software that Partex required. The non-functional requirements were elements and preparation of the program, software, or system that goes on behind the scenes that supported the final application. The Use Cases ${ }^{1}$ and Information Product Descriptions $^{2}$ prepared during the process of liaison and understanding of the project with Partex captured the essential functional and non-functional requirements. Table 1 provides the entire requirements of this project based on identified use cases and information product description.

Table 1. Functional and non-functional requirements based on use cases and information product description.

\begin{tabular}{|c|c|c|c|c|c|}
\hline $\begin{array}{l}\text { Functional } \\
\text { Requirement }\end{array}$ & \multicolumn{2}{|c|}{$\begin{array}{l}\text { Web application: } \\
\text { 1) find, search, query, } \\
\text { geoprocessing functions } \\
\text { 2) select zone of interest, run } \\
\text { buffer for lighting coverage }\end{array}$} & \multicolumn{3}{|c|}{$\begin{array}{l}\text { 1) Software and knowledge to } \\
\text { convert CAD data } \\
\text { 2) Creating desktop analysis to } \\
\text { calculate lighting requirements for } \\
\text { Partex }\end{array}$} \\
\hline $\begin{array}{l}\text { Technical } \\
\text { Requirement }\end{array}$ & \multicolumn{5}{|c|}{ ArcGIS server on local servers or on cloud architecture } \\
\hline $\begin{array}{l}\text { Operational } \\
\text { Requirement }\end{array}$ & Data updates & \multicolumn{2}{|c|}{ Data archiving } & \multicolumn{2}{|c|}{ Data backup } \\
\hline $\begin{array}{l}\text { Transitional } \\
\text { Requirement }\end{array}$ & $\begin{array}{l}\text { Project } \\
\text { Documentation }\end{array}$ & GIS Training & $\begin{array}{l}\text { Data c } \\
\text { future }\end{array}$ & for & $\begin{array}{l}\text { User } \\
\text { acceptance test }\end{array}$ \\
\hline
\end{tabular}

Based on the initial requirement analysis, Partex needed a solution that allowed for input of data for entities and elements that influenced the placement decision of each lighting balloon. The final delivery was a web application and the geoprocessing was run at the server end to enable user efficiency. This was the functional requirement identified for Partex at the end of the requirement analysis.

There were three groups of non-functional requirements in this project: technical, operational, and transitional. For the technical requirements, Partex currently uses the

\footnotetext{
${ }^{1}$ Use case is a description of a system's behavior as it responds to user request. (Wikipedia, 2010)

${ }^{2}$ Information Product Description is a document that includes the description of all the products reasonably foreseen, data and functions required to produce the product (Tomlinson, 2007, 页 8)
} 
Microsoft Office interface for all their work functions. Since the final delivery was a web application, it meant that Partex needed to implement web servers to support the application. For the operational requirements, Partex needed to maintain data backup, update software patches, and conduct archiving of all data. The third and final requirement, transitional, presents the needs of Partex after the project delivery is complete. As data from SGP organizers were in CAD format, Partex needed to consider data conversion and massaging before each project. In addition, Partex had to look into staff training in GIS to understand the application and to improve on the web application. User-acceptance tests and documentation were other requirements that provided a better user experience for Partex.

Among the four highlighted aspects of requirements analysis, the most challenging requirement to implement was the transitional requirement. It was very crucial that Partex be well equipped to carry on with the application and even make improvements on it after the end of the project. The following sub-sections capture more detail on the major functional and non-functional requirements of this project.

\subsubsection{Functional Requirements}

Based on the needs of Partex, the important functional requirements for this project were broken down into three categories. Table 2 below shows the two use cases that helped derive the functional requirements of the project.

Table 2. Summary of functional use cases

\begin{tabular}{|c|c|c|c|}
\hline & Workflow & $\begin{array}{l}\text { Data/Information } \\
\text { Product }\end{array}$ & Procedures \\
\hline $\begin{array}{l}\text { Use Case } 1 \text { - } \\
\text { Location } \\
\text { Map }\end{array}$ & $\begin{array}{l}\text { 1) Manage } \\
\text { 2) Integrate } \\
\text { 3) Share } \\
\text { 4) Act }\end{array}$ & Web application & $\begin{array}{l}\text { 1) Obtained layers from } \\
\text { Partex } \\
\text { 2) Convert and create GDB } \\
\text { 3) Publish to web application }\end{array}$ \\
\hline $\begin{array}{l}\text { Use Case } 2 \text { - } \\
\text { Analysis } \\
\text { capability }\end{array}$ & $\begin{array}{l}\text { 1) Analyze } \\
\text { 2) Transform } \\
\text { 3) Share } \\
\text { 4) Act }\end{array}$ & $\begin{array}{l}\text { 1) Python script tool } \\
\text { 2) Web application } \\
\text { with analysis } \\
\text { capability }\end{array}$ & $\begin{array}{l}\text { 1) Create zones of areas } \\
\text { a. requires lighting } \\
\text { b. avoid lighting } \\
\text { c. where lighting } \\
\text { balloons should be } \\
\text { placed } \\
\text { 2) Create lighting coverage } \\
\text { raster based on lighting } \\
\text { values provided by Partex }\end{array}$ \\
\hline
\end{tabular}

Table 3 summarizes the various functions that were required from each category. 
Table 3. Details of functions and steps by workflow

\begin{tabular}{|c|c|c|c|c|c|}
\hline & Manage & Integrate & Share & Act & Analyze \\
\hline \multirow{5}{*}{$\begin{array}{l}\text { Use Case } 1 \\
\text { - Location } \\
\text { Map }\end{array}$} & 1) Input & 1) Project & 1) Visualize & 1) Inspect & 1) Find \\
\hline & 2) Import & 2) Overlay & 2) Publish & 2) Repair & 2) Query \\
\hline & 3) Edit & 3) Align & & & \\
\hline & 4) Convert & & & & \\
\hline & Analyze & Transform & Share & Act & \\
\hline \multirow{4}{*}{$\begin{array}{l}\text { Use Case } 2 \\
\text { - Analysis } \\
\text { capability }\end{array}$} & 3) Find & 1) Calculate & 1) Visualize & 1) Decide & \\
\hline & 4) Query & 2) Classify & 2) Publish & 2) Exploit & \\
\hline & 5) Model & 3) Merge & & 3) Inspect & \\
\hline & 6) Act & & & 4) Repair & \\
\hline
\end{tabular}

The first category included requirements related to the web application, which is a product of the first use case. They consisted of the basic ability to find and query features in the web map. Next, the web server needed to be able to execute the search processes and geoprocessing analysis quickly. Finally, as each geoprocessing service required between two to five minutes, it had to run as an asynchronous process in ArcGIS Server. This meant that the web application allowed users to continue using the web application while executing the analysis at the server back end.

The second category consisted of requirements specifically associated with the analysis. First, Partex needed the ability to select zones of interest for the analysis, and create areas of varied priority in each zone for the analysis. Next, Partex selects the location and types of lighting balloons, and buffers were generated that represented illuminated areas on the ground using the lighting balloon specifications.

The third and final category relates to processing the data from its raw state. As the data from Partex came in CAD format, it was necessary to convert the CAD data into GIS compliant formats. In order to facilitate these functions, Partex required software and knowledge to execute these functions quickly and efficiently.

\subsubsection{Technical Requirements (Non-Functional)}

In terms of system and server configurations, Partex did not have a complex system configuration. They utilized common office tools to manage all their projects. The lighting balloon inventory was managed and maintained with Microsoft excel, and the company had a server that links the staff onto a common file network. The network ran on LAN connection and there were no added technology regulations in Partex. In addition, there were no programming environments within Partex's technology infrastructure. The recommendation, based on the above information of their existing system, was for Partex to acquire a web server hosted either within the current server or 
on cloud architecture. This facilitated the usability and scalability of the application after the end of the project.

\subsubsection{Operational Requirements (Non-Functional)}

Due to the nature and frequency of use of the analysis, data updates were not a crucial and not a top operational priority for Partex. The expected data update takes place on a yearly basis, or whenever Partex receives communications about changes to the circuit park.

Although Partex did not own any GIS servers, the project recommended that they purchase their own versions of GIS desktop software and servers. In this case, these servers need to run back-up, archiving of data and install patches for the software that they will be using to support the analysis.

\subsubsection{Transitional Requirements (Non-Functional)}

For the project deployment phase, Partex required proper documentation as a guide and reference while they familiarized themselves with the application. The document had to explain the purpose, components, and functionality of the delivered applications. Ideally, the delivery of the documentation was a part of the application, so that instructional videos could be included in the documentation package. However, due to limitation of time, the help documentation delivered was only in hard copy, without any instructional videos.

Before the deployment of the application, it was recommended that Partex staff attend basic GIS courses offered in the commercial sectors so that the staff were adequately familiar with GIS and could supply constructive feedback about the web application and its functionalities.

Over the course of the project, data conversions from CAD to GIS formats, and the subsequent analysis of the converted data were the most time consuming and exhaustive steps. As these steps were done as part of the project, Partex needed to be informed about the considerations and assumptions that went into the analysis and the design of the geodatabase. Partex then needed to analyze the efforts of such conversions for subsequent projects that they plan to analyze.

Finally, the deployment process provided access to the web application over the internet for the staff of Partex to concurrently access, test, and execute the various functions available. The application went through a test on its ability to sustain multiple concurrent users with processes running on the server without lag time. For this project, Partex defined the window of acceptance for performance and completed a system acceptance test at the end of the project.

\subsubsection{Challenges}

Among all the requirements of the project, the most challenging to execute was the transitional requirement. The process of handing over project to the client is crucial in all projects. Much effort and detail went into the planning of the transitional stage, as it set the path for future works and usability of the delivered application. If not conducted 
adequately, Partex could not fully utilize and further improve the application for their benefit.

There are currently no political obstacles but the requirements evolve constantly from year to year. However, over the course of this project, Partex ensured that there were no changes in the technical and operational requirements; the event was in its third year and many of the event planning procedures was already in place. However, Partex constantly provided new information on the functional requirements and transitional requirements until September 2010. This was due to the reliance of the functional requirements on Partex's client requirements. Partex was responsible for evaluating the changes, deciding if the changes were crucial to the success of the project and if they affected the timeline for the project completion. During the year, there were several minor changes to the SGP circuit park details. However, Partex decided that the changes were not crucial for their requirements within project, and hence the project could proceed as discussed.

\subsection{System Design}

"Design is not just what it looks like and feels like. Design is how it works." - Steve Jobs (Brainy Quote). Steve Jobs equated design to the art of technology. It is important that behind every technology, target users should be able to connect themselves easily with the product.

The final product for this project was the web application with analytical capabilities. The interim product was a web application without the analysis capability. The basic concept for the interim product focused on the cartography of the GIS layers in the web application. The map used shades of gray for the non event-related layers. This allowed for use of slightly more prominent colors, which provided a contrast between original ground features and event-related ones. The interim web application was intended for Partex to learn from and familiarize themselves with the map layout for the final web application.

Next, the web application design took into consideration that Partex required a simple GIS interface to work with. The design of the map also reflected the theme of SGP - a night event. This section elaborates the consideration taken when designing the web application for functionality and simplicity.

Finally, with any product, there has to be a system that supports its functionalities. The system architecture for this project followed ESRI's author, serve and use paradigm and it is simple to set up - from data collection and manipulation, to publishing of maps and geoprocessing, and finally to consumption by the users.

For successful continuity of the project upon completion, Partex had to look into how the company was able to scale its technologies, in terms of hardware and software, in order to support more GIS application in their events. At the same time, identifying the right training needs was and essential for them to understand the concepts and usage of GIS.

\subsubsection{Map Design}

The map component of this project fulfilled the requirement of Partex to have a better understanding of the SGP circuit park. The GIS layers captured within the project provide 
essential information that Partex needed for this event. The map design applied cartography to two categories of feature classes using distinctly different styles.

First, there is the base layer, which was an important reference material that included information about non-event features. The map in Figure 3-1 shows the intended design of the base map. It highlights the permanent features of the circuit park during non-

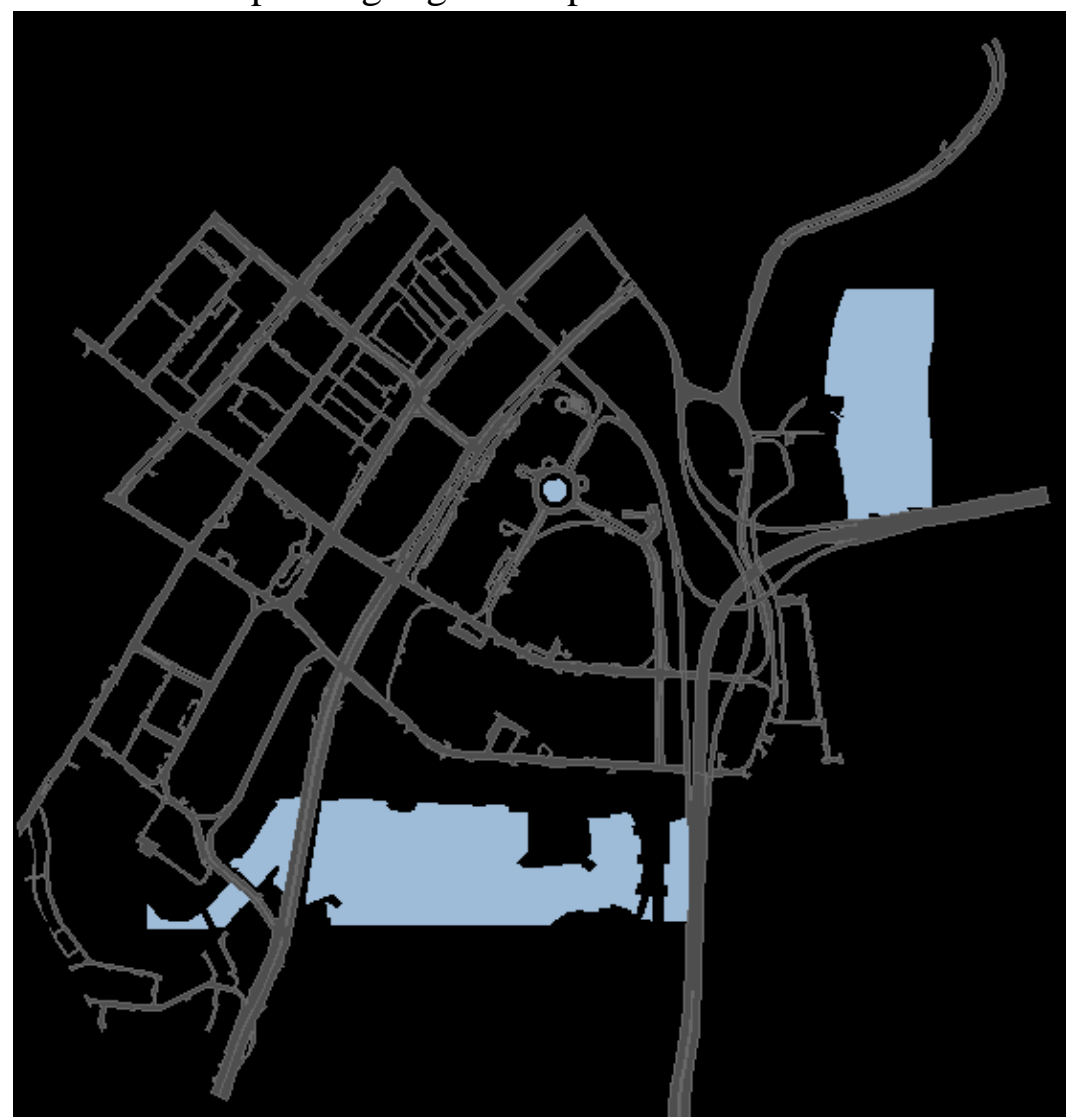

Figure 3-1: Representation of study area at full extent

event days. The colors used on the base map were in shades of gray as it sufficiently highlighted the features and placed them at the foreground of the entire map in comparison to the event layers. The choice of gray also matched the theme of the web application and event, which is a night event. Finally, the use of gray tones allowed for use of brighter colors that made event related layers stand out in the map.

The next category of layers referred to the SGP layers. These were layers provided by the event organizers and were temporary set-ups for the purpose of the SGP (Figure 3$2 \mathrm{a}$ and 3.2b). Brighter and shades of brighter colors were used to represent these layers. The rationale behind this method was to enable differentiation between SGP layers and the base layer. Since the aim was to enhance the user's familiarity to the event site, this design consideration hoped to enhance the process, even for novice GIS users like the staff in Partex. 


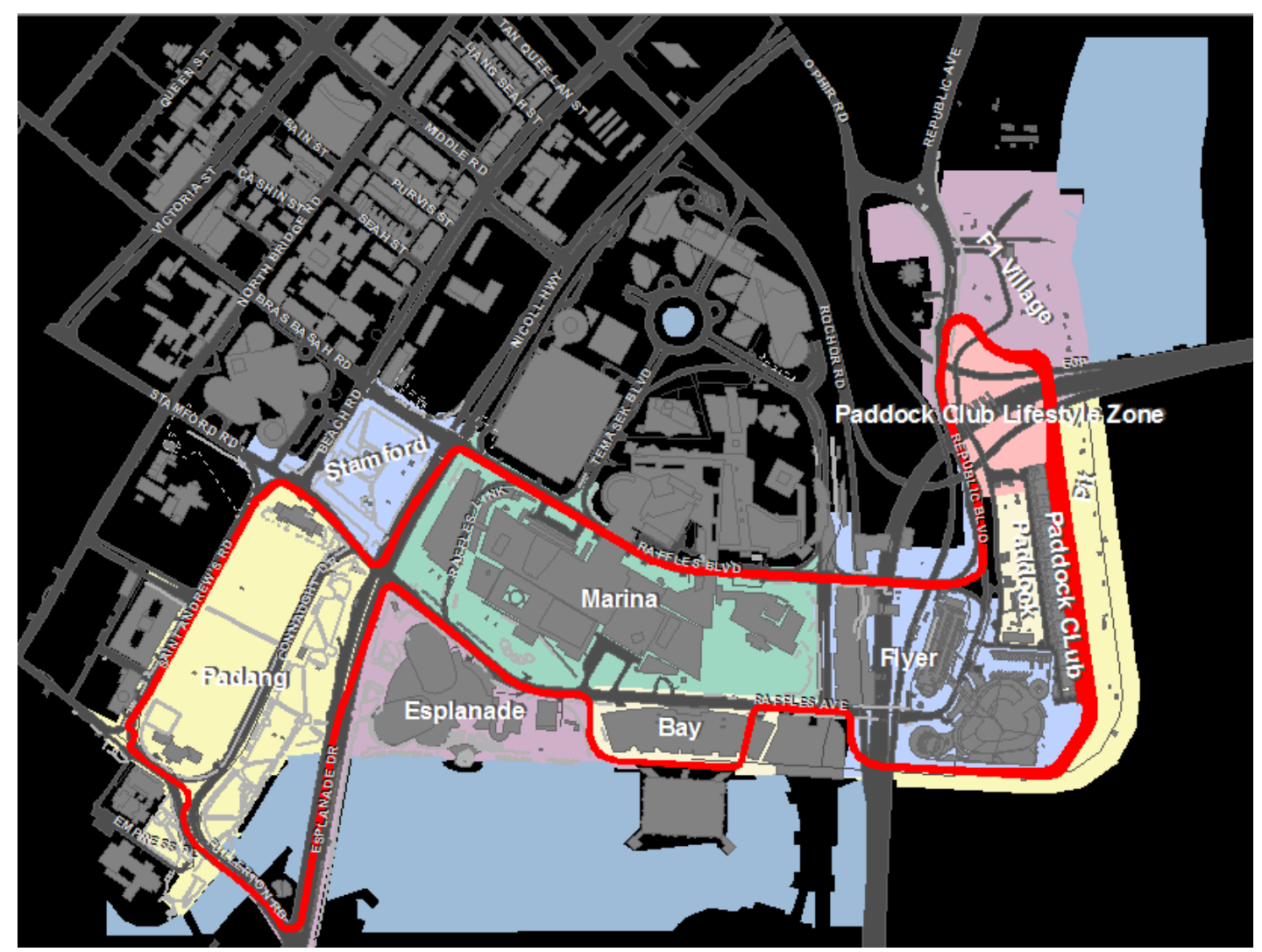

Figure 3-2a: Representation of study area at 1:10,000.

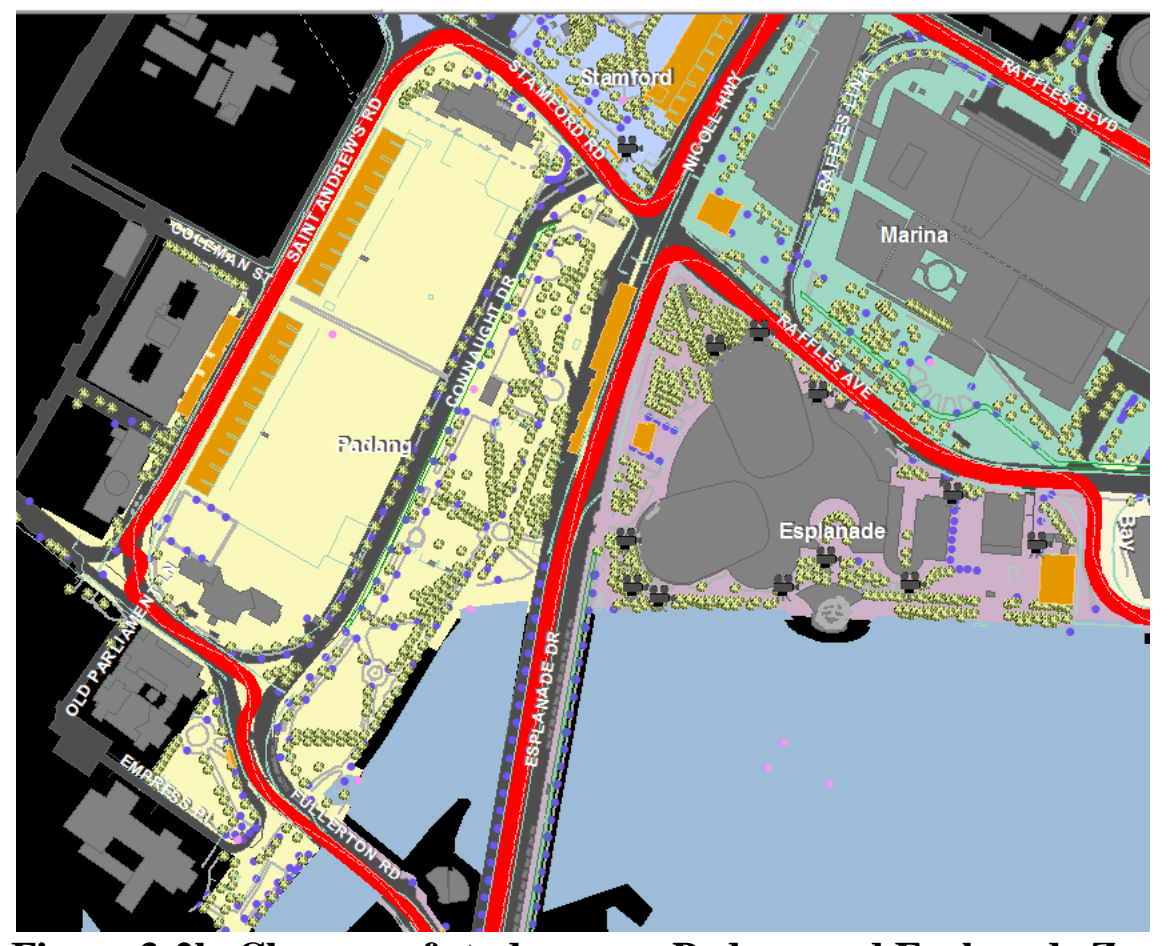

Figure 3-2b: Close up of study areas: Padang and Esplanade Zones at 1:3,624. 


\subsubsection{Technology}

The web application was the core of this project's technology and served as the final delivery. Figure 3-3 shows a prototype of the web application created from Photoshop.

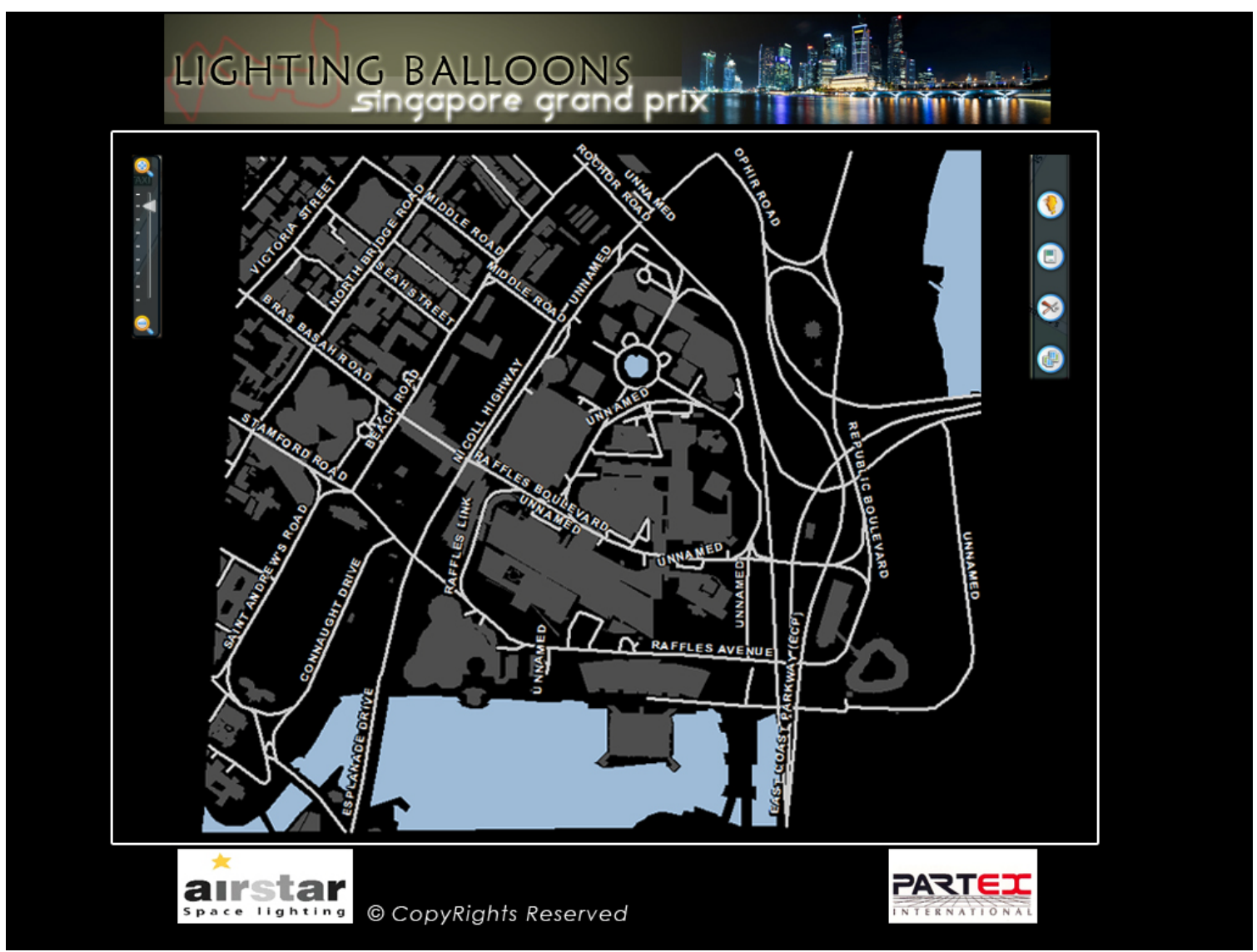

\section{Figure 3-3: Prototype of the final web application}

Taking a cue from currently available web map designs, this web application also allowed Partex to turn on/off between the base layers and event-related layers. The toolbar buttons on the right corner of the map facilitated these functions. The web application also had built-in query, search, and geoprocessing tasks. The first geoprocessing task required Partex to select the zone for analysis, specify distance away from a feature that should not be lighted, and specify distance from a feature that needed to have lighting. The server then executed an asynchronous geoprocessing and the time needed to run the geoprocessing task ranged between two to five minutes. The first geoprocessing tasks returns a layer that indicats areas of recommendation for lighting balloons. The second geoprocessing task required Partex to input planned locations of lighting balloons and the analysis creates a lighting coverage raster that allowed Partex to evaluate the suitability of the lighting balloon placements. 
The overall layout of the web application was simple and aimed at having as few items as possible to minimize time spent on learning its functions. The entire web application took on a black scheme to reflect the nature of the event, and the header projected the concept of night and light themes in this project.

\subsubsection{System Architecture}

The system architecture required to support the project, represented in Figure 3-4, followed the Author, Serve, Use concept from ESRI. The author phase had the data and processes required for final consumption on the user end prepared. Data for each project came from various sources: government agency (base layers), event coordinator (eventrelated layers) and in-house reconnaissance. A single desktop, or server desktop, was required to consolidate the data and create geoprocessing workflows for publishing. This consolidation platform had to be equipped with the GIS software and managed by a GIS analyst.

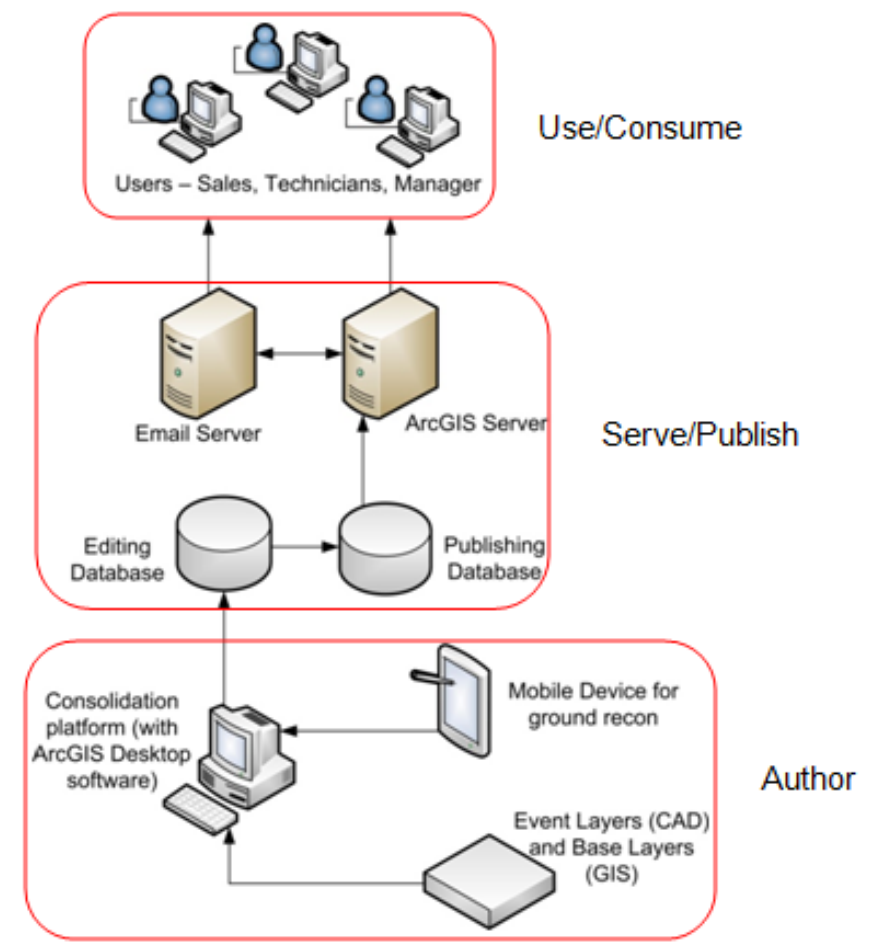

Figure 3-4: Recommended system architecture for Partex.

The next phase was to publish these data and geoprocessing tasks onto a simple web application interface, as described in the technology section of the system design. This phase went through the process of compiling the necessary workflows, analysis, and tasks required by the end user. Finally, the web application was created using Flex, accessing the layers and geoprocessing services via the service directory's REST API.

Various level users within the organization used the final product: the sales team, technician team and the manager. The sales team was able to utilize it for discussion with SGP organizers on zones that required lighting, and to recommend lighting balloon locations. It also served as a guide for the technician team during placement of each 
lighting balloon and a platform for discussions. The manager utilized it as a reference for the placement plans and event layout. Generally, the web application placed everyone in Partex on the same level of understanding regarding the event's requirements, decisions, and helped facilitate cross-department discussions.

\subsection{Project Plan}

To fulfill the overall goal of this project, three strategic goals framed the purpose and needs articulated in the early stages of the project.

The first strategic goal was to provide Partex with improved situational knowledge of the circuit park when event set-up was complete. This was because of considerable differences in landscape in the circuit park before and after set-up of event facilities. In order to account for these differences, Partex had to conduct frequent reconnaissance to ensure better and updated knowledge of the event site. This process took up time and resources and was insufficient for them to gain knowledge of lighting coverage based on placement decisions. In order to resolve this, the proposed solution was to create a 2D and $3 \mathrm{D}$ visualization capability for Partex. This solution allowed off-site, online access to the SGP circuit park.

The second strategic goal was to provide a recommendation for optimized location of each lighting balloon. The project needed to identify features that needed prioritization of lighting and also to avoid over lit areas (i.e., the race tracks) in case the glare from the lighting balloons become a source of distraction for the F1 drivers. This was essential as the current placement process overlooked pockets of areas where there was insufficient lighting and was not safe for the public. Partex's solution to this problem was to either note the location for the subsequent year or by adding lighting balloons if the event coordinator's budget allowed for it. They were not able to reallocate the lighting balloons quickly, as it meant movement of them in the entire affected zone. The time between setup of lighting balloons to the event start was not adequate for complete re-allocation. Hence, an analysis function was required to categorize the features in the zone of analysis based on priority of need for lighting before applying the final analysis. Partex provided the criteria for prioritization.

The third and final strategic goal related to the total amount of lighting emitted by lighting balloons placed by Partex. In order to maximize the coverage of each balloon and consequently the event site, the project utilized the area of illumination on ground of each lighting balloon for the analysis. Partex provided the lighting charts to be used for this analysis. The solution was a script that required user input of lighting balloon locations and calculated a lighting coverage raster based on the lux information provided by Partex.

\subsubsection{Timeline}

The design of the strategic goals articulated in the previous section followed the three phrases discussed in the Methods section closely. This was to facilitate efficient monitoring of the entire project in a progressive manner. The initial three phases as seen in the Gantt chart (Figure 3-5) were to create a 2D web application, followed by creating lighting priority zone and lighting coverage analysis, and finally incorporating the analysis into the web application. 


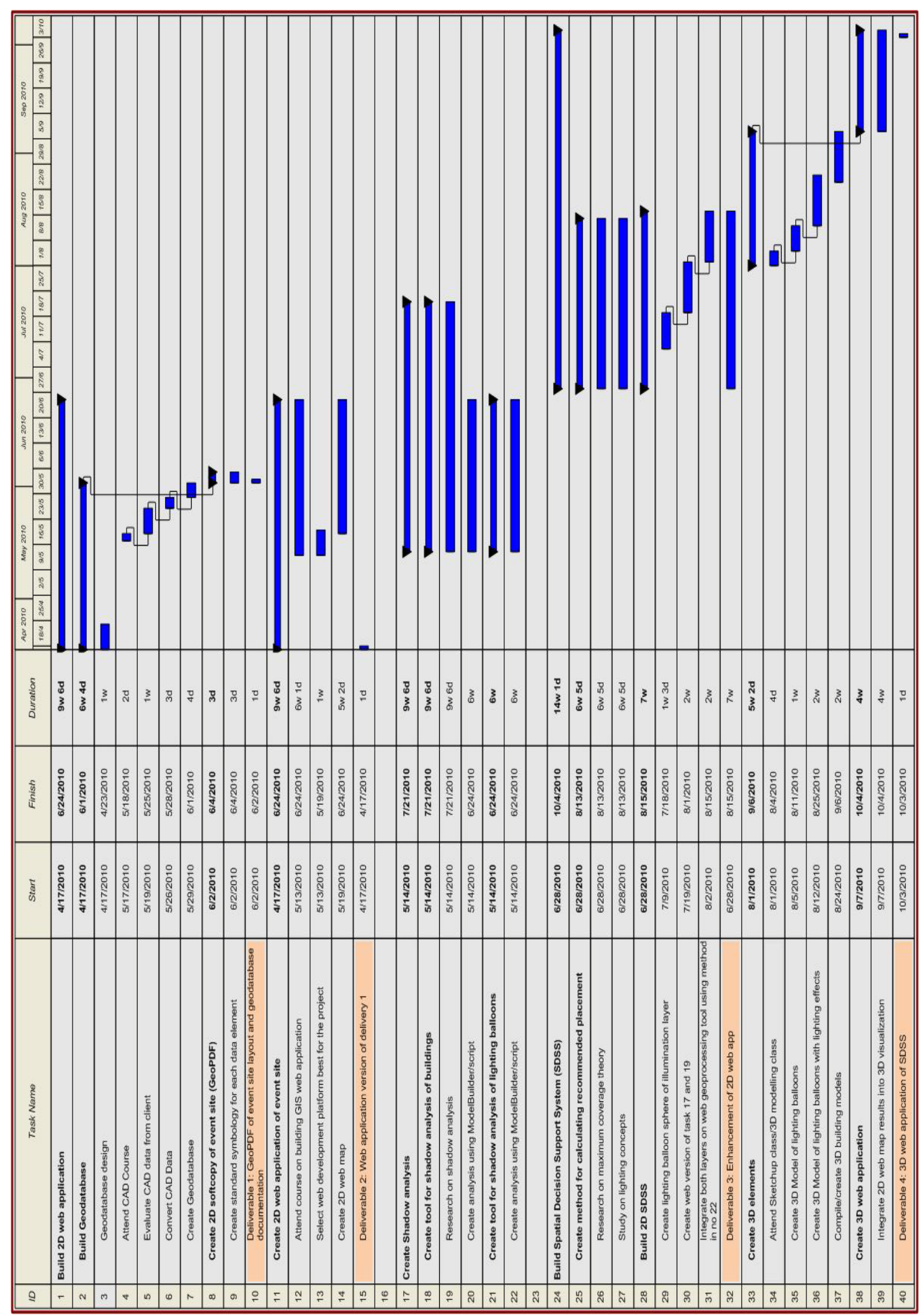

Figure 3-5: Initial timeline for the project plan 
The first phase was broken down into three milestones with two deliverables. The first milestone ensured the adequate design of the geodatabase, and the second milestone aimed to build a standard symbology for each data element within the geodatabase. The first milestone required acquisition of new knowledge and in-depth analysis of CAD data. The first delivery was comprised of a preliminary GeoPDF of the circuit park with documentation highlighting the design and structure of the geodatabase. This set the base for the project as it progressed. The final milestone in this phase was to bring the cartographic representation of data from the Geo PDF into a web GIS environment. This was the second deliverable for the project.

The next phase was broken down into two parts. The first was the study of area of interest to determine the priority lighting zones with information specified by Partex. The result recommended areas around the zone of interest for lighting balloon placements. The second was the creation of analysis to calculate the total light coverage of lighting balloons placed by Partex.

The third and final phase of the project was to produce and incorporate the final analysis on the recommended locations for lighting balloons into the web application. In the midst of this phase, there were also studies done to understand the concept of circle packing and algorithms related to it better. The third deliverable of the project was to be an enhancement of the 2D web application, with added geoprocessing capabilities. After this deliverable, the process of 2D map elements onto a 3D visualization platform began. That was to be the final product for Partex on this project.

\subsubsection{Deliverables}

As mentioned in the previous project plan section, there were four deliverables for the project. The first, a simple 2D map of the event site delivered in GeoPDF format together with the geodatabase design document, was a snapshot of the final product in its simplest form. The decision to provide this map was so that Partex had time to understand the aesthetics of the map design. With the delivery of incremental products, they would understand the new products easily. The geodatabase design document provided Partex with an overview of the types of data needed for their projects, a base for them to work on if they wanted to build similar prototypes for other projects. The purpose was to first minimize the learning curve of the client, and allow them to make use of the initial map as a reference for preliminary planning. Early feedback from Partex was another important reason to have the incremental product. The second deliverable was a 2D web application of the first deliverable. It was based on the GeoPDF except that the web application had dynamism and interactivity added to the data represented. It brought Partex closer to the look and feel of the final product and they had to be familiar with the interface. The third deliverable brought in the required analysis onto the 2D web GIS platform and provided the placement analysis recommendation for Partex. It was to integrate the lighting priority zones and lighting coverage analysis into the web application. This was the main delivery for this project. There was an added function to the main delivery that was scheduled depended on availability of time and resources. This addition to the final delivery was to create a $3 \mathrm{D}$ version of the $2 \mathrm{D}$ web application, which would have been the fourth delivery. This added functionality could potentially enhance Partex's visual capabilities of the circuit park. 


\subsubsection{Assumptions}

For every project executed, it was important to mention assumptions that will shape the expectations of the entire project. It was assumed that Partex's data provided adequate information for the analysis based on the articulated requirements, and the project was not required to collect data separately. Considering Murphy's Law, each task had a buffer time of one to two days so that time did not become tight in any inadvertent situation. In addition, many of the tasks overlapped, as it was good to get started on each task earlier to pre-empt unknown risks embedded in the tasks. As the famous quote goes, "prevention is better than cure", early mitigation is always preferable to last minute resolutions.

\subsubsection{Critical Success Factor}

Based on the project management paradigm, it was important to have a criterion to measure the relative success of the project. For this project, the focus was to improve and enhance Partex's decision-making for their lighting balloons. In order for it to be successful, the client had to give feedback on how the application has improved the general workflow of each decision. The feedback included areas such as whether the user-interface helped Partex understand the circuit park better and provided them with new knowledge of the area (as seen from a top-down perspective), whether the application reduced planning time, and if the recommended locations are adequate for each zone. A successful resource allocation would show significant optimization of placement compared to previous years as well.

\subsubsection{A Reality Check}

This project plan did have its share of setbacks. From the beginning, the ESRI online course that planned for in May did not take place until the 8 June 2010. This was due to the available seats and scheduling of the course. This pushed the entire project timeline back by one month. Thereafter, the process of analyzing, converting the data took longer than expected as more uncertainties and questions about the data arose during the process. It was very important to take note of activities outside the project that took time away from the project and allocate the time wisely in this sense. Beyond that, the time allocated for each individual task was too tight. There was no buffer time given for each task, although there was some allocation to the overall milestone expectations. Due to this delay, the project team decided to merge the first and second delivery, and only deliver the maps together with the first draft of the web application to Partex as described in the first chapter.

The second phase of the project changed, as well, as the project progressed along. The initial communication with Partex was that they needed to know the areas that were very dark, with extra shadows to prioritize the placement. From here, the initial approach was to conduct shadow analysis on features in zones to find shadows. On further and deeper communication with them, the project team realized that Partex already had the dark areas approximately identified based on certain criteria. These were areas identified from previous SGP experience. In addition, the project team overlooked a requirement communicated in an email due to lack of understanding. The requirement surfaced while the team was reviewing the email correspondence from Partex in August 2010. It 
involved placing lighting balloons at booths for directional signage. Although the lighting balloons were in approximately the same area, there were various options around each booth where they could be placed and might affect how well public was able to see the lighting balloon. This involved executing a viewshed analysis, which replaced the shadow analysis in the project as the second phase. This mistake was potentially detrimental to the project if identified in the later part of this project, as it meant that the project failed to meet Partex's requirements. Based on the realigned time schedule, the number of deliverables went from four to two: the GeoPDF map deliverable was integrated with the 2D web application deliverable, and the fourth deliverable of 3D web application was eliminated. This was a lesson learned that what the client was thinking might not be the same as the project team. It was very important to reiterate each other's understanding to eliminate misunderstandings and miscommunications of any kind. Figure 3-6 shows the updated version of this project's timeline, adjusted with the conditions that arose throughout the project.

\subsection{Summary}

This chapter provided an overview of the considerations that went into the system analysis and design of the project. The requirements of the project identified through a process of communicating and understanding the problem statement in depth with the client later influenced its design. With the important components of system analysis and designs identified, the project team proceeded to develop a project plan meant to carry the project to its fruition. However, along the way of the project execution, issues and situations occurred that changed the plans. The importance of clear communication was a major lesson learned during the period of readjustment in project plans and the timeline. 


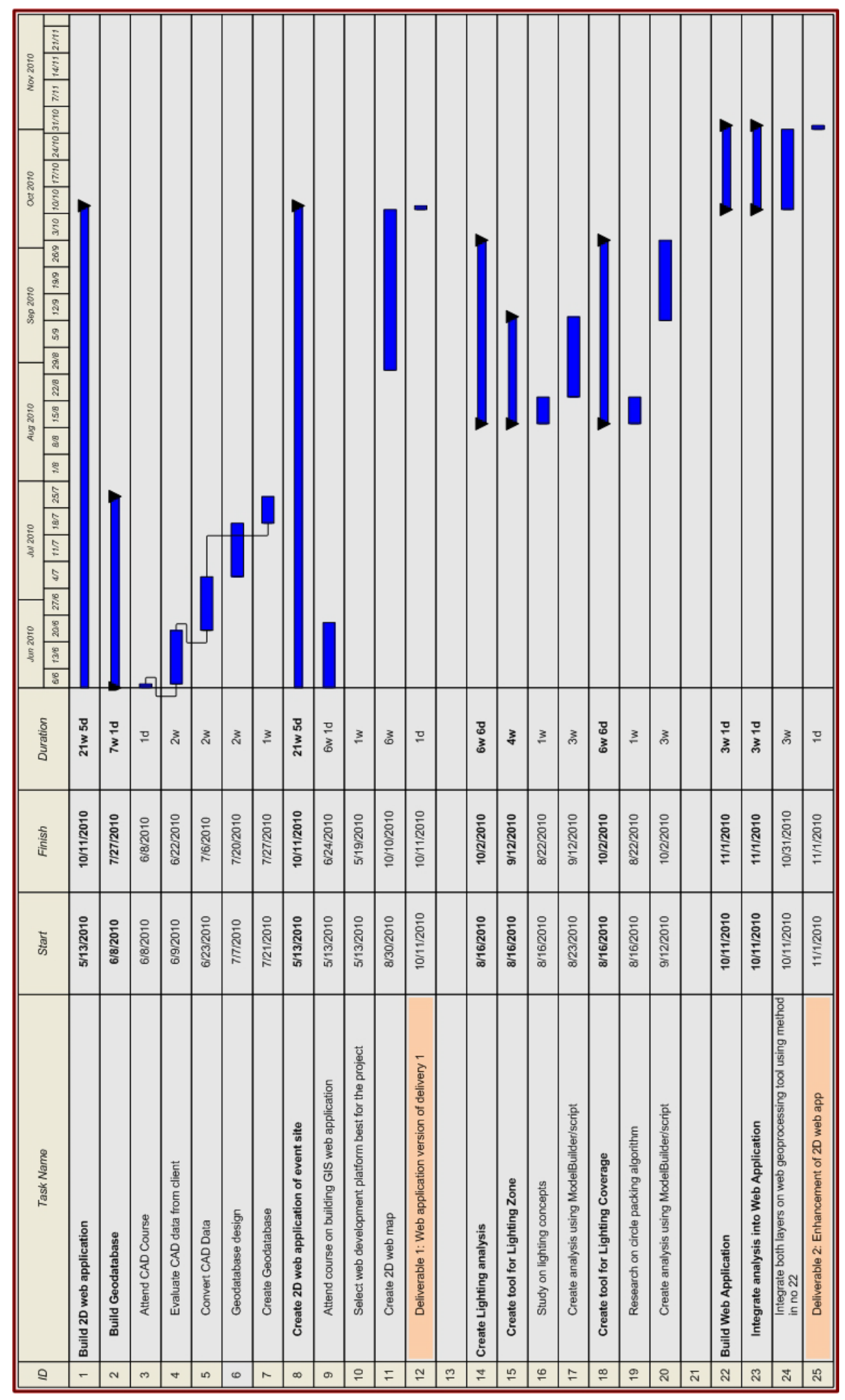

Figure 3-6: Updated project timeline 


\section{Chapter 4 - Database Design}

Once the conceptual planning and requirement analysis for this project was completed, work moved on to the first step of the implementation, which started with building the project's geodatabase. This is a very important step for any GIS project, as it is not good to have irrelevant data in the final geodatabase. The analysis and requirements in this project helped frame the conceptual design of the geodatabase. Furthermore, it required an adequate understanding of the data in order to finalize the detailed process of the analysis. As the SGP event layers came in CAD format, the project team took on an individual study that enhanced the understanding of CAD data and used the knowledge to build a geodatabase that aligned to the conceptual data model of the project. This chapter first describes the conceptual design of a database that meets the project requirements; next, it articulates how the conceptual data model led to the logical data model, which framed the creation of the ArcGIS geodatabase. Beyond articulating the design of the geodatabase, it also documents the process of the data acquisition and data massaging processes.

\subsection{Conceptual Data Model}

With the basic requirements outlined, the project team drafted the conceptual model that fulfilled it. Figure 4-1 shows a diagram of the conceptual model drafted by the project team.

Based on the nature of events, there will be permanent and temporary physical entities represented in the circuit park. Hence, the conceptual design was split into two parts: permanent and temporary elements. The permanent elements captured all the required information that was pertinent to the landscape. The temporary elements had key features used in the event.

Figure 4-1 very distinctly highlights the sub-classes that fell into each element. Within each element, the relevant relationships among sub-classes were determined and symbolized according to the unified modeling language (UML) diagram specifications. For the permanent element, there were seven sub-classes: tree, road, building, traffic sign, lamp post, footpath, and person. The conceptual data model showed the relationships between a tree, traffic sign, building, and lamp post that were found along a road. Besides that, it also showed that a person was typically on a footpath or in a building. For the temporary elements, nine sub-classes depicted the important features for the event. The entire circuit zone defined the event boundary and every subclass was typically located within an operational zone. At the same time, there were relations between racetrack, fence, and grandstand classes. The fence bound the racetrack while the racetrack determined the location of grandstand. The last relationship within the temporary element sub-classes was the one between generator and lighting balloon. The generator was required to provide power for each lighting balloon. After the relationships within each element were finalized, the conceptual model highlighted relationships between subclasses from across both elements. The first set of relationship identified was that the racetrack is part of the road and that grandstands always face the road. The second set of relationships was between the lighting balloon and all the sub-classes. This was the basis for the first analysis of this project. 


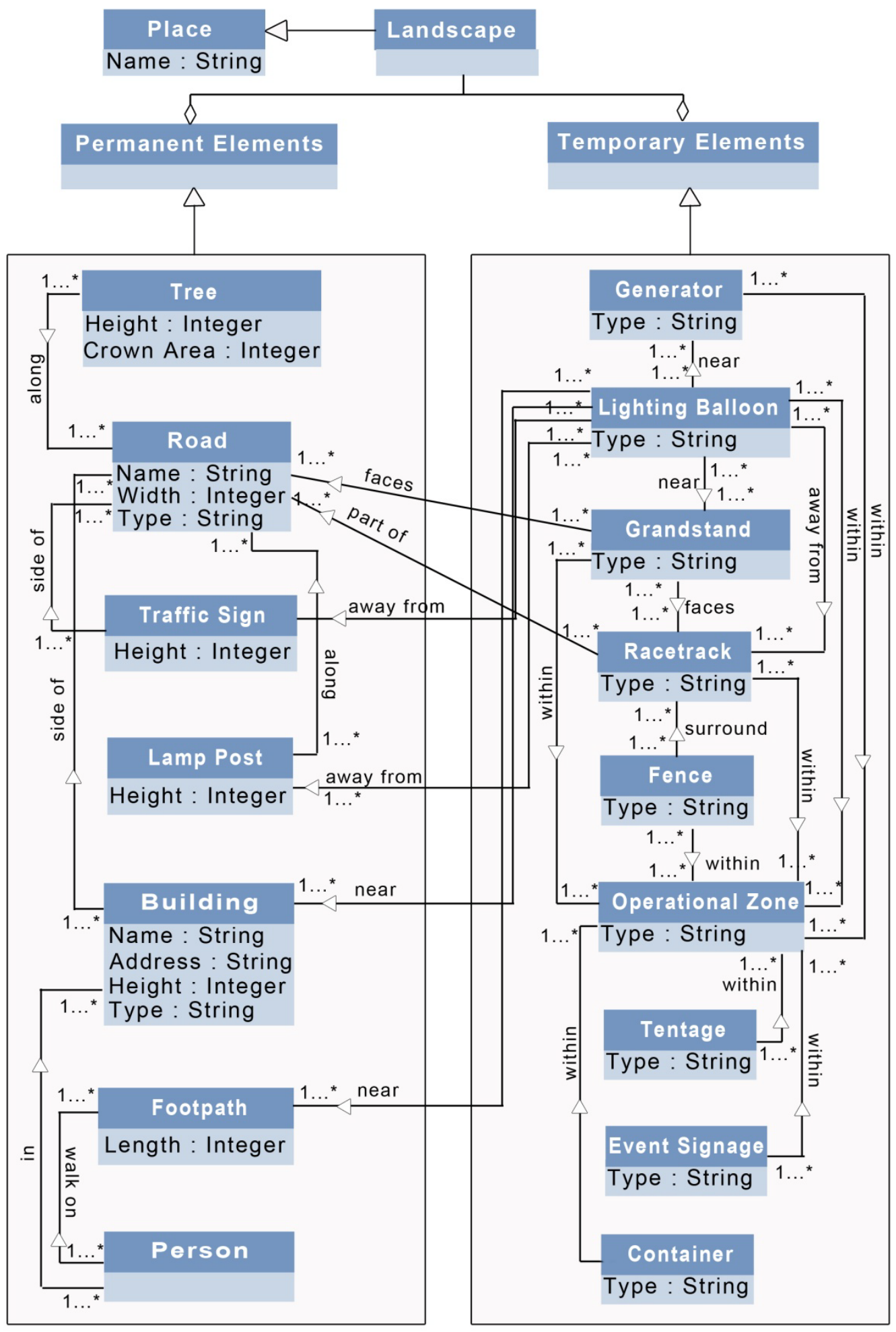

Figure 4-1: Conceptual Data Model Design 


\subsection{Logical Data Model}

After finalizing the design of the conceptual model, the project implemented it into a logical data model using the ArcGIS geodatabase. It was completed during the process of the individual study, as the implementation involved drawing concepts and knowledge of CAD data.

After the conversion of important CAD feature classes was completed, there were still 271 layers. The project decided that 271 layers were too many for this project's geodatabase. Hence, the characteristics and definitions of each feature class were studied in an attempt to group similar features together. The feature classes were grouped into the finalized 19 feature classes, described in the following paragraph. The method used to group the 271 features into the final 19 features was simple and straightforward. First, features that had single data types were set aside. The project team studied each feature class and fitted them into one of the key feature class that best described or defined it. Next, the project team examined features represented by two feature types. From each feature type and the way it was drawn or represented, the most suitable feature type was chosen based on its intended functionality within the project scope. The number of features in each feature type were studied to see if they corresponded to each other and the magnitude of difference between them. The magnitude of difference refers to features with a lack of consistency when comparing between lines and points. In several cases, a few lines were required to represent a feature and only one point was sufficient to represent it. In many other cases, a feature represented in lines may or may not have a corresponding point, and vice versa. The inconsistency in representations made it very difficult to judge the completeness of the data. It was decided to make a general rule to load the feature type with the most features and eventually data scrubbed it into the required feature type. The last step applied a similar approach in which features were represented using three feature types. Details of the process output were also captured in an excel sheet (Appendix A) while it was executed within the ArcCatalog environment.

After the initial study of the data provided by Partex, placing all data into a compact 19 feature classes The 19 feature classes were based on the general names of the features, the project identified two categories that all data fell into: the Base Layer and SGP Layers. The categorization indicated the nature of the feature classes, and whether they were permanent features or temporary event features. In the final geodatabase, there were ten feature classes created under the Base Layer category: building 10k, building 5k, road, street furniture, trees, hydrology, road edge line, road edge polygon, utility, and footpath. These feature classes fulfilled both analytic and cartographic requirements of the project. The analytical layers are the building $5 \mathrm{k}$, street furniture, trees, road edge line, road edge polygon, and footpath. The remaining four layers of building 19k, hydrology, utility, and road served as cartographic additions that helped Partex with situational awareness of the circuit park. As mentioned above, these features classes captured permanent features within the SGP circuit park boundary. For the SGP-related layers, there were nine feature classes identified at the end of the study. They included: fence, event structures, media, operational zones, miscellaneous points, miscellaneous lines, miscellaneous area, lighting balloons, and event roads. The event structures, operational zones, event roads, and lighting balloons were layers involved in the analysis. 
The identification of required SGP layers from the mass of data in the CAD files used the same criteria as the base layers. This was an indication that the data and information required for this project did not call for every feature in the CAD file. Figure 4-2 shows a screen shot of the layers in the final geodatabase.

\begin{tabular}{|c|c|c|}
\hline Contents |Preview | Metadata | & & \\
\hline Name & Type & Size \\
\hline 国 Building_10k & File Geodatabase Feature Class & $1.00 \mathrm{MB}$ \\
\hline 团 Building_5k & File Geodatabase Feature Class & $1.01 \mathrm{MB}$ \\
\hline It] EventRoad & File Geodatabase Feature Class & $17.99 \mathrm{~KB}$ \\
\hline 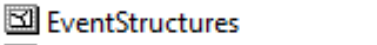 & File Geodatabase Feature Class & $814.20 \mathrm{~KB}$ \\
\hline 1 Fence & File Geodatabase Feature Class & $1.13 \mathrm{MB}$ \\
\hline II Footpath & File Geodatabase Feature Class & $240.61 \mathrm{~KB}$ \\
\hline 国 Hydrology & File Geodatabase Feature Class & $58.14 \mathrm{~KB}$ \\
\hline 团 Kerb & File Geodatabase Feature Class & $528.69 \mathrm{~KB}$ \\
\hline$\because$ LightingBalloons & File Geodatabase Feature Class & $6.36 \mathrm{~KB}$ \\
\hline$\because$ Media & File Geodatabase Feature Class & $12.63 \mathrm{~KB}$ \\
\hline MiscArea & File Geodatabase Feature Class & $24.24 \mathrm{~KB}$ \\
\hline I] MiscLine & File Geodatabase Feature Class & $736.61 \mathrm{~KB}$ \\
\hline$\because$ MiscPt & File Geodatabase Feature Class & $97.95 \mathrm{~KB}$ \\
\hline 团 OpZone & File Geodatabase Feature Class & $16.98 \mathrm{~KB}$ \\
\hline A OpZoneAnno & File Geodatabase Feature Class & $41.15 \mathrm{~KB}$ \\
\hline A OpZoneAnno2 & File Geodatabase Feature Class & $42.53 \mathrm{~KB}$ \\
\hline II Roads & File Geodatabase Feature Class & $44.50 \mathrm{~KB}$ \\
\hline 쇼 RoadsAnno2 & File Geodatabase Feature Class & $93.17 \mathrm{~KB}$ \\
\hline 쇼 RoadsAnno3 & File Geodatabase Feature Class & $81.16 \mathrm{~KB}$ \\
\hline$\because$ StreetFurniture & File Geodatabase Feature Class & $146.25 \mathrm{~KB}$ \\
\hline$\because$ Trees & File Geodatabase Feature Class & $270.98 \mathrm{~KB}$ \\
\hline \pm Utility & File Geodatabase Feature Class & $571.42 \mathrm{~KB}$ \\
\hline Q7. FinalDesktopTools & Toolbox & \\
\hline هiflexLC & Toolbox & \\
\hline
\end{tabular}

Figure 4-2: Layers from the final geodatabase

After finalizing the number of feature classes and their categorization in the geodatabase, the focus shifted to ensuring that the necessary attributes were available in each feature class. For the buildings from the base layer, attributes included building name, building type, and address, as they were the key attributes that would provide Partex with information about the features within the SGP circuit park. The address field was sub-divided into "road name," "block number," and "Postal Code." This was to simplify the search function configured within the web application. The road feature class captured road names, one-way information, road classification, and speed limit. This information was provided by the military mapping unit and kept for possible use in the future. The rest of the layers extracted from the CAD files only had "name" and "type" information due to the lack of attribute information from Partex. For analysis purposes, a new height field was added to the building $5 \mathrm{k}$, building $10 \mathrm{k}$, event structures, and street furniture feature classes. This was to facilitate the viewshed analysis in the future. The detailed data and schema report of the final geodatabase generated from the ArcGIS Diagrammer are complied in the final CD of this project. 


\subsection{Data Sources}

As Partex did not have a GIS system running, the data provided by them were of spatial and non-spatial nature. The spatial information and data were CAD-based DGN files, provided to them by the SGP organizers. These CAD files went through conversion during the individual study to GIS formats for analysis and cartographic purposes. The non-spatial data provided were technical datasheets of relevant lighting balloons, and a spreadsheet that kept track of deployment details of lighting balloons and zones. They also provided operation zones (Figure 4-3) in the circuit park area, as well as photometric specifications of the lighting balloons.

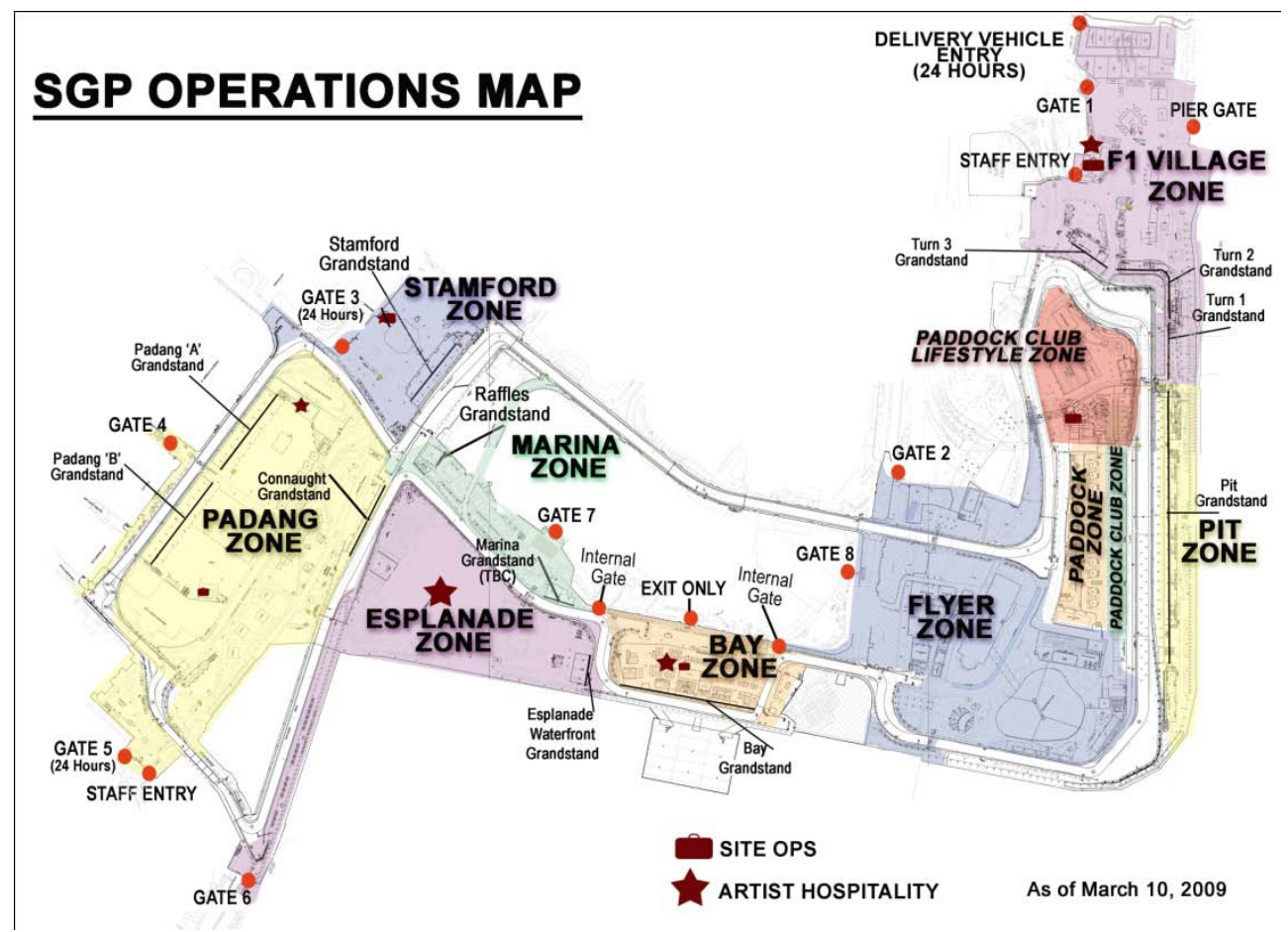

Figure 4-3: The Operational Zones of the SGP Event. 
Photometric specifications provided the diameter of the sphere of illumination and the amount of lux (a measure of illumination) emitted as the distance away from the bulb increased (Figure 4-4a,b).

\section{Sirocco 4000W HMI}

\section{The balloon
(33ft / 49ft)}

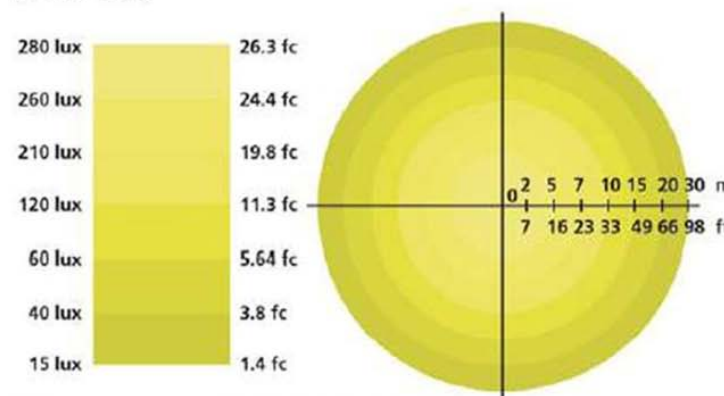

\section{Sirocco 2000W Halogen}

The balloon offers an optimal light between 2.5 and $5 \mathrm{~m}(8.2 \mathrm{ft} / 16.4 \mathrm{ft})$

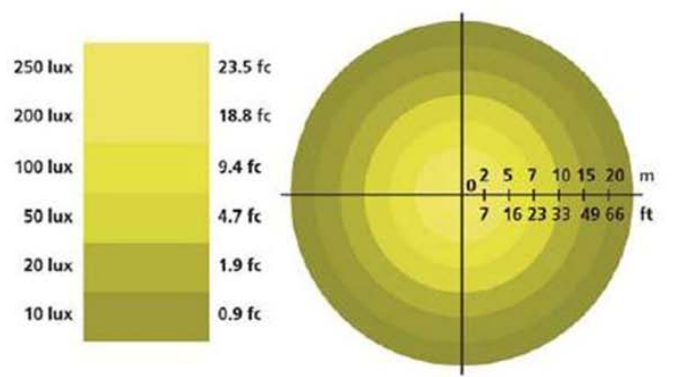

\section{Sirocco 3000W HTI}

The balloon offers an optimal light at $8 \mathrm{~m}(26 \mathrm{ft})$

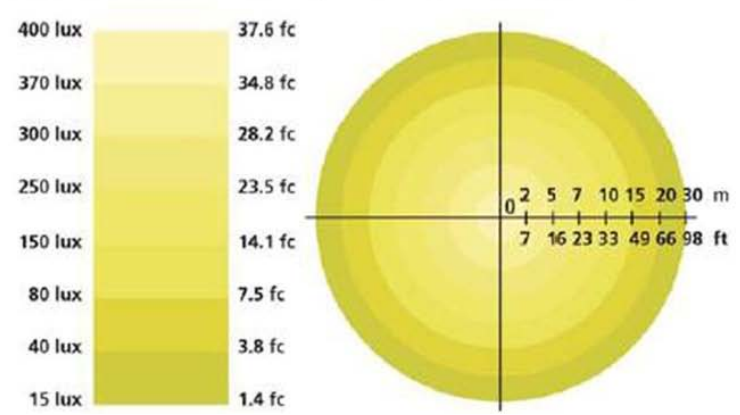

\section{Sirocco 1200 W HMI}

The balloon offers an optimal light between 2.5 and $5 \mathrm{~m}(8.2 \mathrm{ft} / 16.4 \mathrm{ft})$

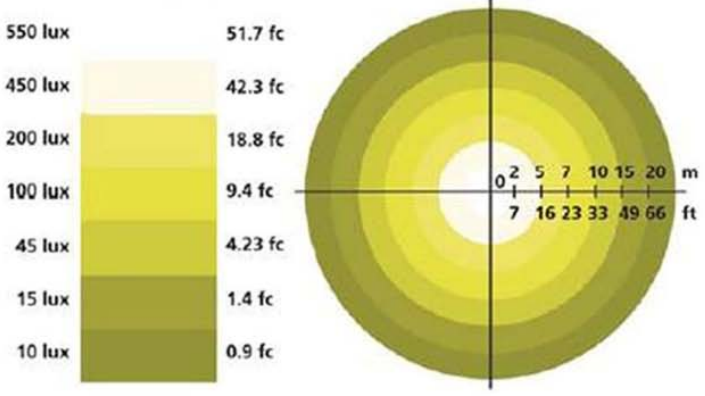

\section{Sirocco 1000W HTI}

The balloon offers an optimal light between 2.5 and $5 \mathrm{~m}(8.2 \mathrm{ft} / 16.4 \mathrm{ft})$
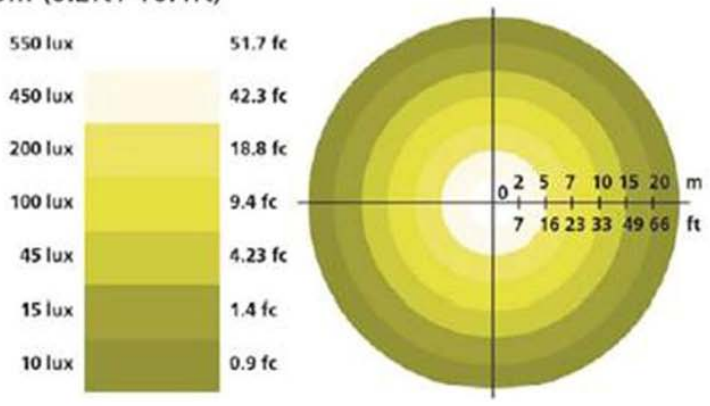

\section{Figure 4-4a: Photometric Specifications of Sirocco Lighting Balloons}


Crystal 160

2000 W halogen

$40 \mathrm{~m}$

<surtace $>$

$1200 \mathrm{~m}^{2}$

at a height of $5.5 \mathrm{~m}$

114 lux

1 lux

200 lux

1 lux

at a height of $5.5 \mathrm{~m}$

at a height of $5 \mathrm{~m}$
Crystal WR

2400 W halogen

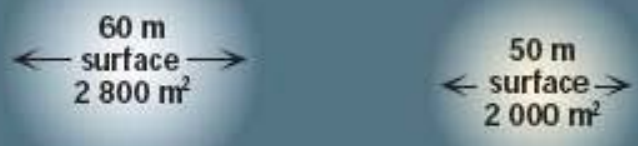

Figure 4-4b: Photometric Specifications of Crystal Lighting Balloons.

The project also obtained spatial data from the Singapore Armed Forces Mapping Unit (SAFMU). They provided vector files of key buildings, roads, hydrology, and satellite image of the SGP circuit area. This information was crucial as a reference for working with the CAD data layers and as base layers for this project.

\subsection{Data Scrubbing and Loading}

After attending the ESRI Understanding CAD virtual class, the project team sought to apply the knowledge garnered and further explored the data in-hand. This process helped tremendously in understanding the nature of the aquired data and provided a deeper study of various types of features represented by the CAD data.

Due to the amount of data provided by Partex, and the uncertainty of what many data represented, the project combed through the entire data extent of the CAD files and compared it with satellite imagery to provide a rudimentary definition of features in the CAD files. Over several comparisons of data, the project team noticed that polylines, polygons and points used to represent the same feature types did not have the same feature count for each data type (i.e., there would be 1000 polyline features, 500 polygons and 800 points for the same feature type). This knowledge increased the amount of time spent on interpreting and processing each feature.

Data conversion was the first step taken to bring the data closer to a GIS compliant state. First, the project team overlaid each of the three CAD files onto the satellite imagery provided by SAFMU to geo-rectify them. Then, the project team applied the Fit to Window function in ArcGIS Geo-referencing tool that fitted the first CAD file with the satellite image extent. Next, the CAD file was shifted around to obtain a best-fit position, using building outlines and curb-lines on the satellite image as references. After finalizing the CAD file position, the project team saved the geo-referencing information as a world file, for application onto the next two CAD files. However, the next two CAD files did not successfully fit onto the imagery. The CAD file took up only a small fraction of the entire image and the "Fit to Window" and "Scale" functions in the Geo-referencing tool were not successful in making any changes to the CAD file. After one day of trial 
and error without any success, an Arc Script written by Don Kuehne (arcscripts.esri.com) was found that applied the world file onto CAD data through the AutoDesk software. This method worked and both CAD files aligned successfully to the imagery.

Subsequently, the CAD files were converted to feature classes, and extracted based on CAD-indicated type and spatial type (i.e., polygon, polyline, point). At the final extraction, there were 91 features in the first CAD layer (Figure 4-5), 51 features in the second CAD layer (Figure 4-6), and 129 features in the third CAD layer (Figure 4-7). The numbers were high due to the way CAD data had been organized and represented; some features had points, lines, and polygons representing them. With the original CAD data separated, the project team went through the data and identified, and defined each feature with the help of the client. This enabled filtering of the essential layers for the project. An observation was that for most features, the polyline representation provided the most details about each feature and hence the polyline feature was usually the choice of layer to be loaded into the final feature class. Exception occurred when features like water hydrant, trees, lamp post, traffic light etc. were identified as point data and preferred over lines or polygons for cartographic reasons. In addition, for many features, the initially chosen line feature was not the ideal feature type for representation. Hence, the data went through further cleaning, converting among types and topology checks to bring it up another level, and ready for analysis. 


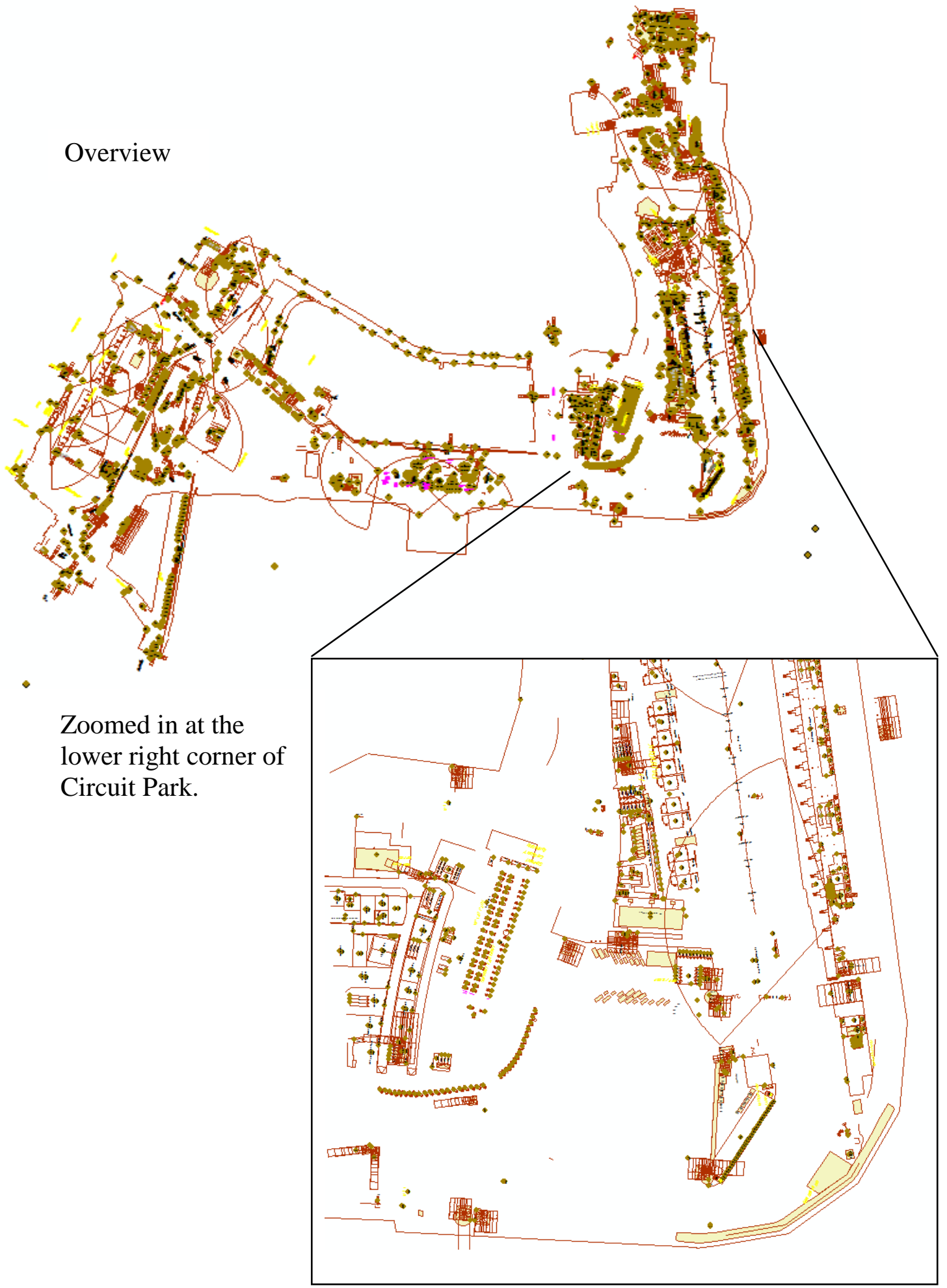

Figure 4-5: CAD layer 1 with layers in circuit park not related to racing. 


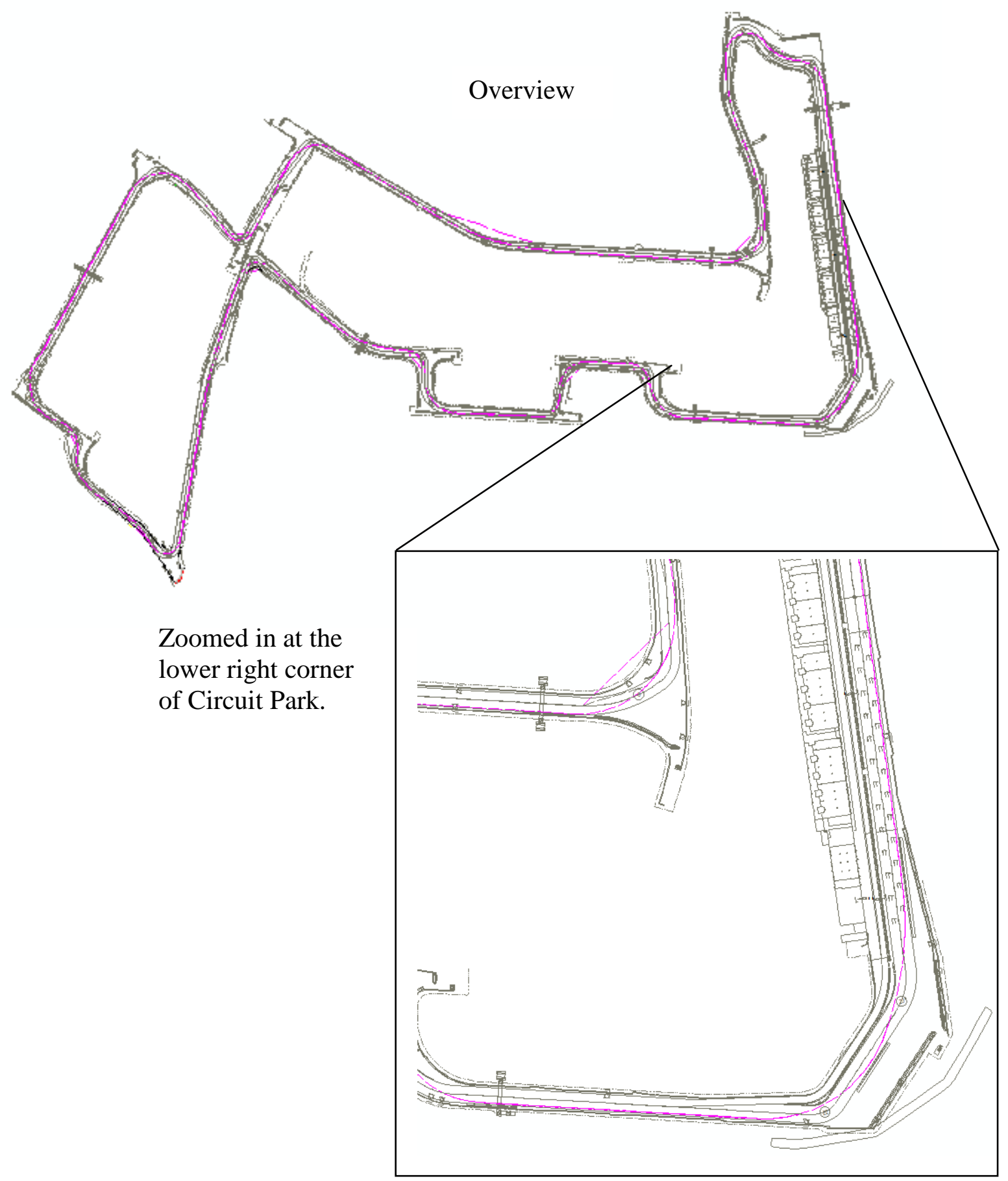

Figure 4-6: CAD layer 2 with layers pertaining specifically to racing. 


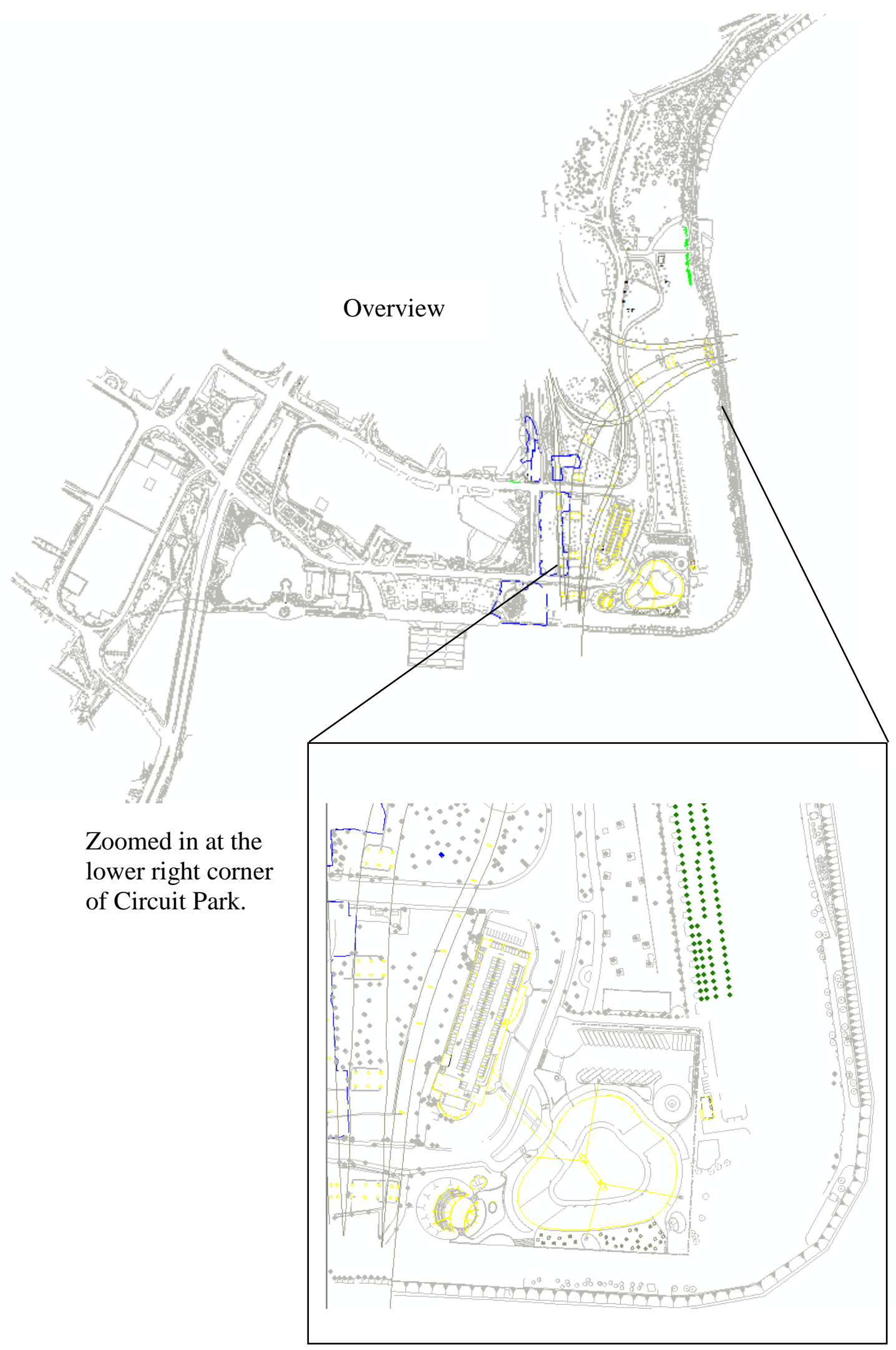

Figure 4-7: CAD layer 3 with permanent features in the circuit park. 


\subsection{Summary}

This chapter was devoted entirely to describing the process of building the project geodatabase, often acknowledged as the most crucial and most difficult part of a GIS project. The data for this project came from two main sources: Partex and SAFMU. The chapter started by introducing the conceptual design of the geodatabase derived from the raw inputs of the project requirements. Following the conceptual design, the logical database design generated drew mostly from the specific analysis and cartographic requirements of the project. The logical design also captured the considerations and process of creating the final geodatabase. Finally, the chapter ended by describing the details and process of converting the CAD data to feature class. With the completion of the geodatabase, the project transitioned into the implementation phase, which focused on analysis and solution for the project, discussed in Chapter 5. 


\section{Chapter 5 - Implementation}

Once the foundation of the project was set, the project team started working on the two analyses required to meet the client's requirements. The analyses were the crux of the entire project. All the planning done for this project prepared and expedited this phase, and ensured a smooth process. The process and challenges of this project phase was used as an indication of how well the project planning was done.

This chapter first communicates the concepts, design, and approaches that the project team took to create each analysis. The first created by the project team was the lighting zone analysis, which identified areas that required lighting within each operational zone. It captured the process of designing the analysis flow and transferring it onto the model builder in ArcCatalg. Next, the section discusses the steps taken to create the analysis on Python and the reason for choosing Python as the analysis environment. Before moving onto the second analysis, the section examines the results from the analysis.

The second analysis was of lighting coverage that provided the lux values based on user input. The project team first sought to understand the concept of lighting charts provided by Partex. Instead of working with Model Builder as the first cut before bringing the analysis into the Python-scripting environment, the second analysis worked directly with Python. The second analysis section also covers how the team worked on designing an analysis flow with specific tools selected for the scripting. It then delves into the key parts of implementing the analysis into Python and an explanation of the output rasters.

Finally, this chapter highlights and discusses the challenges and lessons learned in the process of creating the analyses.

\subsection{First Analysis - Lighting Zones}

The first analysis during the project analysis and design stage was to identify areas within the operational zone Padang that required lighting. The following sub sections will describe in more detail about each phase that the project team went through to complete the analysis. Figure 5-1 shows the general phases undertaken by the project team for the first analysis. 


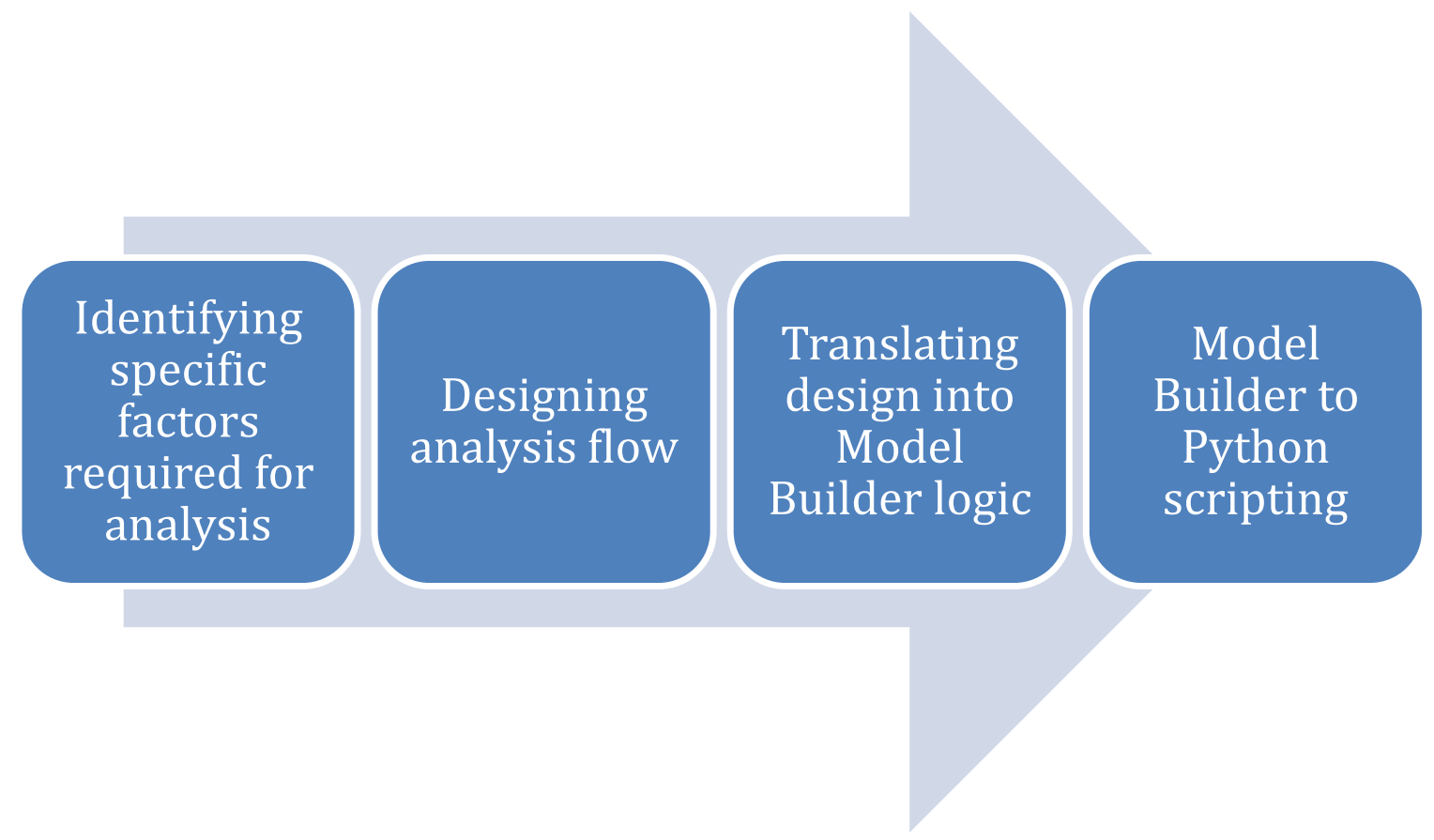

Figure 5-1: Workflow for creating first GIS analysis

The project team first collected information from Partex on areas and factors they looked out for when placing the lighting balloons. Next, the team worked on designing a workflow fitted into the context and scope of the project. After designing the analysis flow, the team implemented the flow into the model builder. The final step was to translate the entire Model Builder analysis into a Python script used for the final web application.

\subsubsection{Factors required for analysis}

After the preliminary project planning, the project team conducted further discussions and correspondence with Partex to understand the specific conditions and environments in the circuit park. In the early stages of planning, the lighting requirements as articulated by Partex were for safety, directional signage, and aesthetics. However, these were very generic and did not provide a deeper definition of what constituted safety or directional signage. Moreover, these were the basic requirements set by the SGP organizers for Partex. Hence, Partex made use of experience from past events and placement errors to decide on the final position of each lighting balloon. The project team worked with Partex and discussed in detail how they had placed the lighting balloons over the past two years. Partex worked through the entire procedures over the two years of SGP and singled out features that they would avoid and features that need lighting. From here, the project team moved on to assigning priority levels for each feature identified by Partex. There were two levels of priority setting: negative, which referred to features avoided by Partex, and positive, which indicated features requiring lighting. Table 4 shows the grouping of features by priority levels. 
Table 4. Priority levels based on features

\begin{tabular}{|l|l|}
\hline Features to avoid (Group 1) & Features that require lighting (Group 2) \\
\hline 1) Racetrack & 1) Buildings \\
2) Roads & 2) Monuments \\
3) Event Signage & 3) Footpath \\
4) Traffic Signage & 4) Lamp post blocked by trees \\
5) Grandstand & \\
\hline
\end{tabular}

In Group1, the considerations were as much for safety as they were for practical and logical reasons. First, lighting along the F1 racetrack emulated daytime light as closely as possible for the drivers' safety. Hence, Partex had no interest in placing the lighting balloons along the racetrack as it was already well lit. Almost similar to the racetrack were the avoidance of lighting balloons near the roads. Avoiding roads was not due to existing powerful lighting, but that the glare and reflection effect between the lighting balloons and roads might have adverse effects on drivers. At the same time, Partex did not want lighting balloons to be too close to any signage. The logic given by Partex was that the similar height of lighting balloons and signage previously blocked the signage from pedestrians' sight. The last feature to avoid was the grandstand. Grandstands had to be avoided as they were near the racetrack and pedestrians were limited from walking directly under the grandstands. Hence, Partex felt that by avoiding it, they were able to light up areas where pedestrians were mostly found.

Group 2 highlighted the features that require lighting. The buildings, monuments, and footpath needed lighting as these were locations with the most pedestrians. The lighting balloons not only provided lighting, but also aesthetics around these features for pedestrians to enjoy. The last requirement for lighting that Partex mentioned were areas where the trees blocked lampposts lighting. This was to supplement lighting for such areas.

The next step in the creating the analysis workflow was designing the analysis flow. These priorities and requirements set the basis for the project team to design the analysis flow. The next sub-section covers the process in determining the analysis flow.

\subsubsection{Designing the analysis flow}

The first step in designing the analysis workflow was to filter out feature classes that contained the required features identified in the previous sub-section. Next, the project team had to decide how the analysis quantified features that needed to be near lighting and features that needed to be away from lighting. Partex only provided criteria and conditions for lighting.

Working with this information, the project team decided that each feature had to have a boundary around it with some distance indicated by Partex for lighting placement. This was because for each feature that the lighting balloons were to avoid, there had to be a minimum distance specified. Likewise, for features that required lighting, it was not 
possible to place the lighting balloons by the features as the lighting glare causes discomfort for pedestrians. The project team inquired about the distance that the lighting balloons had to be from the identified features. Partex did not have an established distance and hence, the project team decided to include the distance as a user-input parameter in the analysis. The project team decided on using the Buffer tool in ArcCatalog to indicate the distance inputs from each feature. The output was a buffer of the features based on distance indicated by user. This provided the generic boundary for placement of lighting balloons within an operational zone.

After finalizing this step, the project team realized that it had overlooked an important component of the analysis. Whenever a buffer was created, the default setting for output combined the feature and buffer zone. This was acceptable for the features that lighting balloons needed to avoid, but not for the features that required lighting, which needed to have lighting around them, to illuminate them, but not on top of them. This realization led the project team to study the buffer tool closer to find a solution. The team discovered that the buffer tool had an option to indicate that the output only contained the difference between buffer area and feature (i.e., outside_only). The team then had to include the actual boundaries of these features with those that the lighting had to avoid. With this solution, the project team sketched the analysis flow shown in Figure 5-2.

As mentioned in the first paragraph, the project team identified the relevant feature classes and extracted the relevant features as required. Step 2 was required as some features were subtypes of feature classes and several feature classes held more than one feature class relevant to the analysis. Next, the analysis grouped the layers based on priority and ran the buffer tool with distances derived based on the priority level. There were two approaches branching out from the previous step leading to the final output of the analysis. Both approaches took areas that did not fall into the priority levels as neutral, which indicated recommended areas to place lighting balloons. The initial approach merged all buffers regardless of priority and negated the layer with the operational zone to get the neutral areas. After much discussion within the project team, it was decided that retaining the priority levels in the final output was a more desirable and complete output. Hence, the project team put together the second approach used in the final analysis flow. The next sub-section describes the process of translating the analysis flow into ArcGIS Model Builder and the project team's decision on the optimal output format for the analysis. 

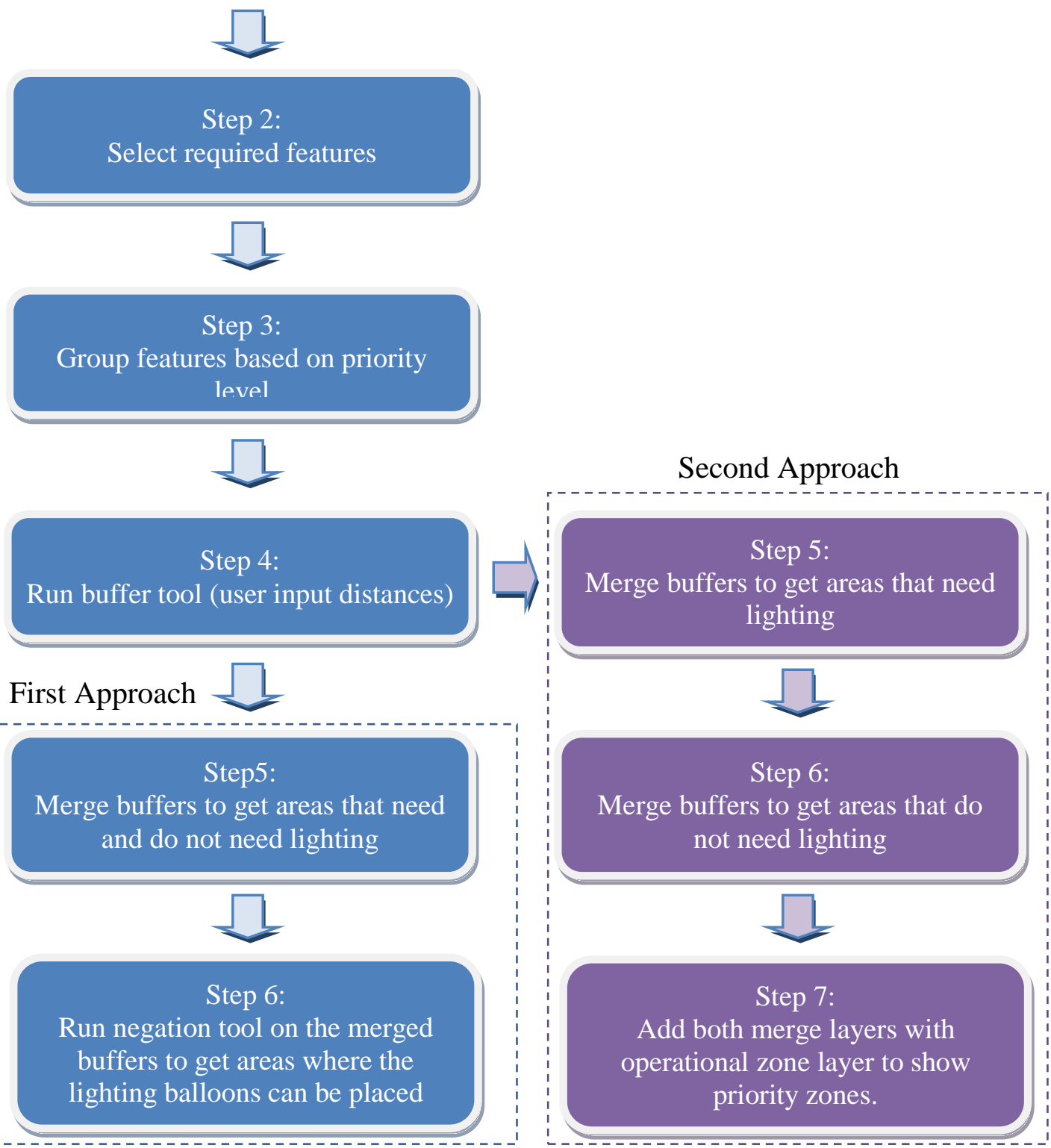

Figure 5-2: Analysis flow to find areas where lighting balloons can be placed.

\subsubsection{Creating the analysis in Model Builder}

Once the analysis flow was in place, the project team started work on the model builder. The team first put all the feature classes required for the analysis into the model builder workspace, followed by the necessary tools. Figure 5-3a shows steps one through four carried out for each feature while Figure 5.3b shows the workflow for all required features for the analysis. In Figure 5-3a, the select tool with region of interest as output 
were addition of new tools to the model that were not discussed in the analysis flow. It facilitates analysis focused within the study area. The study area identified in Chapter 1 was Padang and Esplanade, which were part of the operational zone feature class. In order to extract features within this study area, the user had to select the region of interest and clip the features within the zone.

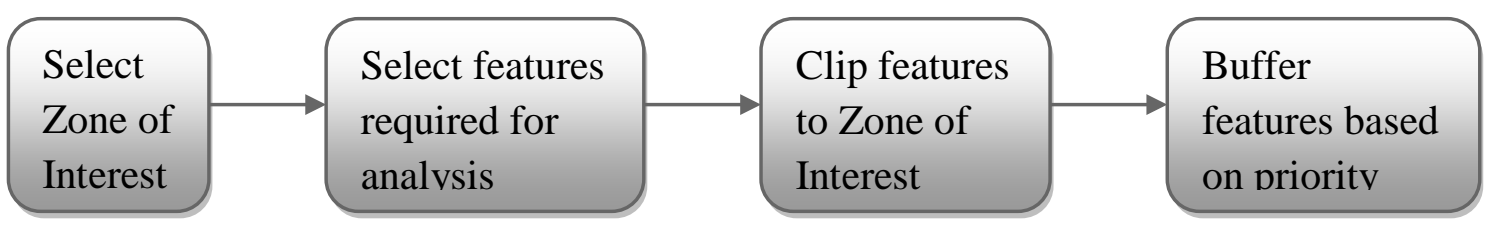

Figure 5-3a: Analysis flow captured in model builder for each required feature.

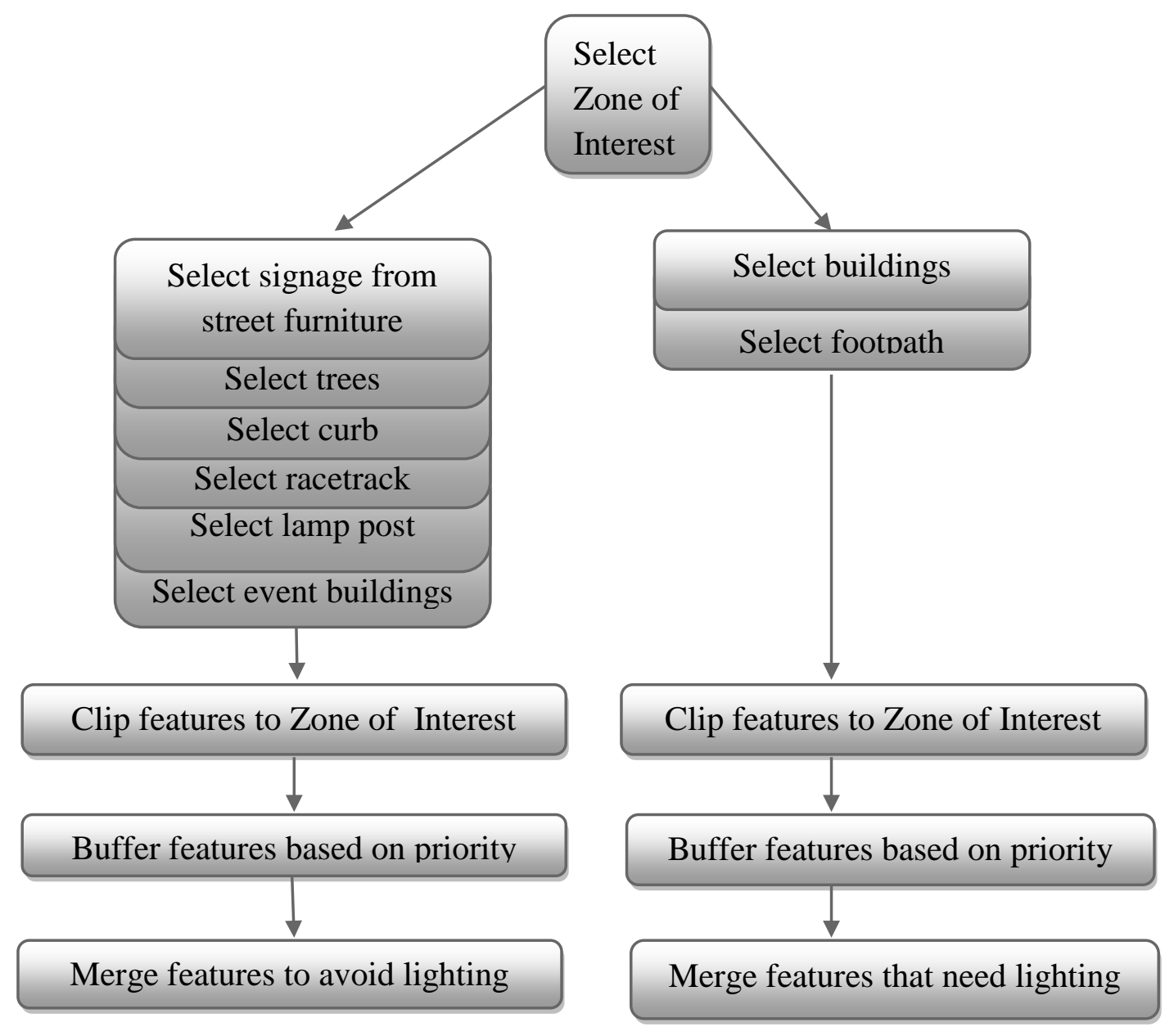

Figure 5-3b: Entire flow in model builder for all features in analysis.

Figure 5-3b shows a distinct grouping and arrangement of model components by priority levels. It helped organize the analysis and structure it for the next steps, which included merging the buffered layers by priority. Figure 5-4 shows the steps taken and tools used to calculate the final output of priority zones in vector format. 


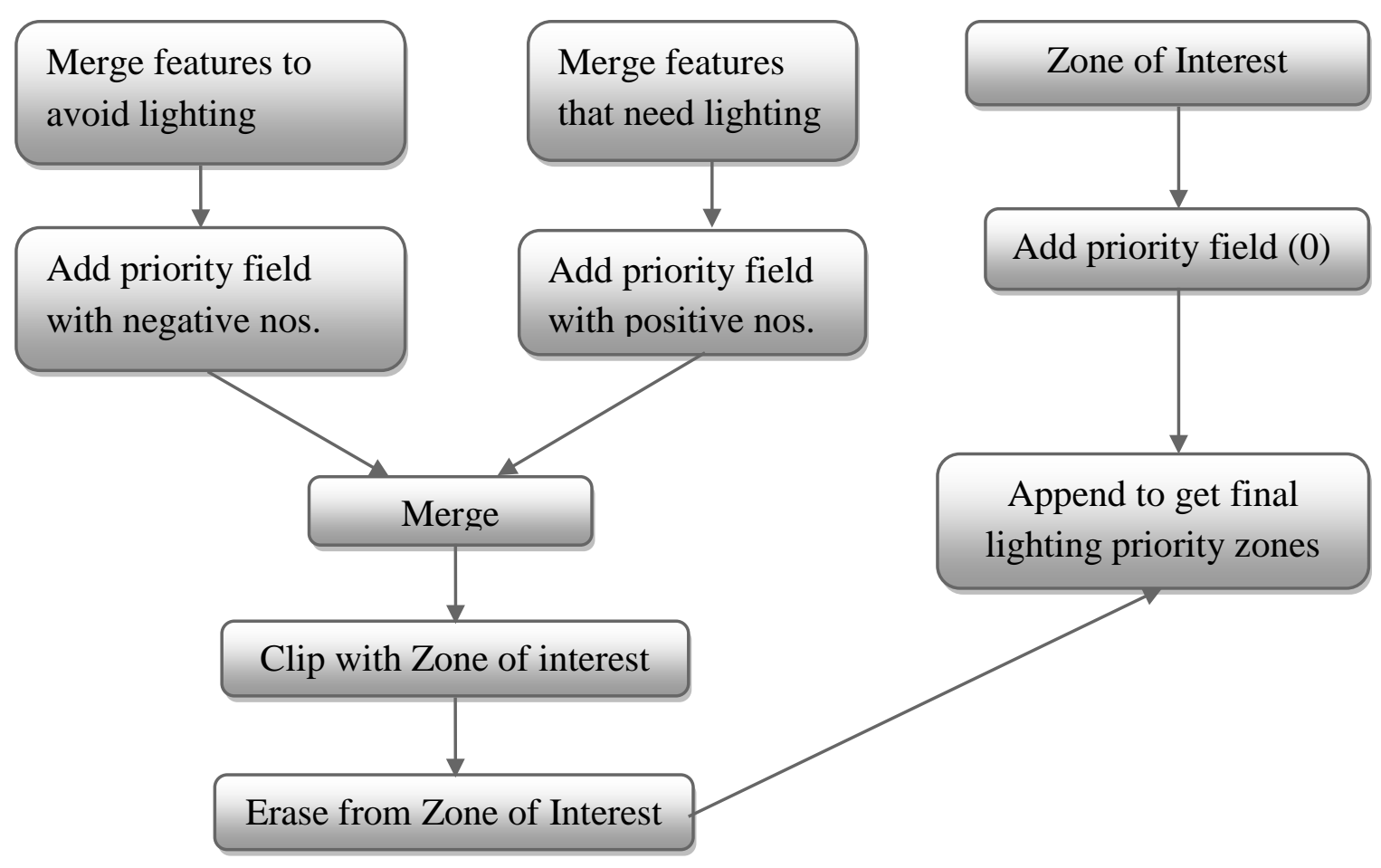

Figure 5-4: Merging buffered layer and combining them into final output.

The first steps in Figure 5-4 were to merge the features by priority of lighting. After merging the relevant features from each priority, the team had to add a new field to each merged layer, and used the calculate field tool to indicate the lighting requirements. This step was necessary to provide an identity for each layer for the later steps where the merge and append functions were applied. Similar add and calculate field tools were applied to the region of interest layer selected by the user. In order to get the final layers with the three different lighting requirements, the project team had to first merge both buffers where lighting was required and not required. Subsequently, a clip tool was applied to it in order to keep the buffered areas within the study area, and an erase tool used to separate areas where placement was recommended. Once the model generated all the relevant layers, it appends the three layers together for the final output.

The project team next reviewed the analysis and experimented with using raster as an output instead of vector. Figure 5-5 shows the difference in steps when adopting the raster output workflow. 


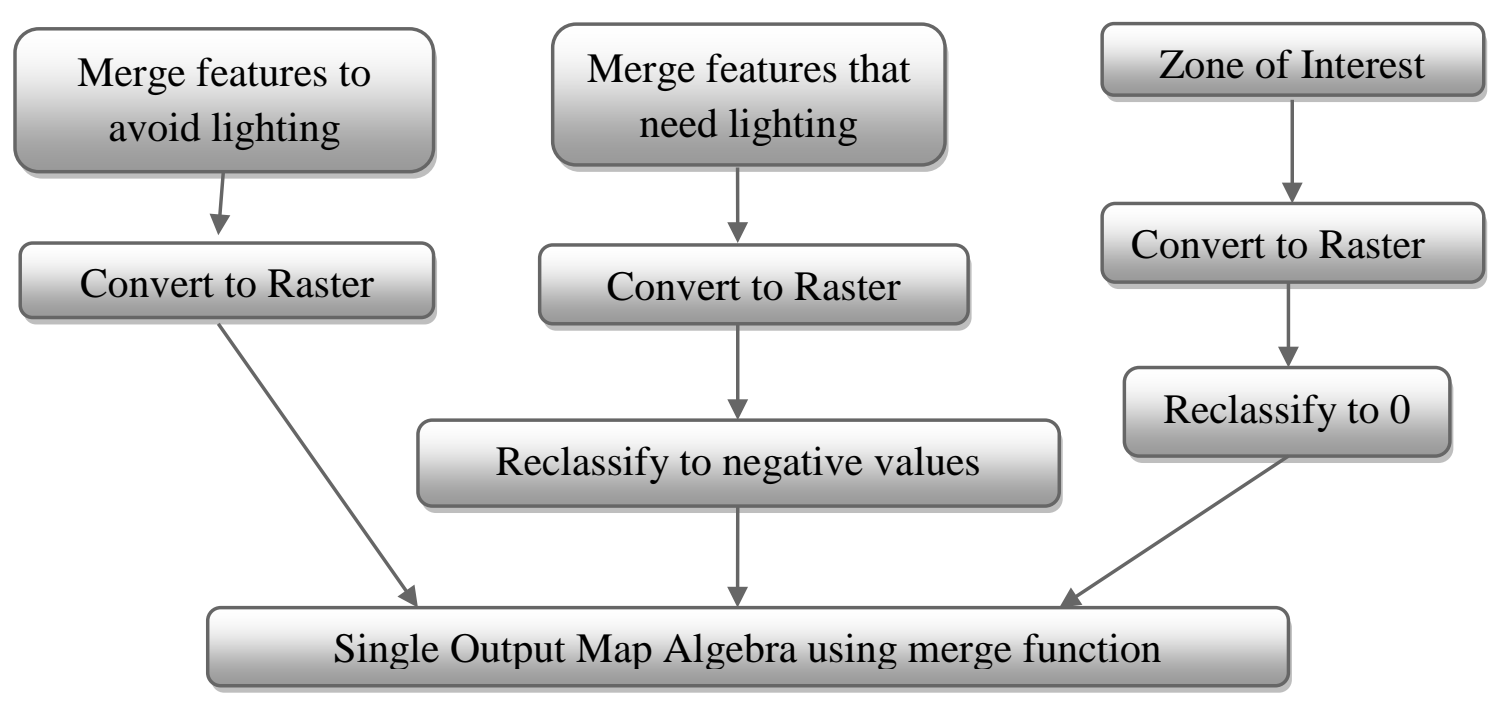

Figure 5-5: Model builder workflow for raster output.

The raster workflow showed a significant reduction of steps required to reach the same final output. This was due to functionality in raster tools in the way it calculated the sum of cells and it was possible to specify the extent of raster for analysis. In the raster approach, the region of interest and two merged buffers went through conversion to raster datasets. Next, the layers were reclassified to hold values relevant for the final output raster. Positive values went to the layer that held buffers that required lighting while the layer with features and buffers to avoid lighting had negative values assigned to it. In both layers, each positive or negative value represented each feature used in the analysis. Finally, the Single Output Map Algebra tool executed a merge function on the three layers to produce the final raster output that captured priority zones within the study area or any other region of interest. This model ran significantly faster than the previous model due to the reduction of steps and the use of ArcGIS's in-memory functionality. The in-memory function allowed temporary storage of intermediate vector outputs in the computer, hence reducing time taken to commit the layers into any workspaces.

In the final model, there were seven parameters in the model where six were the distances from features. The first parameter was a user-specified input of region of interest that determined the study area for the analysis. Refer to Appendix B for snapshot of entire analysis on model builder.

\subsubsection{Model Builder to Python Scripting}

After the project team was certain that the analysis was sound and worked well, it moved on to work on the user-friendliness and editing ability of the tool. Two key factors influenced the project team's decision to bring the entire analysis from model builder into the python-scripting platform. The first factor was the complexity of the model. With so many components linked to each other, the model made it difficult for anyone looking at it for the first time to understand it.

The second factor was due to the method of selecting the region of interest. The default method of selection was using SQL query in the select tool. The project team felt 
that it was not necessary for Partex to learn and go through the process of creating and SQL statements. The team wanted the parameter to have a drop down bar that indicated the available zone selections so that Partex only had to select the zone of interest, as shown in Figure 5-7.

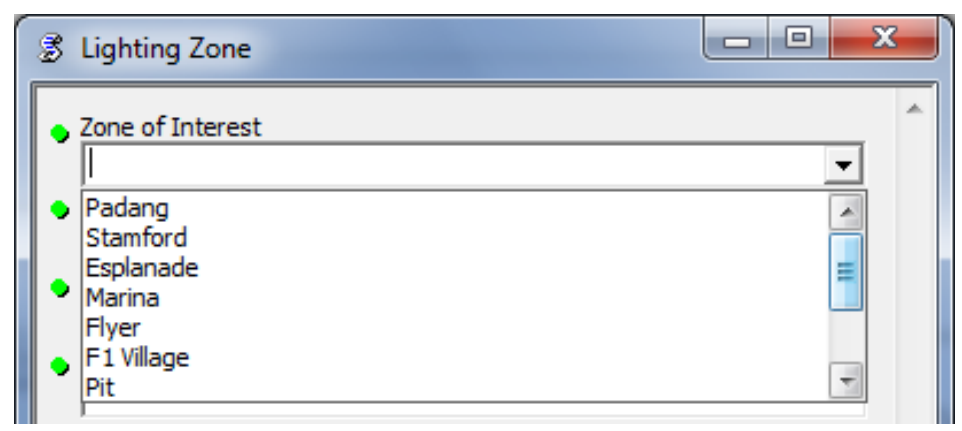

Figure 5-6: Drop down bar for Partex to select zone of interest.

The figure above allowed Partex to select specific zones without having to know SQL query. With these two factors, the project team worked on creating the script that allowed the use of value list through python and simplifying the analysis organization. The process was quick as model builder allowed exporting of the analysis into the python-scripting environment. The project team used the exported script as a basis to build the final Python script for the lighting zone analysis. At the end of the script, the project team added a step not in the model builder. Other than classifying the important features in the final output, a new field was added to the output raster, which indicates the lighting requirements using almost Boolean functions. Areas that required lighting had "Yes" assigned to the field; areas that lighting balloons needed to avoid had a "No"; and areas recommended for placing lighting balloons had "Neutral." Neutral was used to indicate that there were no lighting requirements and hence good for lighting balloon placements. Figure 5-8 shows the final analysis interface launched from ArcCatalog.

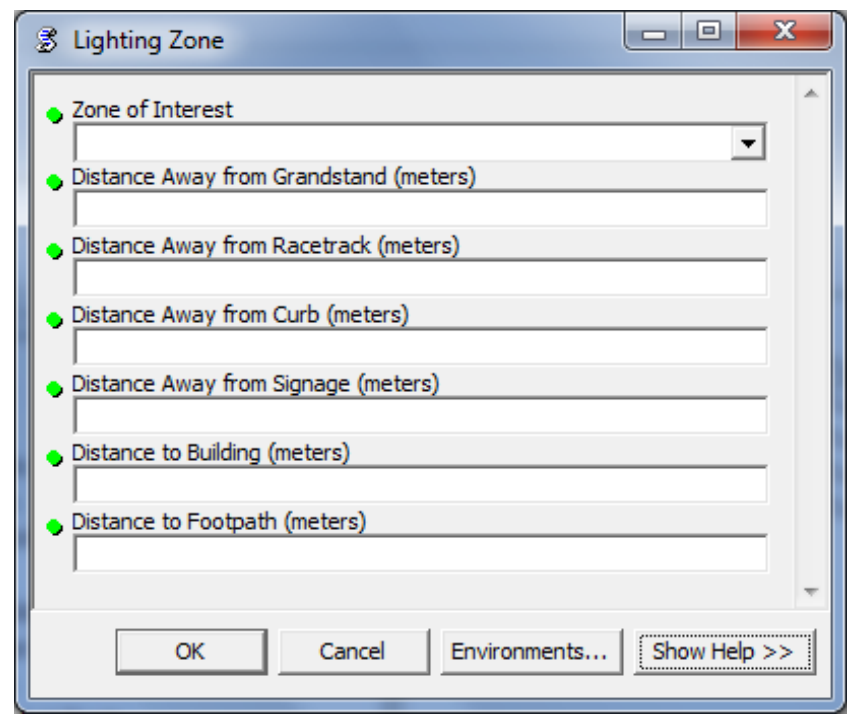

Figure 5-8: Final analysis interface 


\subsubsection{Results}

Throughout the design process and creation of the analysis, the project team had in mind what the output needed to capture. Figure 5-9 is a screen shot of the final raster output for lighting zone analysis.

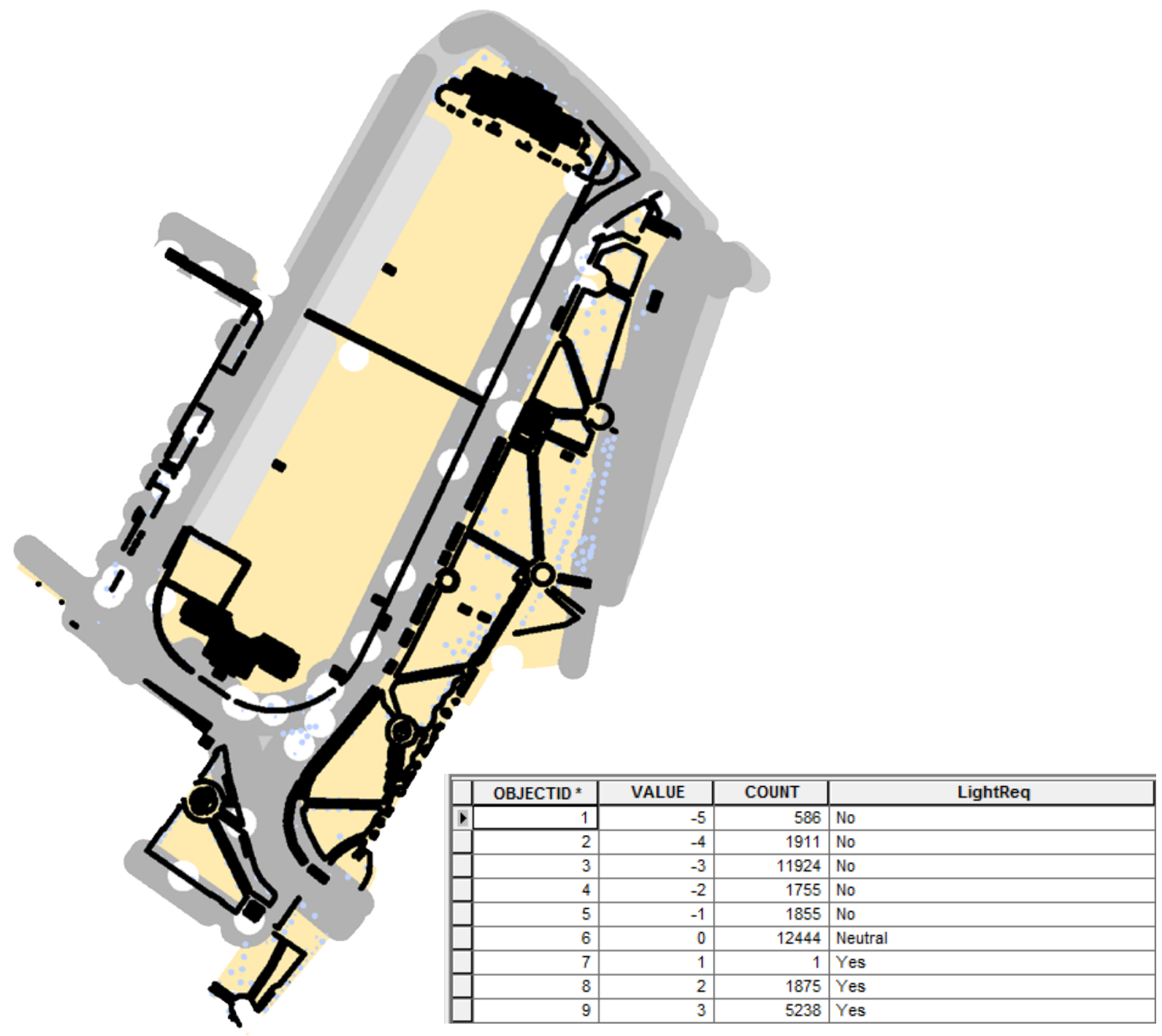

Figure 5-9: Final raster output

In this layer, all the relevant features were still retained in it through the reclassification process. The signage layer was assigned the value of -4 , the road edge layer assigned the value of -3 , the racetrack assigned the value of -2 and the grandstand assigned the value of -1 . In the positive range, lamp post covered by trees had the value of 1 , buildings the value 2 and footpath the value 3 . Figure 5-10 shows the attribute table of the final lighting zone area discussed above. 


\begin{tabular}{|c|c|c|c|c|}
\hline & OBJECTID* & VALUE & COUNT & LightReq \\
\hline 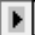 & 1 & -5 & 586 & No \\
\hline & 2 & -4 & 1911 & No \\
\hline & 3 & -3 & 11924 & No \\
\hline & 4 & -2 & 1755 & No \\
\hline & 5 & -1 & 1855 & No \\
\hline & 6 & 0 & 12444 & Neutral \\
\hline & 7 & 1 & 1 & Yes \\
\hline & 8 & 2 & 1875 & Yes \\
\hline & 9 & 3 & 5238 & Yes \\
\hline
\end{tabular}

Figure 5-10: Attribute table of final output layer

\subsection{Second Analysis - Light Coverage}

The second analysis took on a slightly different approach from the first analysis. Learning from the process of the first analysis, the project team decided that the second analysis was to use the Python-scripting platform right from the start instead of going though the Model Builder process. It was also decided to work using rasters instead of vectors due to the ease of processing. Hence, this section will run through the planning, designing, and important considerations taken by the project team to build the second analysis. The second analysis's purpose was to calculate the amount of light coverage within a zone of interest based on user input locations and specifications. Figure 5-11 indicates the process used to build this analysis.

Understanding lighting charts from Partex
Designing analysis flow
Working in python

Figure 5-11: Process for building the second analysis. 


\subsubsection{Understanding the lighting charts from Partex}

Recapping Chapter 4 on data sources, the lighting charts provided by Partex were very useful for this analysis. These charts originated from Airstar lighting. According to Partex, Airstar lighting obtained these readings by manual measurements using the lux meter, recorded at specific distances. Figure 5-12a and $12 \mathrm{~b}$ reiterate the photometric specifications highlighted in Chapter 4.

\section{Sirocco 4000W HMI}

The balloon offers an optimal light between 10 and $15 \mathrm{~m}$ (33ft / 49ft)

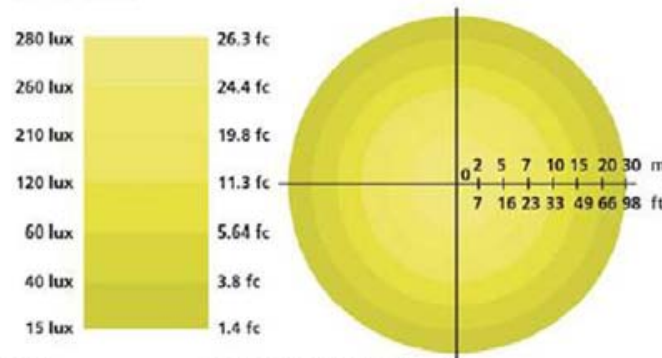

Sirocco 2000W Halogen

The balloon offers an optimal light between 2.5 and $5 \mathrm{~m}(8.2 \mathrm{ft} / 16.4 \mathrm{ft})$

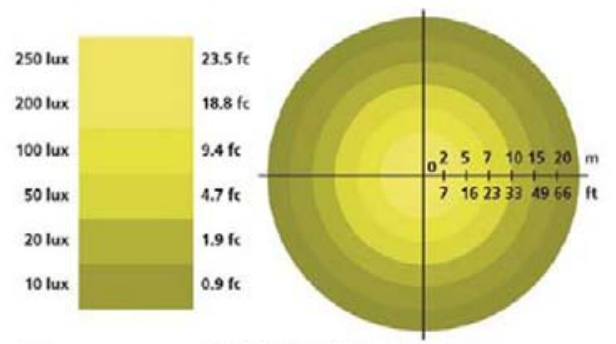

\section{Sirocco 3000W HTI}

The balloon offers an optimal light at $8 \mathrm{~m}(26 \mathrm{ft})$

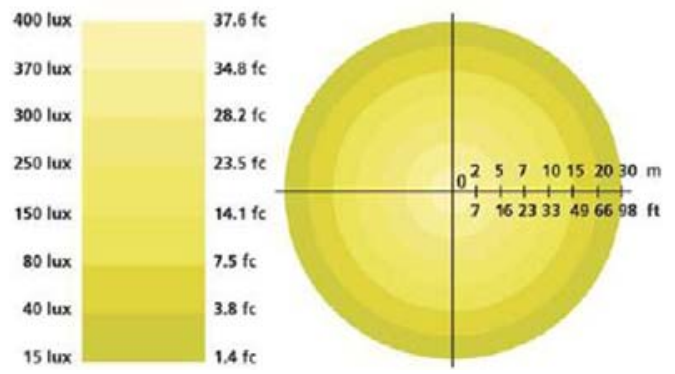

\section{Sirocco 1200 W HMI}

The balloon offers an optimal light between 2.5 and $5 \mathrm{~m}(8.2 \mathrm{ft} / 16.4 \mathrm{ft})$

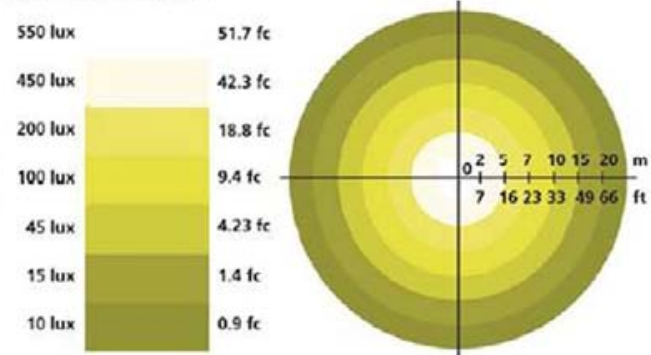

\section{Sirocco 1000W HTI}

The balloon offers an optimal light between 2.5 and $5 \mathrm{~m}(8.2 \mathrm{ft} / 16.4 \mathrm{ft})$

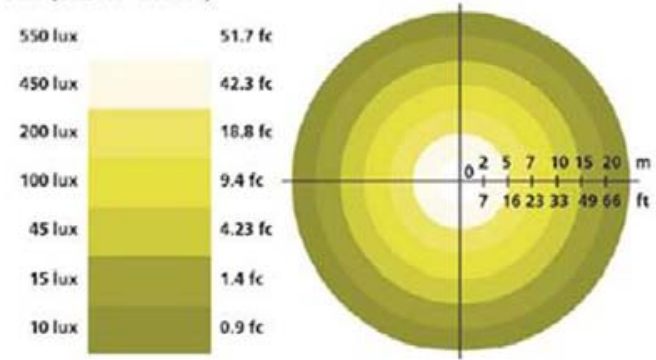

Figure 5-12a: Photometric specifications for the crystal lighting 


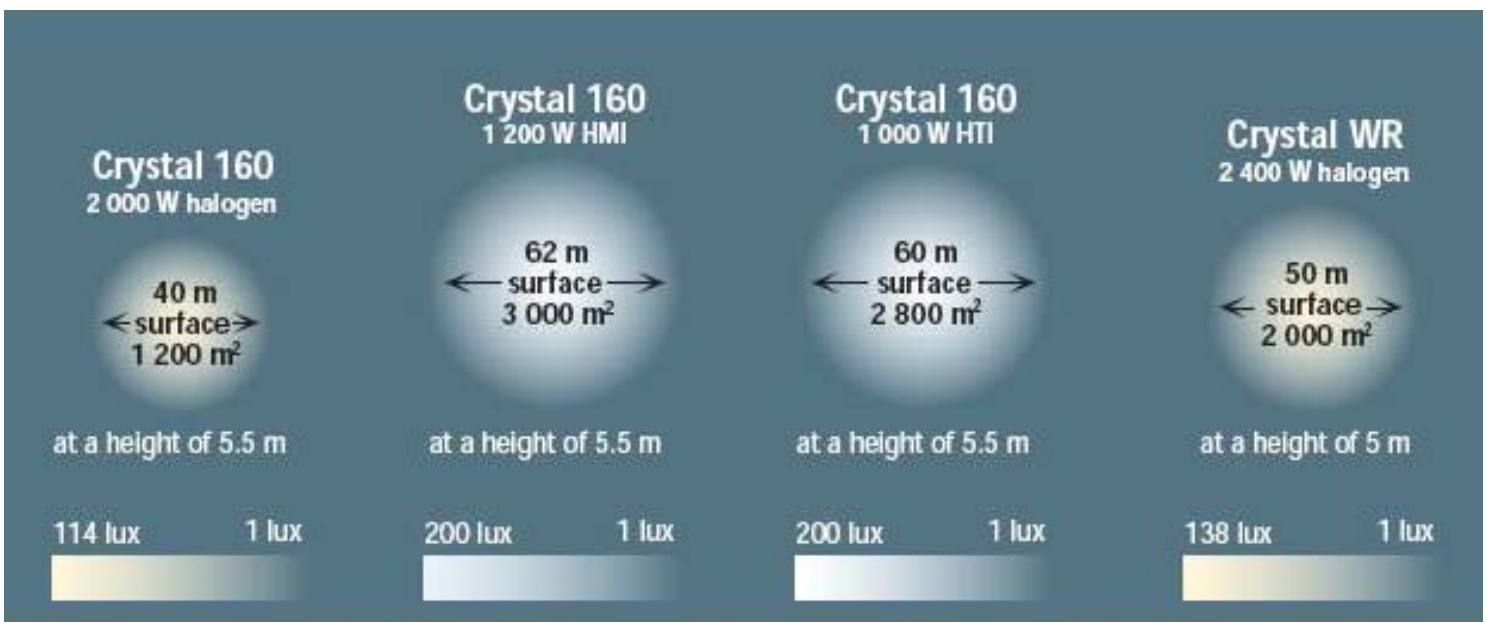

Figure 5-12b: Photometric specifications for the crystal lighting

The project team started studying the photometric specifications by matching them to technical data sheet provided by Partex. The purpose was to verify that all the available lighting balloon models had a corresponding photometric specification. Based on the technical data sheet, there were nine types of crystal lighting and eleven types of sirocco lighting. However, the photometric specifications sent by Partex did not match up with the total number of lighting balloon models. Further discussion with Partex brought about more understanding of the types of lighting balloons required specifically for the SGP event. Table 5 summarizes the discussion with Partex and the final required types used in the analysis.

Table 5. Summary of lighting balloons used in analysis

\begin{tabular}{|l|l|l|l|}
\hline Type & Model & Spec & Final Decision from Partex \\
\hline \multirow{5}{*}{ Crystal } & C90 500w Halogen & No & $\begin{array}{l}\text { Required; proportion using 2000w } \\
\text { lighting chart }\end{array}$ \\
\cline { 2 - 4 } & C130 1000w Halogen & No & $\begin{array}{l}\text { Required; proportion using 2000w } \\
\text { lighting chart }\end{array}$ \\
\cline { 2 - 4 } & C160 2000w Halogen 230V & Yes & Required \\
\cline { 2 - 5 } & C160 700w HMI & No & Not Required \\
\cline { 2 - 5 } & C160 1200w HMI & Yes & Required \\
\cline { 2 - 5 } & C160 1000w HTI & Yes & Required \\
\cline { 2 - 4 } & CWR 2400w 230v & Yes & Required \\
\cline { 2 - 4 } & CWequired \\
\hline
\end{tabular}




\begin{tabular}{|c|c|c|c|}
\hline & CWR 1800w 120v & No & Not Required \\
\hline \multirow{11}{*}{ Sirocco } & Halogen 2000w 230v & Yes & Required \\
\hline & Halogen 2000w 230v 2 lamps & Yes & Required \\
\hline & Halogen 2000w 100/120v & Yes & Required \\
\hline & TBT $12 \mathrm{v}$ & No & Not Required \\
\hline & TBT 24v & No & Not Required \\
\hline & HMI 1200w & Yes & Required \\
\hline & HMI 4000w & Yes & Required \\
\hline & HTI 1000w 230v & Yes & Required \\
\hline & HTI 1000w 100/120v & Yes & Required \\
\hline & HTI 3000w 230v & Yes & Required \\
\hline & HTI 3000w 100/120v & Yes & Required \\
\hline
\end{tabular}

From here, the project team delved into understanding the lighting charts. The lighting charts for sirocco lights were much more straightforward. Each lighting chart had a legend next to the rings of distance that indicated the lux value at that distance from the centre of lighting balloon. The project team only had to match the values to the distance for the analysis. However, the team discovered inconsistencies in the labeling of lux values at each distance band. For example, every lighting balloon had seven distance band, but Sirocco 2000w Halogen only had six labels and Sirocco 3000w HTI had eight labels. On clarification with Partex, the project team understood that Sirocco 2000w Halogen's 2-meter and 5-meter bands shared the same lux values. For the Sirocco 3000w HTI lighting chart, the top label indicated lux value at the core of the light bulb, essentially at 0 -meter.

Next, the project team moved on to work on understanding and working out the lighting values for the crystal lighting. The photometric specifications provided for this type of lighting balloon were more general and the project team had to work on the specifications to derive the approximated lux values at each distance band. To derive the distances, the project team applied the inverse-square law to the information given in the specifications starting from 114 lux at 1-meter distance. The inverse-square law states that some physical quantity or strength is inversely proportional to the square of the distance from the source and is commonly used for calculate lighting coverage values for point light sources (Wikipedia, the free encyclopedia, 2010). The derived values of available crystal lighting models are captured in Table 6 below. 
Table 6. Derived lux values of crystal lighting balloonsat various distances

\begin{tabular}{|l|l|l|l|l|l|}
\hline Model & $\mathbf{2 m}$ & $\mathbf{5 m}$ & $\mathbf{7 m}$ & $\mathbf{1 0 m}$ & $\mathbf{1 5 m}$ \\
\hline C90 500w Halogen & 25 & 4 & 2 & 1 & \\
\hline C130 1000w Halogen & 50 & 8 & 4 & 2 & \\
\hline C160 2000w Halogen 100/110V & 100 & 16 & 8 & 4 & 1.78 \\
\hline C160 2000w Halogen 230V & 100 & 16 & 8 & 4 & 1.78 \\
\hline C160 1200w HMI & 225 & 36 & 18.4 & 9 & 4 \\
\hline C160 1000w HTI & 225 & 36 & 18.4 & 9 & 4 \\
\hline CWR 2400w 230v & 156 & 25 & 12.8 & 6.25 & 2.78 \\
\hline
\end{tabular}

Once the project team figured out and understood all the lighting charts, the next step was to finalize the flow of analysis and relevant tools in ArcGIS. The next sub-section provides more information on this area.

\subsubsection{Designing analysis flow}

The process of designing the second analysis flow met with more challenges compared to the first analysis. As the project team was new to Python and planned to work directly on it, the team needed more clarity on the exact tools required without testing them out one by one in the script. Hence, the project team first worked out a generic workflow that captured the essence of the analysis. Based on the lighting chart information, the first step was to create, for each lighting balloon, a multiple buffer ring that corresponded to the distances reflected in the information. Next, the buffer output layer needed a new field in order to include the respective lux value to each buffer distance. Following that, the team needed to overlay the vector buffers and add the lux values of intersecting buffers. The output layer provided the total lighting coverage from all the lighting balloons indicated by the user. Figure 5-13 highlights the flow of the second analysis.

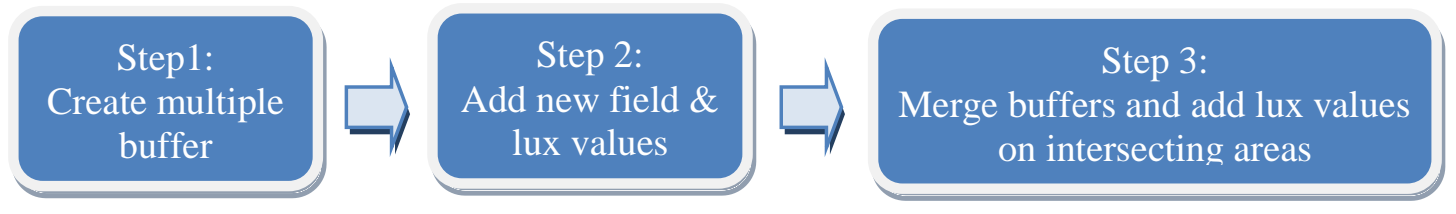

Figure 5-13: Generic analysis flow for calculating light coverage

The project team moved on to identifying potential tools required by the analysis, and ran the individual tool on the lighting balloon feature classes to evaluate the 
suitability of the output feature class. The intent for the analysis was to allow the user to input the features onto ArcMap or the web application to run the analysis. To do this, the input specified in Python had to be the feature set, and the plan was to code feature set into the script once the body of the script ran well. Short of knowing how to script a feature set and for testing purposes on the main body of the analysis, the project team created a feature class as an interim input.

The first tool tested by the project team came up with errors in the output feature class. The multiple-buffer tool successfully created seven buffer rings for each distance indicated. However, when multiple points were added to the feature class, the multiplebuffer tool was not able to generate the right number of buffers for some points. Besides this error, the multiple buffer rings extent consisted of the entire circle from the point of buffer. For this project, the analysis required only the buffer band that held the difference in distance from the previous band. Hence, the project team decided to utilize the buffer tool instead of the multiple-buffer tool. The buffer tool created seven separate buffers for the lighting balloon, converted to raster and merged using the single output map algebra. When the buffer tool was applied to all the lighting balloon points concurrently, the raster merge produced regions that were meant to be a sum of lux values. There was no simple way for the final script to identify each region and tie it to the sum of particular lux values. The project team decided to use the final Python script to run through the analysis on each point rather than collectively on the entire feature class. With this established, the project team ran a reclassify tool for each set of buffers that included the lux value for each band. The final step involved summing the reclassified rasters for the lighting coverage in the entire study area.

Once the project team finalized the tools and flow, they started implementing it into the Python-scripting environment. The next sub-section discusses about considerations taken when scripting and the rearrangement of several steps that helped improve the speed of analysis.

\subsubsection{Working in Python}

In the first part of the scripting, the project team worked on separating all the points within the feature class to facilitate the buffer analysis on each point individually. Initially, the project team adopted a script from the ESRI website that separated features based on a particular attribute defined by the user, and created new feature classes for these features. On further discussion with the project advisor, the project team started working on the search cursor function in Python to run this instead of the previous script. Search cursor was the preferred method as the script needed to specify different reclassification lux values for different models of lighting balloons.

Next, the script needed a way to locate the type of model indicated at each point and run the buffer, feature to raster, merge, and reclassify tools. The approach on Python for this requirement was to use while looping, which enabled the script to go through each feature on the feature class. While the search cursor loop was on a feature, the script called on an if-else statement. The if-else statement tested the model type using the Ftype attribute, and once it found the condition that matched the type, the script ran the entire flow of buffer to raster to reclassify analyses. At the end of scripting the entire analysis, the script repeated the buffer to raster to reclassify flow 20 times due to the number of subtypes present in the feature class schema. When the script ran using the testing feature 
class, it took 10 minutes for ArcCatalog to complete the entire analysis. The time taken was not desirable and the project team worked on modifying the script to improve it.

The project team overcame the problem with time taken on analysis using two methods. The first was to place every vector layer in-memory. This method reduced the amount of time marginally. Through closer observation, the project team realized that the bottleneck for the analysis was the feature to raster conversion after creating a buffer layer. With seven buffer layers for each point, the script had to run feature to raster conversion for each buffer layer and the repeat the same functions for the number of points found within the feature class. Due to this, the team decided that merging buffers in vector form before converting them to raster provided a more streamlined approach to the entire analysis. Using this as a reference, several tools that performed merging functions ran using the buffer layers to determine to most desirable output for the analysis. The tools tested were merge, append and union. Figure 5-14 shows an example of the difference in spatial output of the three merging functions.

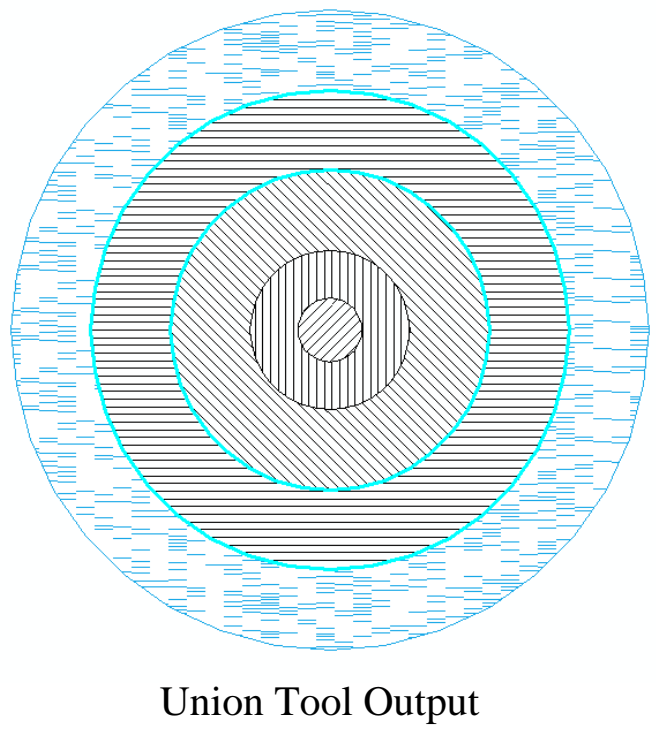

Union Tool Output

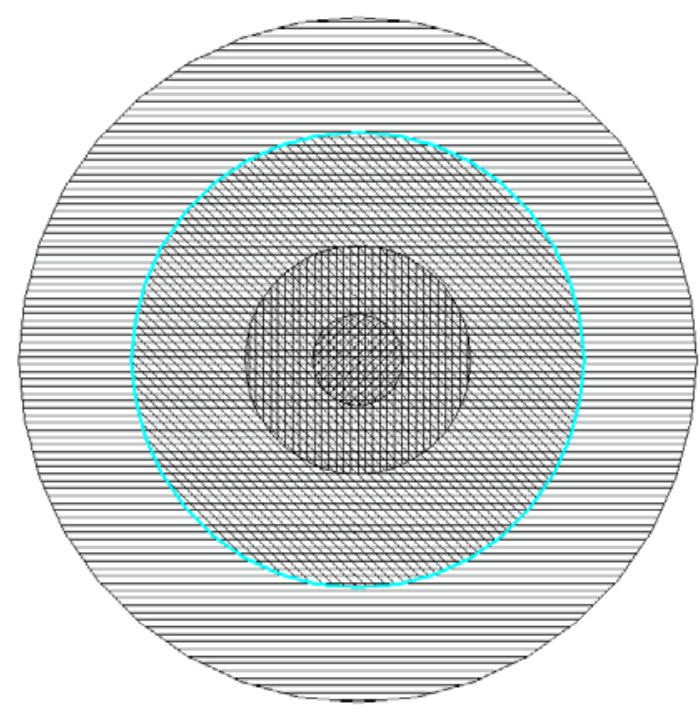

Merge/Append Tool

Figure 5-14: Result output for merge, append and union tools.

As seen in Figure 5-14, the union tool was the preferred function compared to the rest, as its output provided distinct banding for the difference in each distance, while the append and merge tool kept the entire buffer layer shape intact. With the union tool, the script only had to run one feature to raster conversion on the union layer, rather than seven. Other than attempting to reduce the amount of time taken for analysis, it shortened the length of the script significantly. After implementing the union tool into the script, the project team did a test run on it and the result was very good. The changes reduced time taken for analysis to complete from 10 minutes to 2.8 minutes.

Once the time taken for analysis reached a satisfactory level, the project team worked on the three final steps in the analysis before performing further streamlining to the script. After scripting the union tool, the features to raster and reclassification steps as mentioned earlier in this sub-section were added to the script. The last step required in the analysis was then to run the single-output map algebra tool on all the lighting buffers 
created that produced an overall lighting coverage for the entire study area. Next, the team worked on streamlining the script. Despite reducing the number of steps after using the union tool, the script was still long and repetitive in various parts. The project team worked with Nate Strout from the Redlands Institute to combine common processes in the script into a Python definition. Analyses repeated for each subtype were the seven buffers, union, and feature to raster conversion. With the addition of the definition, the length of the entire script shortened significantly. At the end of this step, the script reached a satisfactory state and was able to generate output required by Partex in a relatively short time.

As mentioned earlier in this sub-section, the scripting first used a feature class with points already digitized as a testing input for the analysis while it was being built. The final part to complete the script was to enable interactive selection of features from ArcMap. To achieve this capability, Python required creation of a feature set object into script while setting an analysis parameter for the inputs. Figure 5-15 captures the user interface, for the second analysis, of the completed Python script.

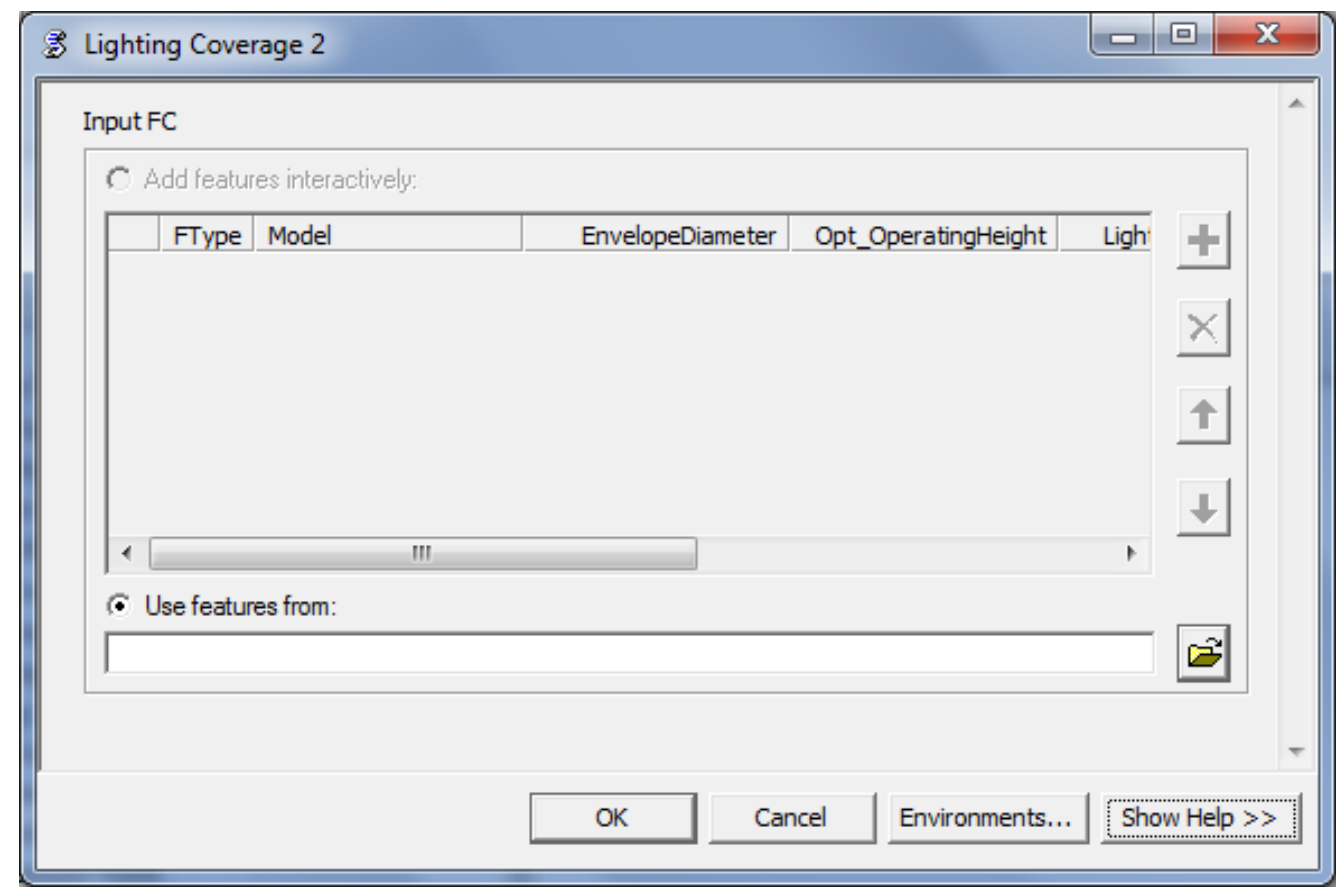

Figure 5-15: User interface for calculating lighting coverage analysis.

\subsubsection{Results}

This section covers the outputs of the analysis and describes how it helped Partex in the lighting balloon placement. The main outputs of this analysis were raster data. First, the user selects the locations of the lighting balloons and indicates the subtype of each point based on the coded numeric value. In the most ideal situation, the user is able to do a selection of subtype based on a dropdown function. However, the capability was not available for interactive selection of features at the point of building the analysis. Figure 5-16 shows how the user is able to select points interactively using the feature set capability. 


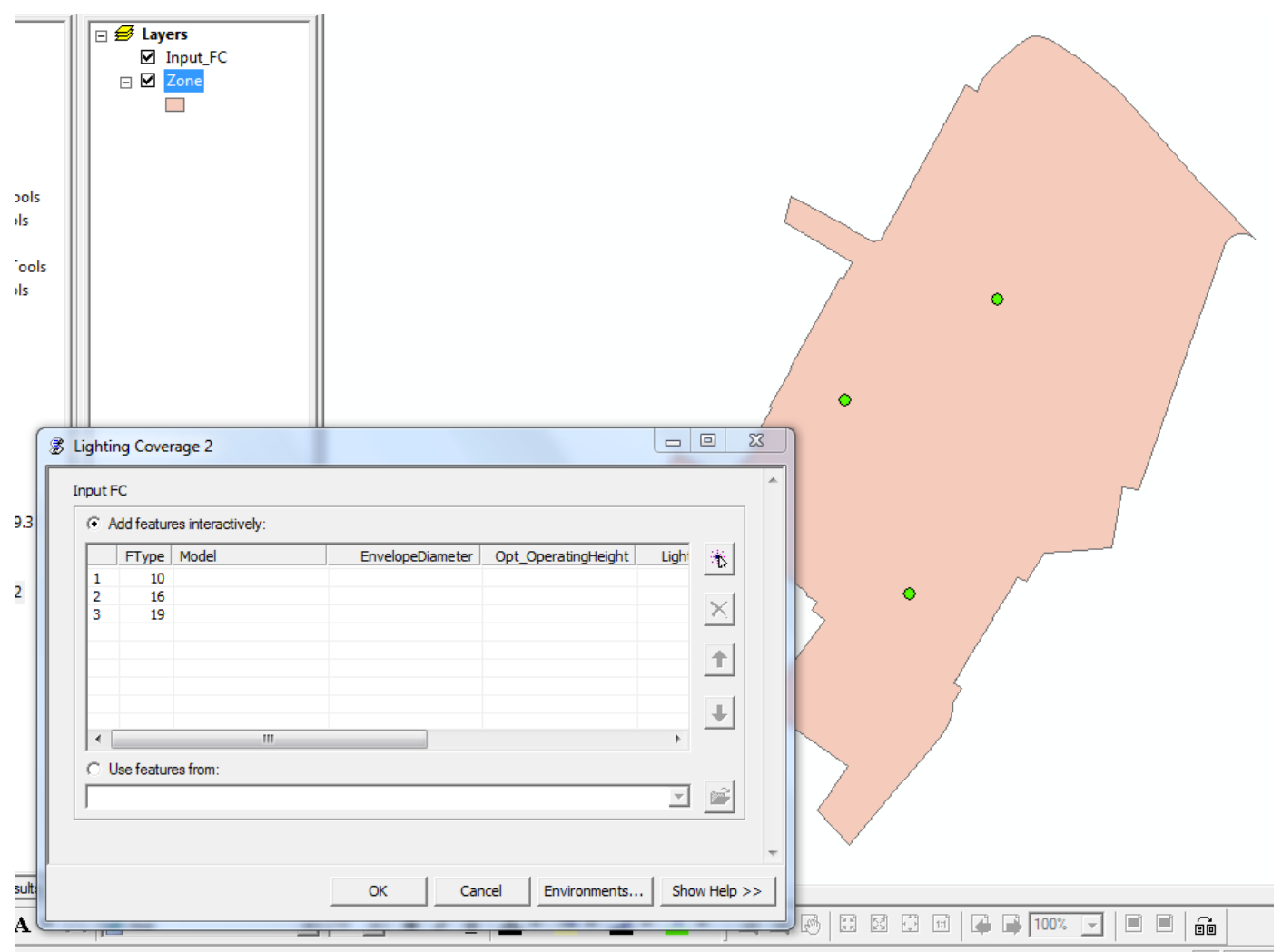

Figure 5-16: Interactive selection of points using feature set function.

Next, the analysis was executed. For each lighting balloon point indicated by the user, the analysis created a lighting buffer that captured the appropriate lux values inferred from its subtype. At the end of the analysis, the final lighting coverage layer produced provided the client with information about the amount of lighting in the selected study area. Figure 5-17 is a screen shot of the analysis process and the time taken to complete the entire analysis.

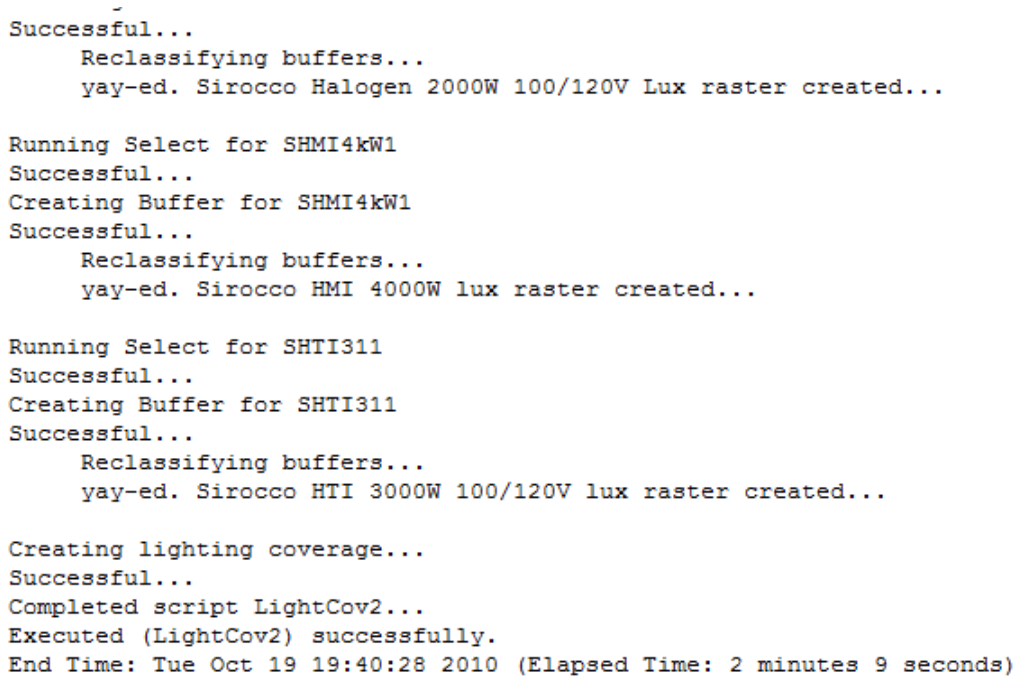

Figure 5:17: Analysis process 
Figure 5-18 and 5-19 shows an example of one of the output lighting buffers as well as the final lighting coverage raster.

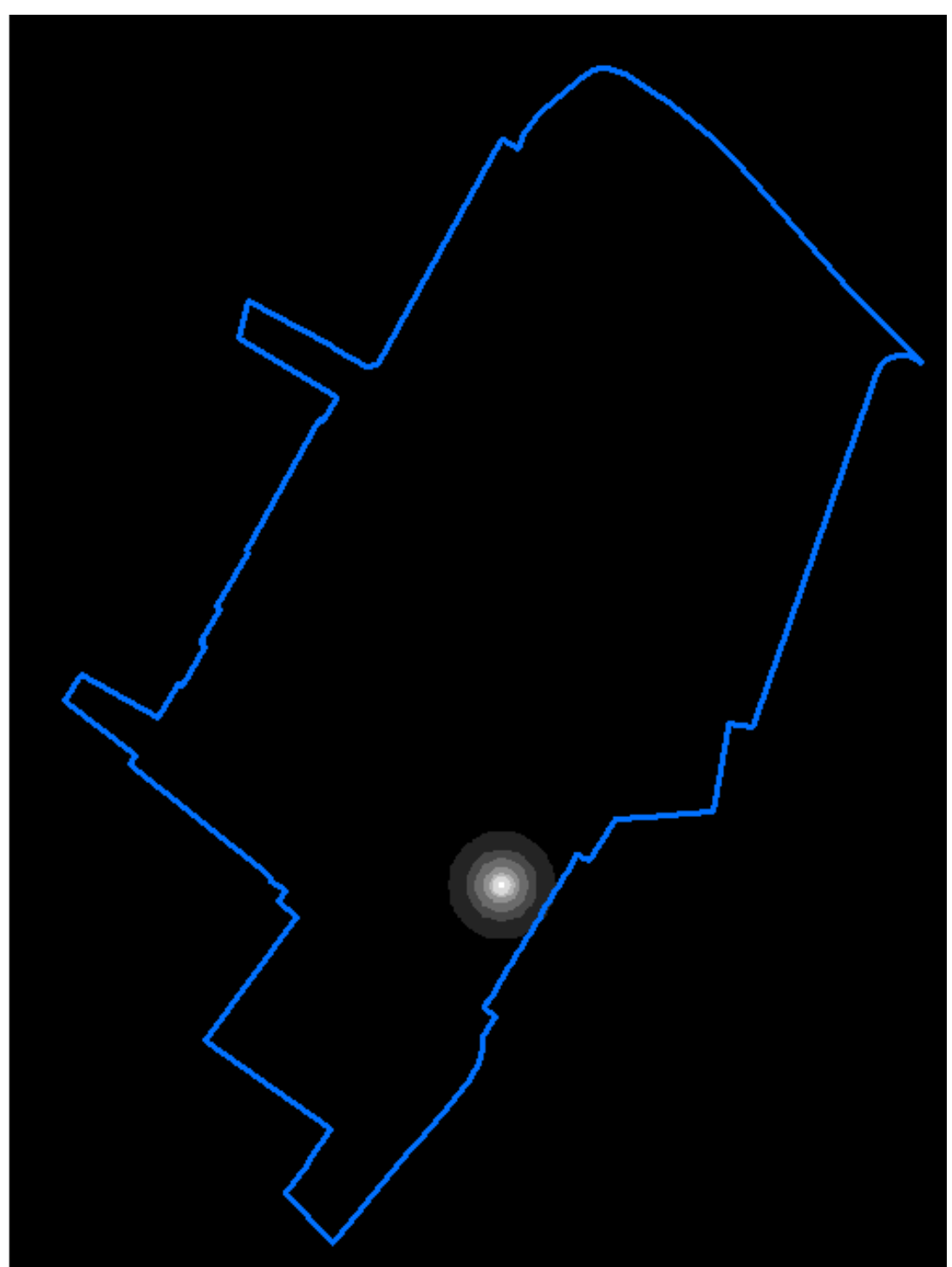

Figure 5-18: Lighting raster with lux value for one lighting balloon point. 


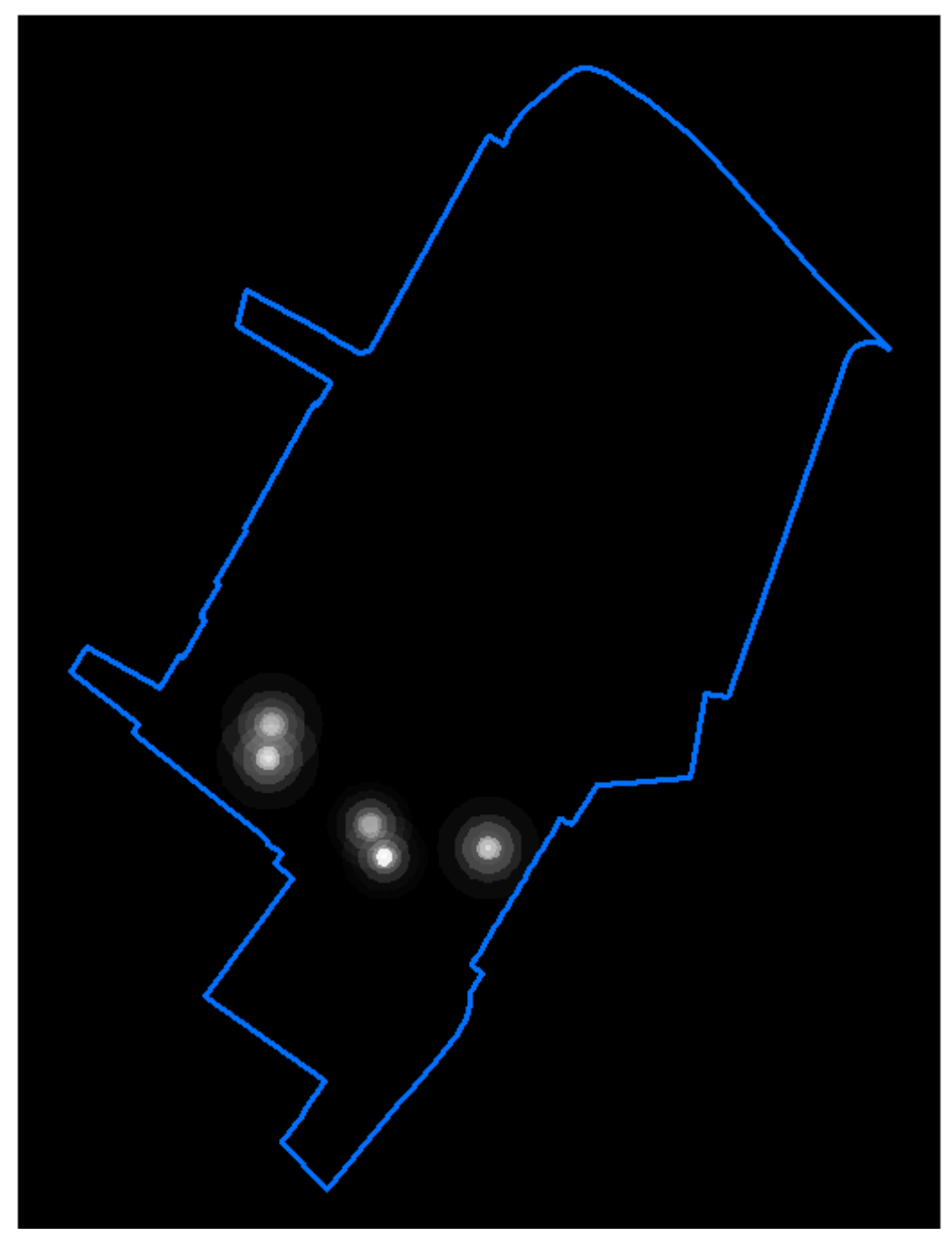

Figure 5-19: Lighting coverage for all lighting balloons indicated in analysis.

\subsection{Challenges}

Throughout these two analyses, the scripts were tested on the ArcCatalog platform. It enabled the project team easy access to study the analysis outputs and make edits to the tools and scripts. The scripting process was very challenging for the project team as it was new to the scripting language. While creating the scripts, the team had to break it down into smaller parts for troubleshooting. It helped the team focus on each portion and get it right before moving on to the next part of the script. Often times, it was time saved working on the project, as small segments of script run quicker than testing the entire script. Once the team was confident of the generated outputs, the entire script was run and tested for syntax and tool related errors. Another challenge was for the project team to think in scripting logic. Being new to scripting, the project team's approach was to run every tool in sequential order rather than using the looping functions available. This made the scripts unreasonably lengthy and the team ended up working with staff from the Redlands Institute to resolve this. The final challenging part of the scripting was to figure 
out how to set the tool interface such that the user did not have to input an SQL statement for the first analysis. The project team spent many days reading up and doing online research to understand and find a way to accomplish it.

\subsection{Summary}

This chapter focused on the two key analyses required for this project. It provided the sequence of creating each analysis and the concepts behind creating them. It also captured the key essence of the analysis and the project requirements in terms of GIS analytical solution. After providing the design and concept, the chapter ran through the scripting development, and results of each analysis. Overall, creating the analyses was an enriching process that enabled the project team to learn more about Python scripting and the logic behind GIS analyses. Now that the project has both GIS analyses accomplished, the project team moved on to create the web application, which served as the final platform for delivery. A web application was the choice of delivery given Partex's current resources and knowledge of GIS. The next chapter will examine the intricacies and details of how the project team built the web application. 


\section{Chapter 6 - Web Application}

Once the analyses were completed on the desktop environment, the project team started work on the web application. This was the final component for delivery in the project. The web application was the platform where the information, data, and analysis tools can be delivered and communicated to Partex in a simple and comprehendible manner.

This chapter highlights the approach taken by the project team in creating the web application and the functionality within it. First, the report presents the reasons behind choosing Flex as the coding platform for the web application over other ESRI supported coding and visualizing platform. After weighing the pros and cons, the project team decided to use Flex coding on the web application.

After finalizing the web coding and building platform, the project team thought through the design that fitted the theme of the project. Once the general design and color schemes were completed, the layout of the web application was developed. The key was to have a simple layout so that the learning time and process were kept, as much as possible, to a minimum. Overall, the layout created borrowed design concepts and layout from Apple's Macintosh OS interface. With the design on hand, the project team worked on creating the static design without the functions.

Next, the tools and functionality required in the web application were developed. This next section goes into detail of what each tool does for the web application. There were two categories of tools, mainly the subtle and distinct tools, based on the visual nature of the tools on the web application.

Finally, the completion of the tools marked the completion of the web application and the next section details the challenges of the creation process.

\subsection{Why Flex}

At the beginning of the project, several visualization possibilities were explored, including ArcExplorer, ArcGlobe and web applications. The fact that these three platforms were free was one of the key reasons to consider them as the visualization interface. The team studied the possibilities of using one of the three as the final project delivery platform. Among the three choices, both ArcExplorer and ArcGlobe had the most GIS functions and capabilities, which was good for the project. However, to use it effectively, Partex had much to learn about operating in both application interfaces. Hence, the web application was chosen, as it was possible to customize the tools and functionality to meet the project's specific needs.

Once the web application was chosen as the final delivery method, the next step was to pick the web scripting language from the range of ESRI supported application programming interfaces (API): Java Script, Microsoft Silverlight/WPF, and Adobe Flex. Based on online research and resources, the project team selected Flex API for several reasons. In terms of functionality, all three APIs delivered the basic functionalities and capabilities in the GIS environment. The JavaScript API was the easiest language to learn and grasp for anyone new to the web-coding environment. However, it did not enable users to build a custom user interface in terms of effects and design that the Flex and Silverlight APIs offered. Between Flex and Silverlight, it was the coding language and 
capabilities that gave Flex the edge over Silverlight. Microsoft Silverlight uses the .NET framework with VB.Net language to build the web application. The project team did not have any experience in VB.Net coding and the battle was half won on Flex's end. In addition to that, Flex supported various web design styling tools like the cascading style sheets (CSS) and action scripts. This functionality provided adequate bandwidth for the project team to create customized skins and interesting designs to the web application to enhance the user experience. With Flex selected as the web-coding interface for the web application, the project team started designing its look and feel.

\subsection{Design and layout}

The project team wanted the design to tie in with the theme of the subject in the project. Hence, the keywords night, cityscape and lights were chosen. The project team then used these keywords as guidelines to design the web application. To create a night effect, the entire web application had a black background applied to it. From this starting point, the project team worked on putting in other components of the web application to create the base for the tools and functions planned for it.

The layout needed to be outlined before the rest of the components, design, and map could be placed into the web application. Keeping in mind the need for simplicity in the application, the layout of the web application had three sections. The title of the project took the top of the web application, which made up of about $4 \%$ of the entire page. Within this header, the team included most of the elements from the guidelines set at the beginning of the design process. The header captured the night, cityscape, and some effects of lights in the header design. Figure 6-1 shows the final design of the header for the web application.

lighting balloon sulitabilifu andlusis

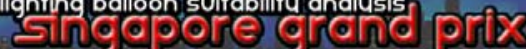

Figure 6-1: Header design of the web application

The city skyline image was taken during the evening, sunset hours hence giving a night feel to the header. The title of the web application was designed using Adobe Photoshop and given slight lighting effects from the emboss tool. The last part of the header design was the reflection of the cityscape images. The reflection effect was part of an effect written on action script by a web developer. The script was obtained from the Tour de Flex application. The project team applied the script into the web application and made minor changes to customize it for the header.

The next part of the web application, which made up the main body, was the map of the SGP event, which took up $92 \%$ of the entire web application. In keeping with the theme, the entire map was designed using the dark gray background. As mentioned in Chapter 3 system analysis and design, the base layers utilized shades of grey while the event areas adopted pastel colors. The only exception was the water features in the map, as it required a slight tint of blue for easy reference. This enabled users to differentiate between permanent and temporary features on the map. The map had five scale levels assigned to it while designing it: 1:24000, 1:10000, 1:5000, 1:3000, and 1:1000. The scale levels corresponded to the scale dependency of most feature classes. In the map document, all layers deemed important for the analysis had scale dependency set to 
1:10000 or 1:5000. The 1:24000 scale showed the features at full extent. The $1: 3000$ and 1:1000 scales were used to enable cartographic flexibility. Symbology of point features zoomed in to a certain level became overpowering in the entire map. Hence, the two largest scales identified allowed changes in the symbology for visual enhancement of the map document. The map document published to ArcGIS server had the same tiling scheme, following the scales of the map design. Figures 6-2 to 6-4 show the map design at various scale dependency level.

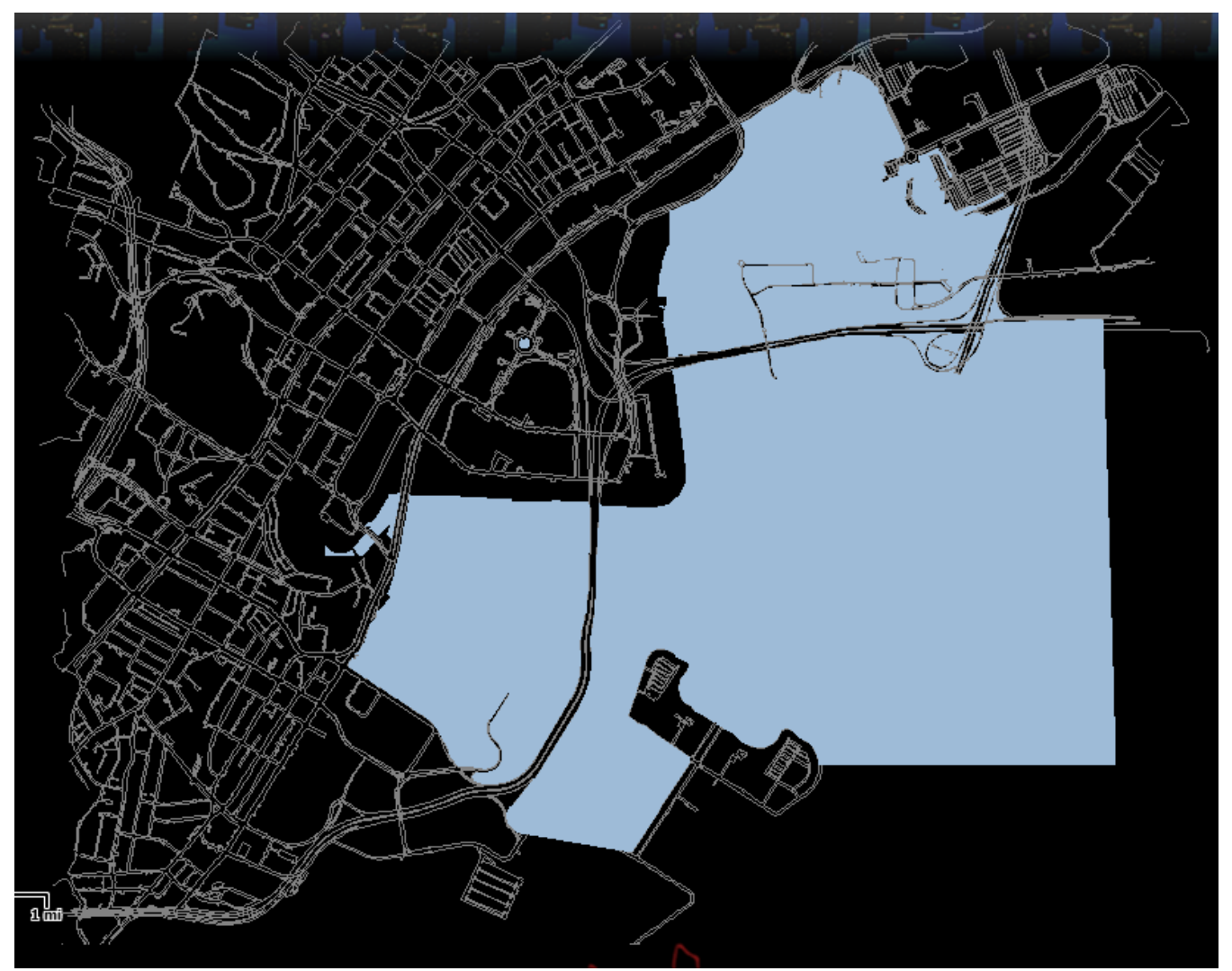

Figure 6-2: Map design at 1:24000 


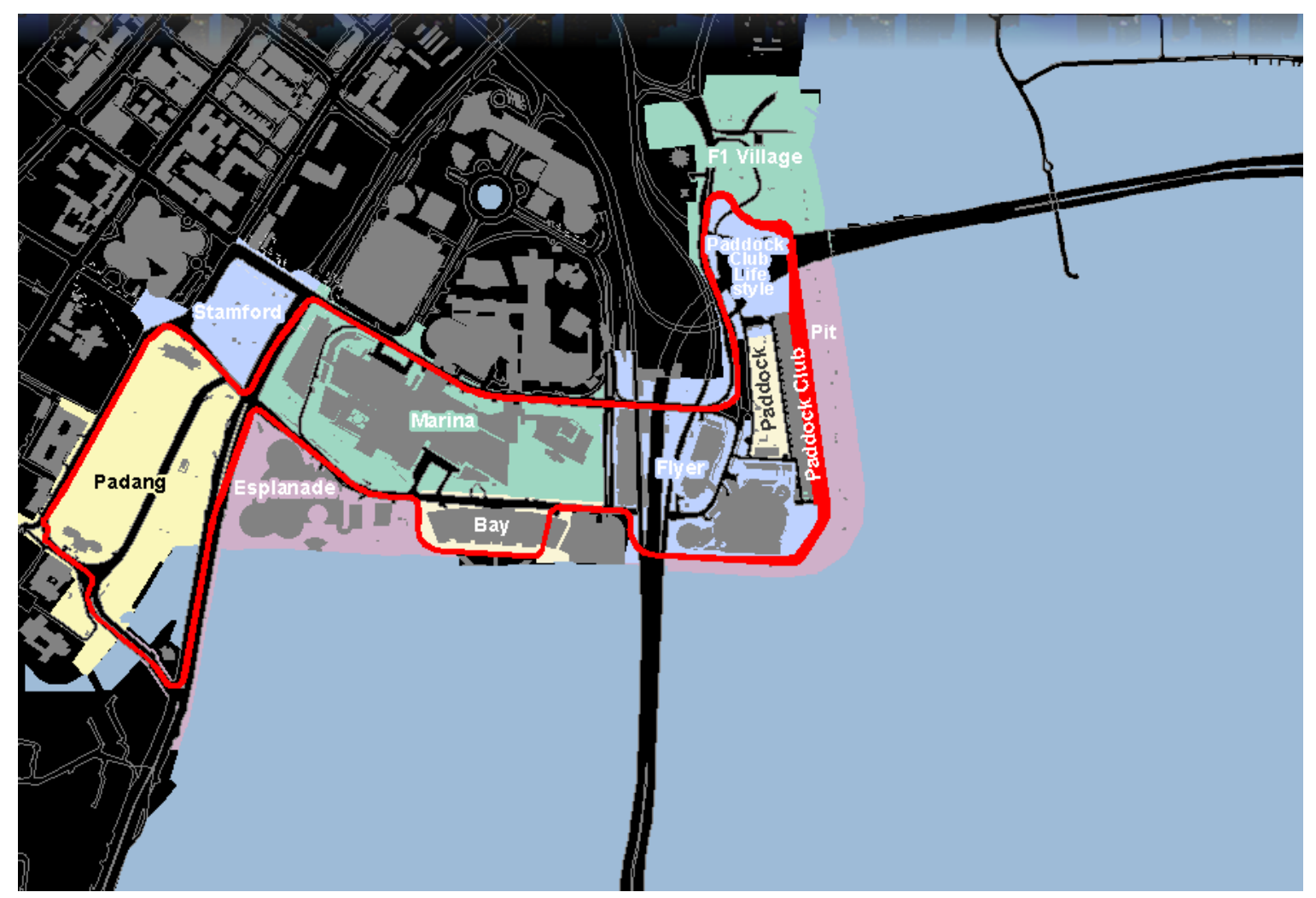

Figure 6-3: Map design at 1:10000

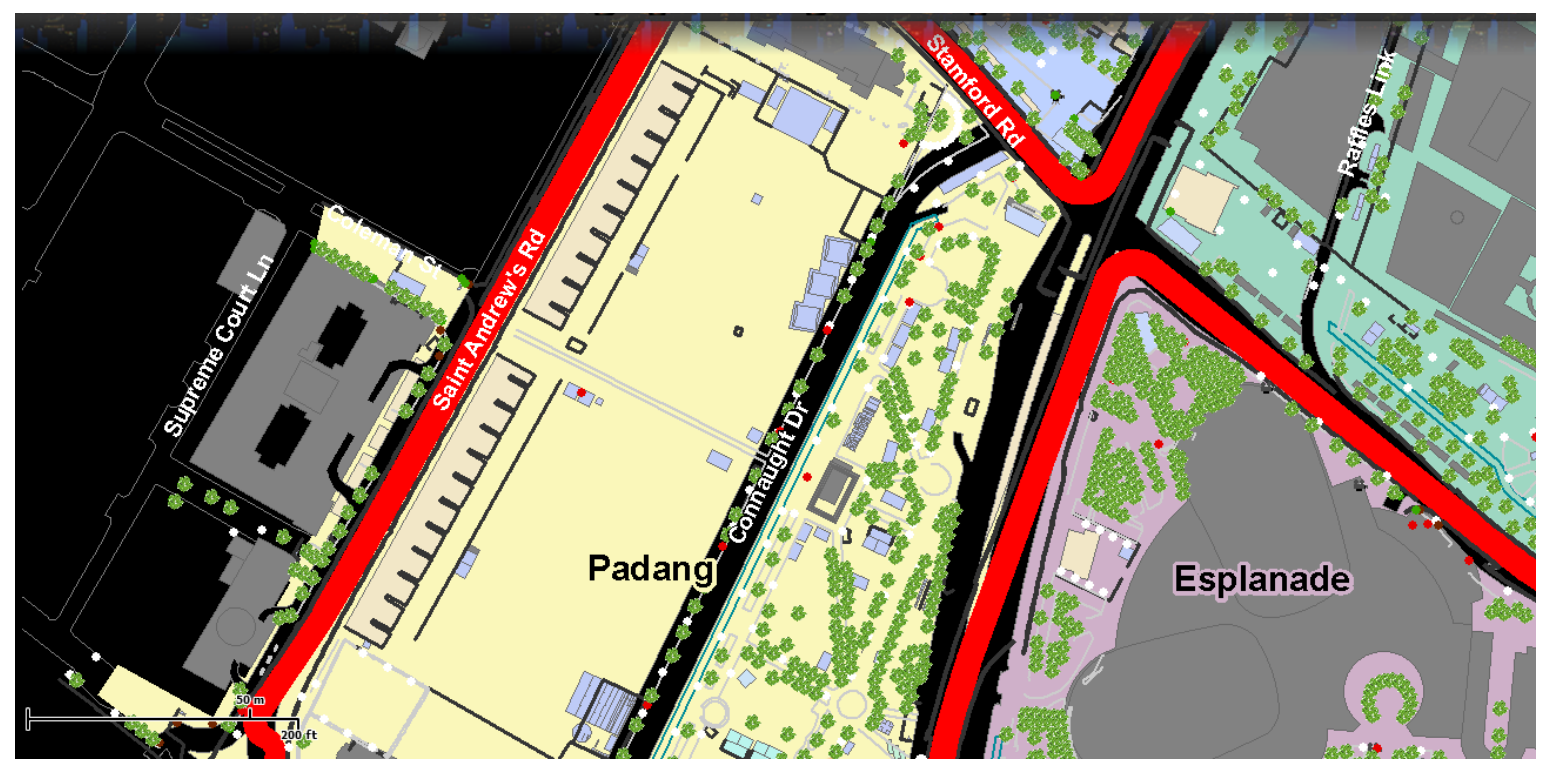

Figure 6-4: Map design at 1:1000

The last part of the layout of the web application was the tool menu bar, which took up the bottom $4 \%$ of the entire page. The tool menu bar consists of six button-styled icons flanked at both ends by the logos of Airstar Lighting and Partex International. Both logos were placed in the map to indicate the relation of the project to Partex and the lighting balloons they carry. The next sub section dissects the tools menu to explain the function built into each tool. The design of each tool followed as closely as possible the 
key function of each tool. Figure 6-5 shows the arrangement of the tools on the web application.

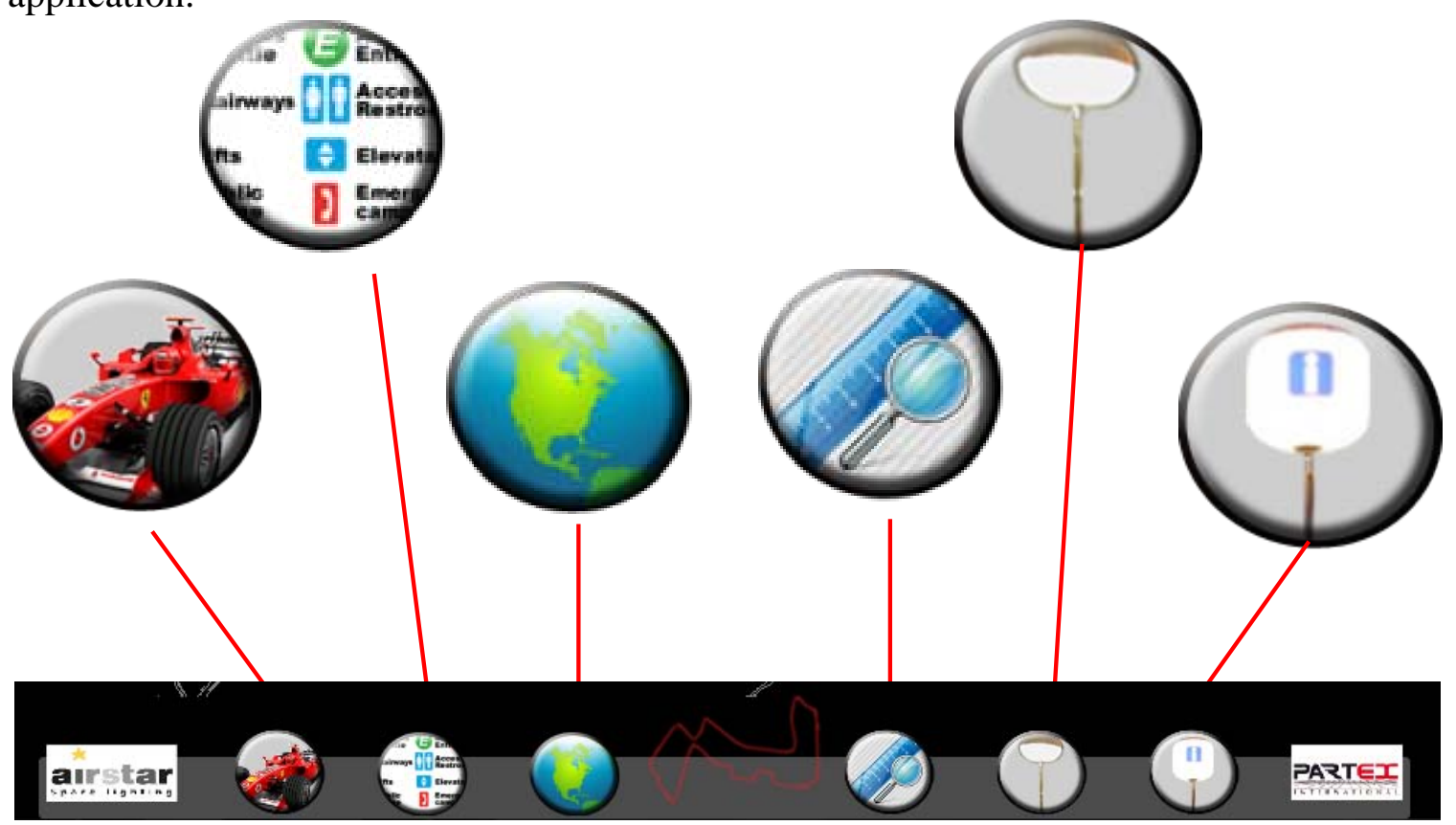

Figure 6-5: Tools menu on the web application

These tools emphasized yet again the simplicity needed for the web application. Each of the functions required in the web application was embedded into one of the buttons in the tools menu. On a mouse click, each button brings up a separate window that holds respective functionality for each tool. Figure 6-6 shows an example of one of the pop up windows.

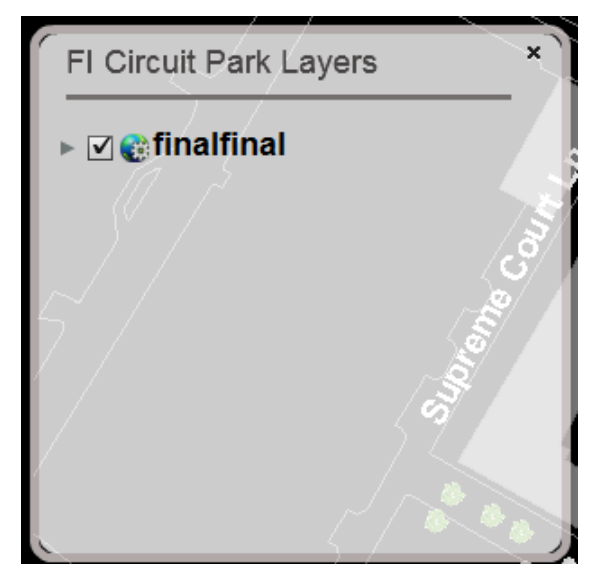

Figure 6-6: Pop up window from one of the tool menu button

The body of the pop up window took on a white background with transparency applied to it, which created an effect similar to that of lights. Even the borders and fonts had lighter shades of gray to complement the window background. When the user activated a pop up window, it provided the entire web application with the night and light contrast, with the background predominantly in black. At the end of the design stage, the final web application had the look and feel shown in Figure 6-7. After the design of the 
web application was finalized, the project team moved on to bringing tools and other functionalities into the tools menu buttons. The next section discusses details of the capability of the web application.

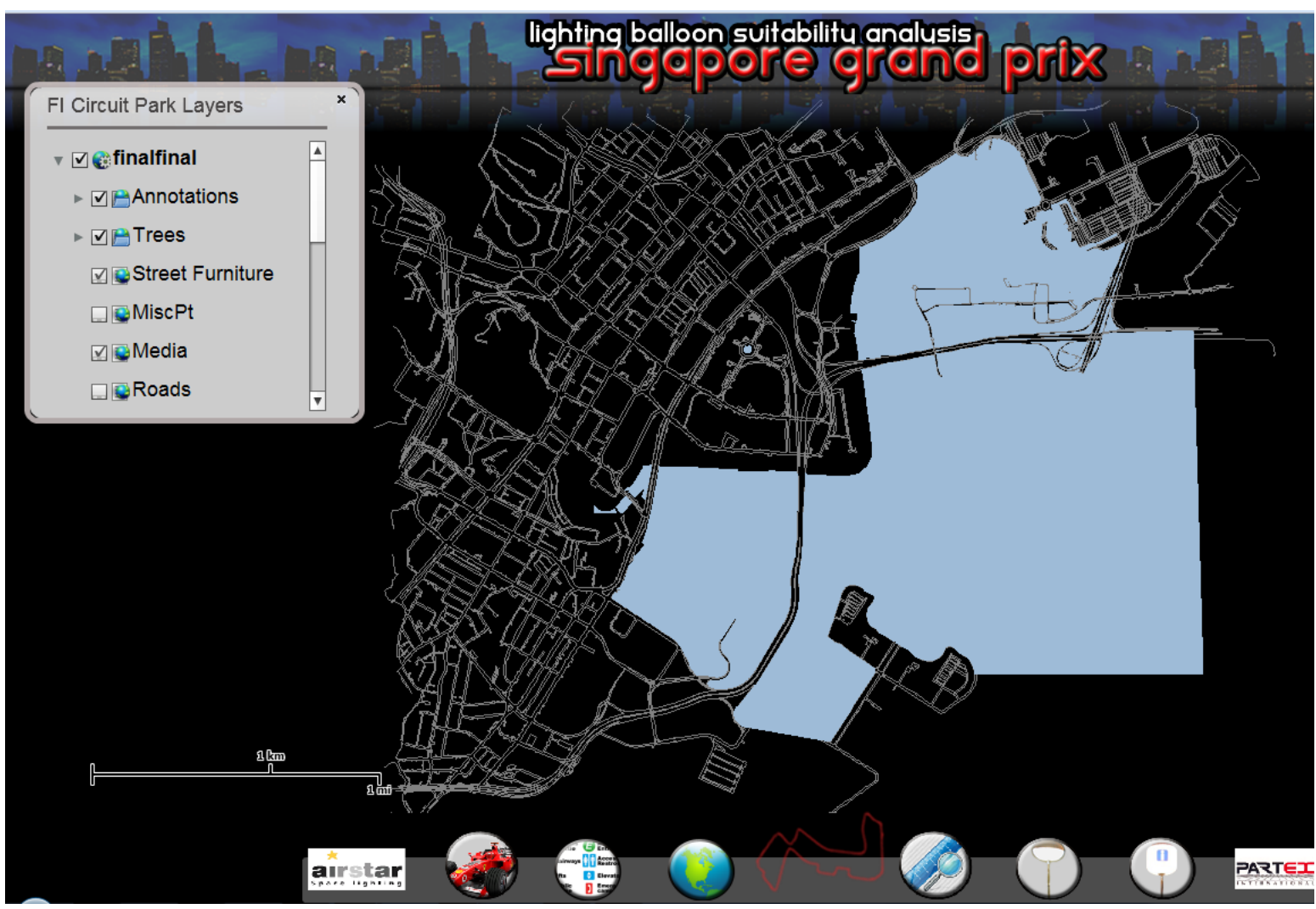

Figure 6-7: Final web application design and layout

\subsection{Tools menu}

Based on the tools menu, there were distinctly six functionalities to the web application. There were also several other functions captured within the web application in a more subtle manner. This section will begin with description of the subtle functions before moving on to providing details about the distinct tools, which incidentally held the key GIS capabilities.

Starting from the map, the project team enabled a query function that returns specific attributes of a feature when the user clicks on it. This is 'information on click' function that brings out a callout that holds the attributes of the feature of interest for the user. 
On the tools menu, the subtle functions were the non-button graphics: Partex and Airstar logos, as well as the centre racetrack graphic. The Airstar logo had a hyperlink coded that brought the user to the Airstar lighting company's main website. The Partex logo had a pop-up window that provided the user with information about the client and the key focus in their line of business. Figure 6-8 provides a screenshot of the client information taken from the web application.

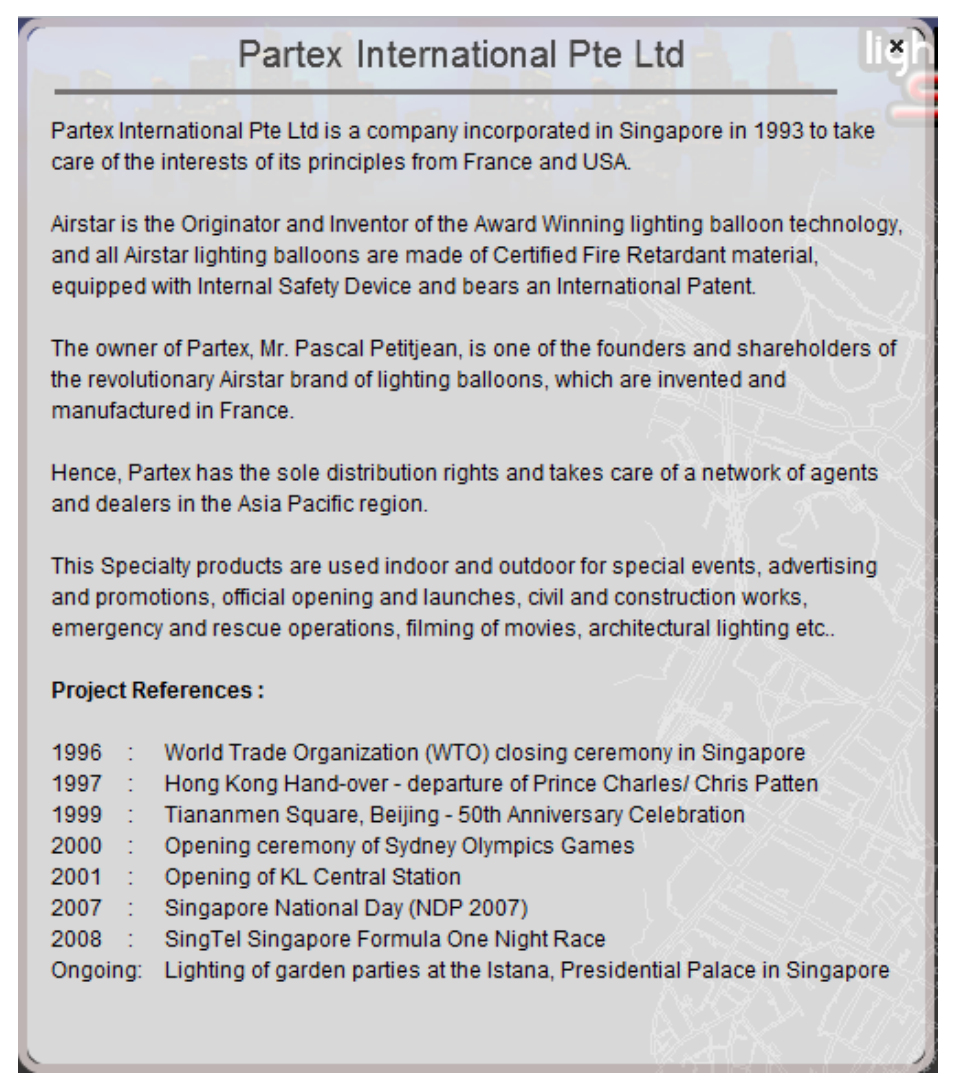

Figure 6-8: Company profile of Partex International

The final racetrack graphic aimed to provide the user with general information on the project. It contained details that explained the project and what it aimed to do as well as, details on the functionalities in the web application and instructions on how to utilize the tools and functions in the web application. The project team decided to have this information captured so that any user had references to the goals of the project, and could learn how to use it on their own by reading the instructions provided. Figures 6-9 and 610 provides the screenshot of the information window and the link to the instructions for using the web application. 
Partex International Pte Ltd is a company incorporated in Singapore in 1993 to take care of the interests of its principles from France and USA.

Lighting balloons are increasingly being used to light up night activities, while providing a better aesthetic environment.

Partex International in Singapore is the sole distributor of one such lighting balloon brand, called Airstar.

Airstar lighting balloons have been used extensively for night related activities like events, construction work, rescue and movie sets.

Partex was contracted to light up the circuit park of the Singapore Grand Prix F1 racing event with the Airstar lighting balloons.

Due to the extent of coverage and lack of site information, Partex faced difficulty in finding the best positions to place their lighting balloons for optimum coverage.

Hence, this project focused on using creating GIS analyses tool that provide better placement solution for Partex.

The two analyses covered in this project included:

(1) tool to find lighting priority zones based on Partex's requirements;

(2) a tool that calculates total lighting coverage based on lux values on lighting balloons input onto map by user.

The end-product of the project included a web application with compiled tools and maps created by the project team for Partex's easy access.

$\underline{\text { Help }}$

Figure 6-9: Information about the project

Contents Index Search

† 1 Introduction

$\oplus \square$ Getting Started

†. U Usina the Analvsis tools

$\boxplus \square$ Usina the Web Application

\begin{abstract}
Introduction
This help system contains information on components of the lighting balloon suitability analysis (LBSA).

The LBSA is a Major Individual Project that has its basis and roots using a geographical information systi University of Redlands Master of Science GIS Program, for a client in the private industry, as part of the prog

International, to produce an web application with desktop ArcGIS tools that helped Partex analyze and optimiz

Copyright c 2010. He Shimei
\end{abstract}

\section{Figure 6-10: Help file in HTML format}


Moving on from the subtle functionalities to the more distinct functions, the remaining part of this section highlights the key GIS-related operations and capabilities created for the web application. The first button graphic on the left of the tools menu operated like a table of contents tool. The project team used an existing script written for custom Flex applications to show the feature layers in a table of contents. Despite making use of an existing script, the team still had to edit parts of the script to customize it to fit into the pop up window activated by a mouse click in the web application. Besides solely creating the table of contents, the script considered the scale dependency levels applied to various feature layers. Figure 6-11 shows the layer arrangements in the table of contents pop up window as arranged and referenced from the map document.

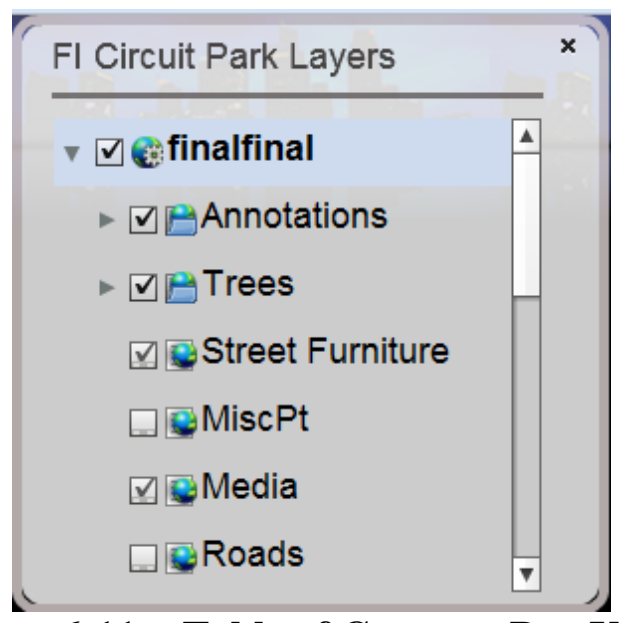

Figure 6-11: Table of Contents Pop Up Window

With a click on the button graphic, the web application provided yet another pop up window that captured the legend of the map in the web application. This was a simple reference tool for the user of the map legend if the user required in-depth knowledge of the feature layers. Rather than being just a reference tool, the project team decided to embed query tasks within each legend graphic. The query task on each legend corresponded to the feature it represented. When the user clicks on the legend, the web application runs a function that highlights the feature and zooms in to its spatial extent. This removed the need to have a Find function where the user entered text of places or features of interest. Next to the legend button was the full extent button graphic. This button allows user to return to full extent without having to zoom out extensively, and with just one click of the button. Figure 6-12 displays the pop up window from the legend button. 


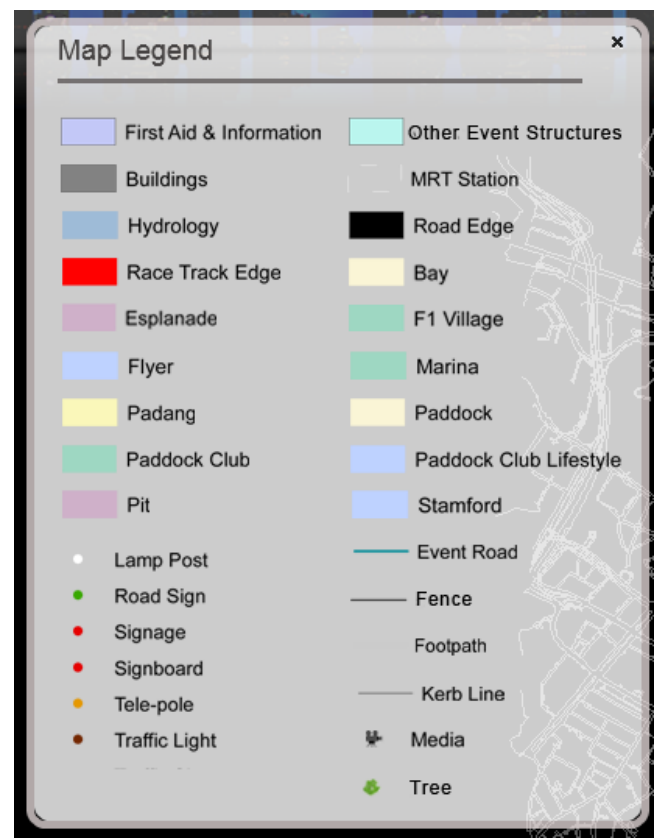

Figure 6-12: Map Legend Pop Up Window

The next button graphic was the measure tool, which contained measuring functions for polylines and polygons. There are two button graphics, one indicating polyline, and the other indicating polygons. Both button graphics utilized the button bar controls component of Flex to facilitate the drawing capability. The button bar control had an built-in toggle function that allowed users to click 'on' or 'off' the button's action. This allowed the users to switch between buttons, which activated and deactivated each tool correspondingly. The polyline tool allows the user to draw a line on the map and an internal web function would return the distance of the line at the end of the drawing. Similarly, the polygon tool allows user to draw polygons, and provide a measurement of polygon area. Figure 6-13 displays the results of using both tools.

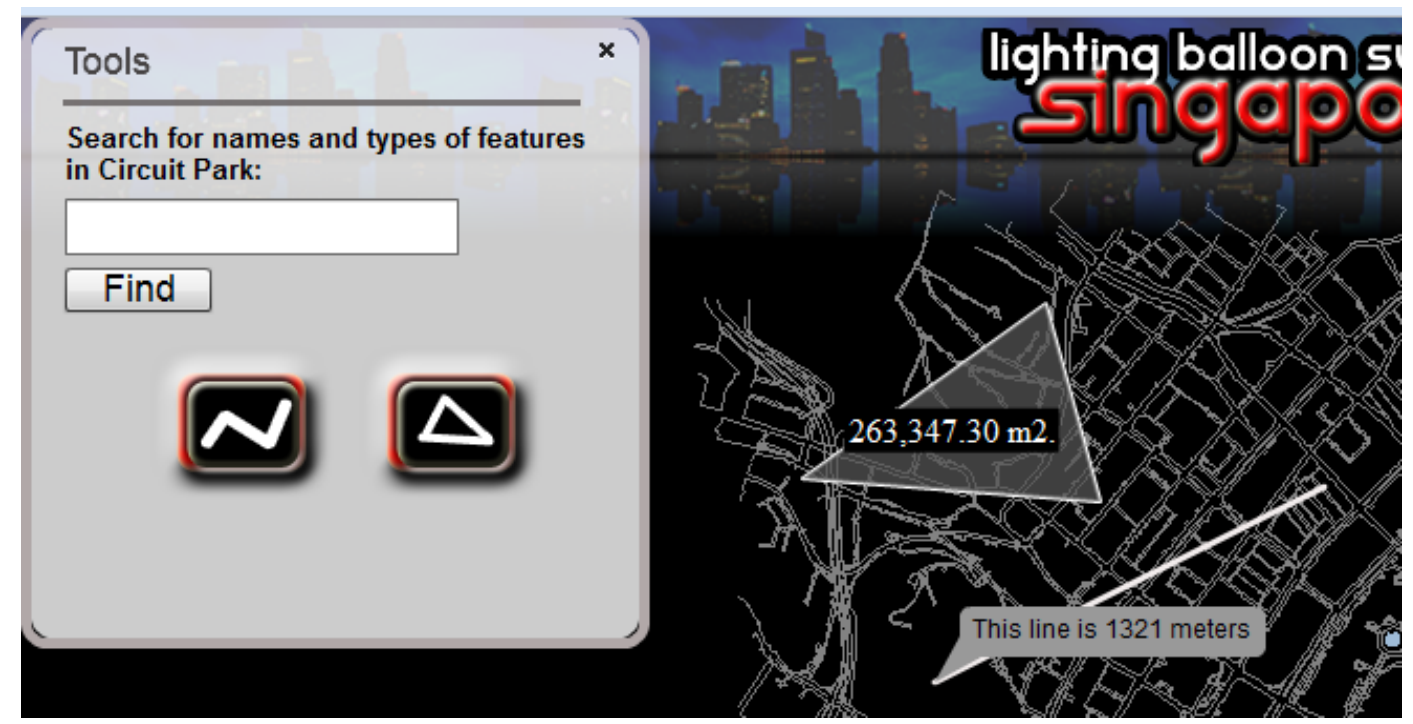

Figure 6-13: Line and Area Measured Using the Measure Tool 
The two final button graphics were the GIS analyses created for this project. The first graphic contained parameters required for the first analysis, which calculated the lighting zone priority for the selected zone of interest. The project team first created the interface for the pop up window that held the parameters required for the analysis. The arrangement of parameters in the title window followed according to the parameter order in the Python script. The first input asks the user for zone of interest for the analysis. The next six inputs require the user to provide distances that they would like lighting balloons to be placed away or near to each of the feature. Once the required parameters were populated, the user clicks on 'Run Analysis' button to execute the geoprocessing service in the ArcGIS server. Figure 6-14 shows what the interface for the first analysis looks like and how the user indicates the zone of interest using a drop down bar. Figure 6-15 captures the geoprocessing output result of the web application. The assignment of symbology to the result output was as such: black for areas that required lighting, white for areas that should not have lighting, and gray for areas where lighting balloons should be located.

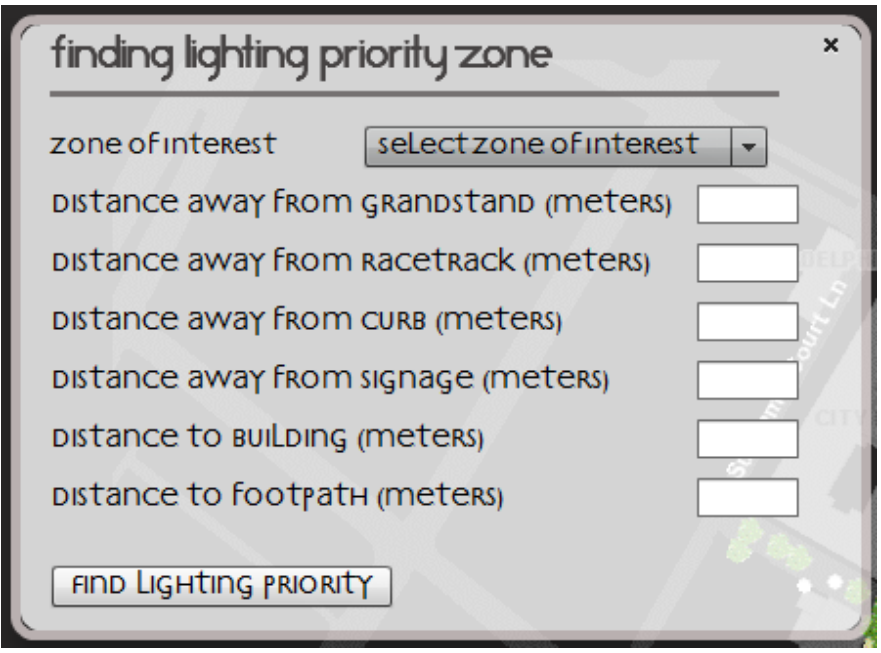

Figure 6-14: Lighting Zone Analysis Tool Interface 


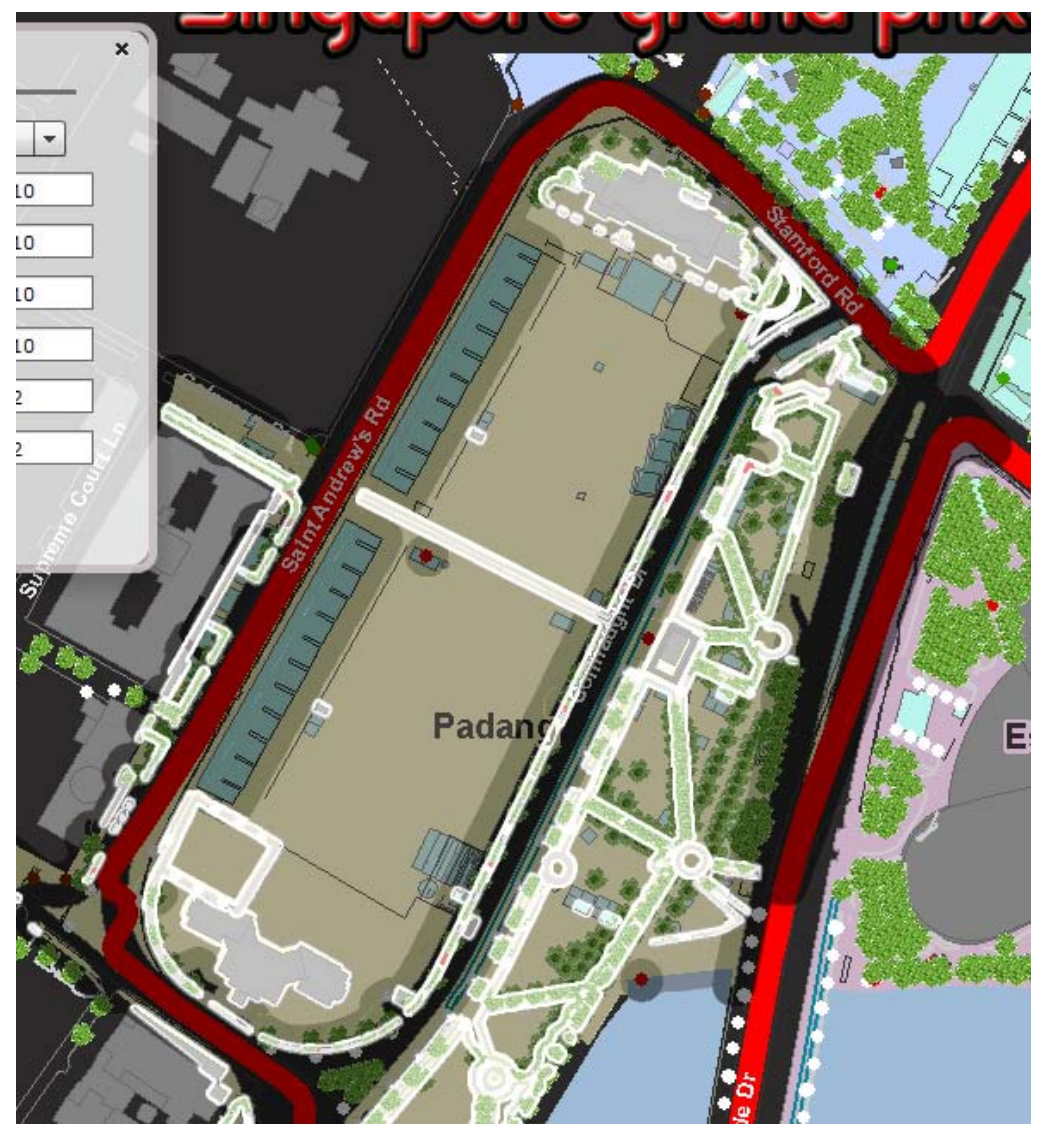

Figure 6-15: Lighting Zone Tool with the Output Result

The second analysis involved calculating the lighting coverage of placed lighting balloons within the analyzed zone of interest. Figure 6-16 shows the interface of the analysis tool. 


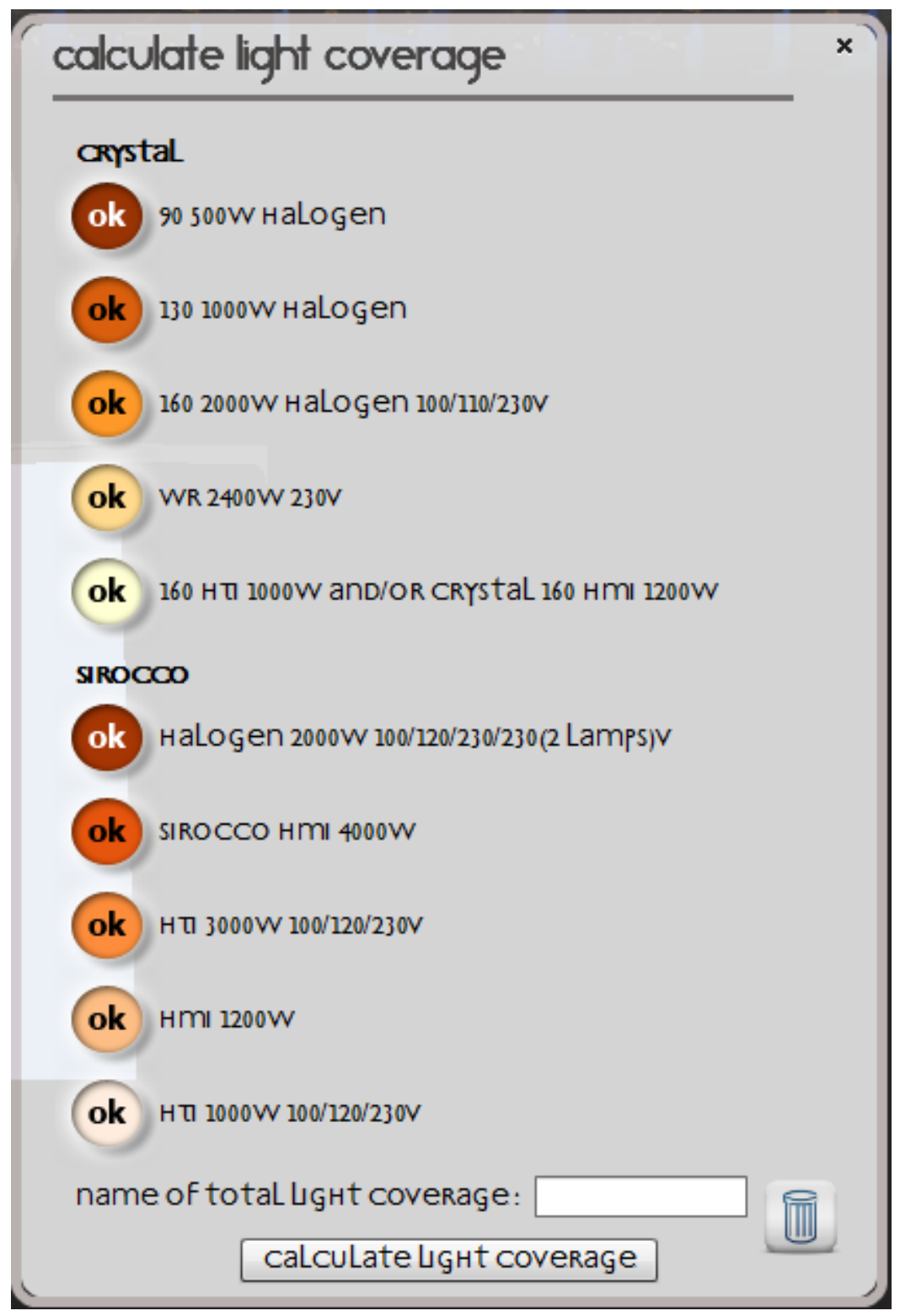

\section{Figure 6-16: Lighting Coverage Analysis Tool Interface}

There are two key lighting balloon types reflected in the tool interface: crystal and sirocco. Each type had five different models of varied lighting specification that were of interest to Partex. In order to use this tool, the user had to identify which lighting balloon models were utilized within the zone of interest. Next, the user had to click on the name of the lighting balloon model. This action activates a 'draw map point' tool that allows the user to point and click locations of lighting balloons. After clicking on the location for a lighting balloon type, the user clicked on the 'ok' graphic to trigger a geoprocessing tool that calculated the lux value of the indicated points. The user had to repeat this step for all lighting balloon types within the F1 SGP scope. At the end of each lighting balloon type geoprocessing, the geoprocessing function triggered a title window with 'Geoprocessing Complete' status instead of displaying the result raster. When the user has all the lighting balloons located and lux values calculated, the analysis tool interface 
requires the user to key in the name of the final lighting coverage result output that summed all the lux calculated by the user in the previous steps. The final step in the analysis creates a feature class with the total lighting coverage in lux, which were used as the display result in the web application. Figure 6-17 illustrates the process of going through one of the lighting balloon type geoprocessing in the tool. Here, the color of each 'ok' button corresponds with the draw point graphic.

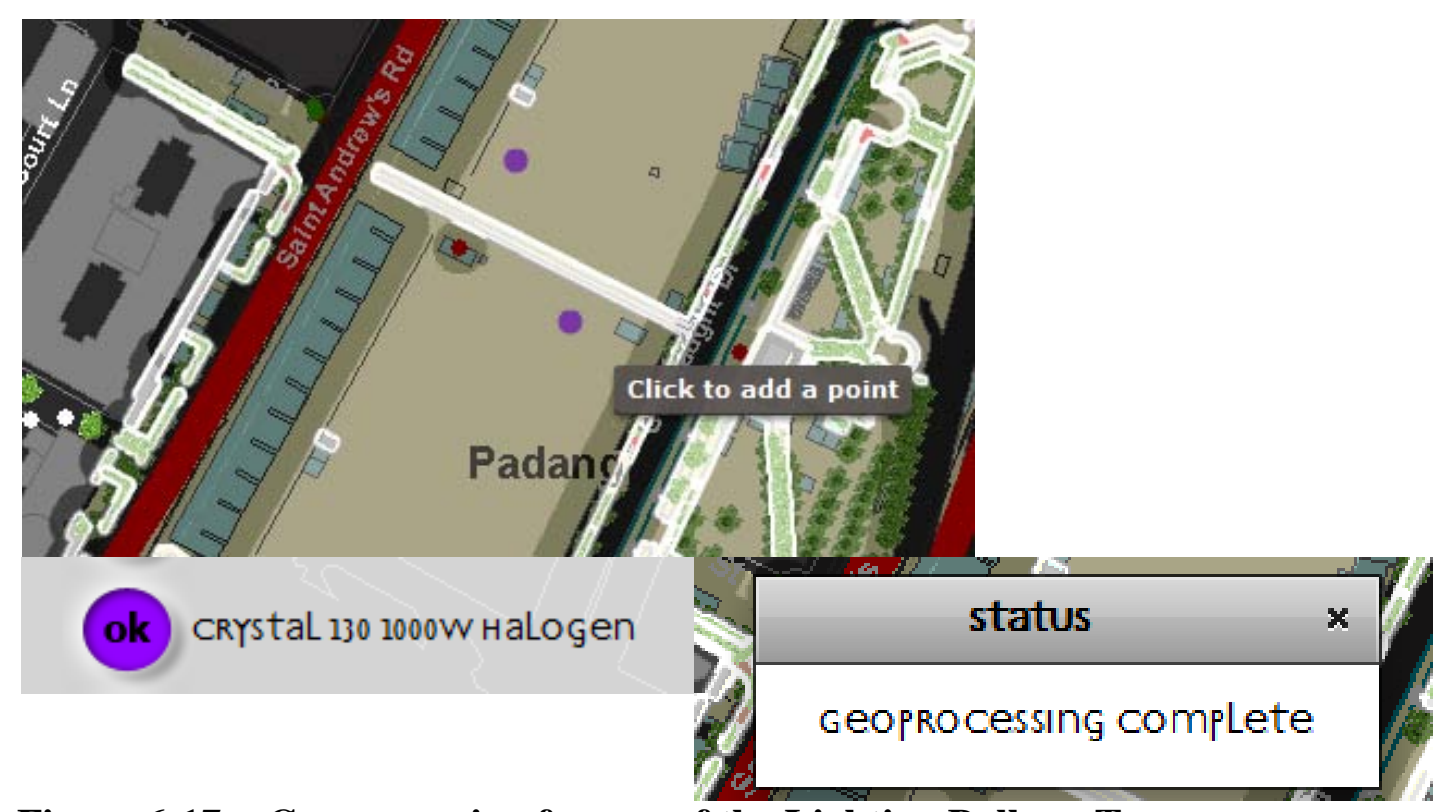

Figure 6-17: Geoprocessing for one of the Lighting Balloon Type.

At the end of the analysis, the output feature class returned the total lighting coverage in terms of lux, as shown in Figure 6-18. 


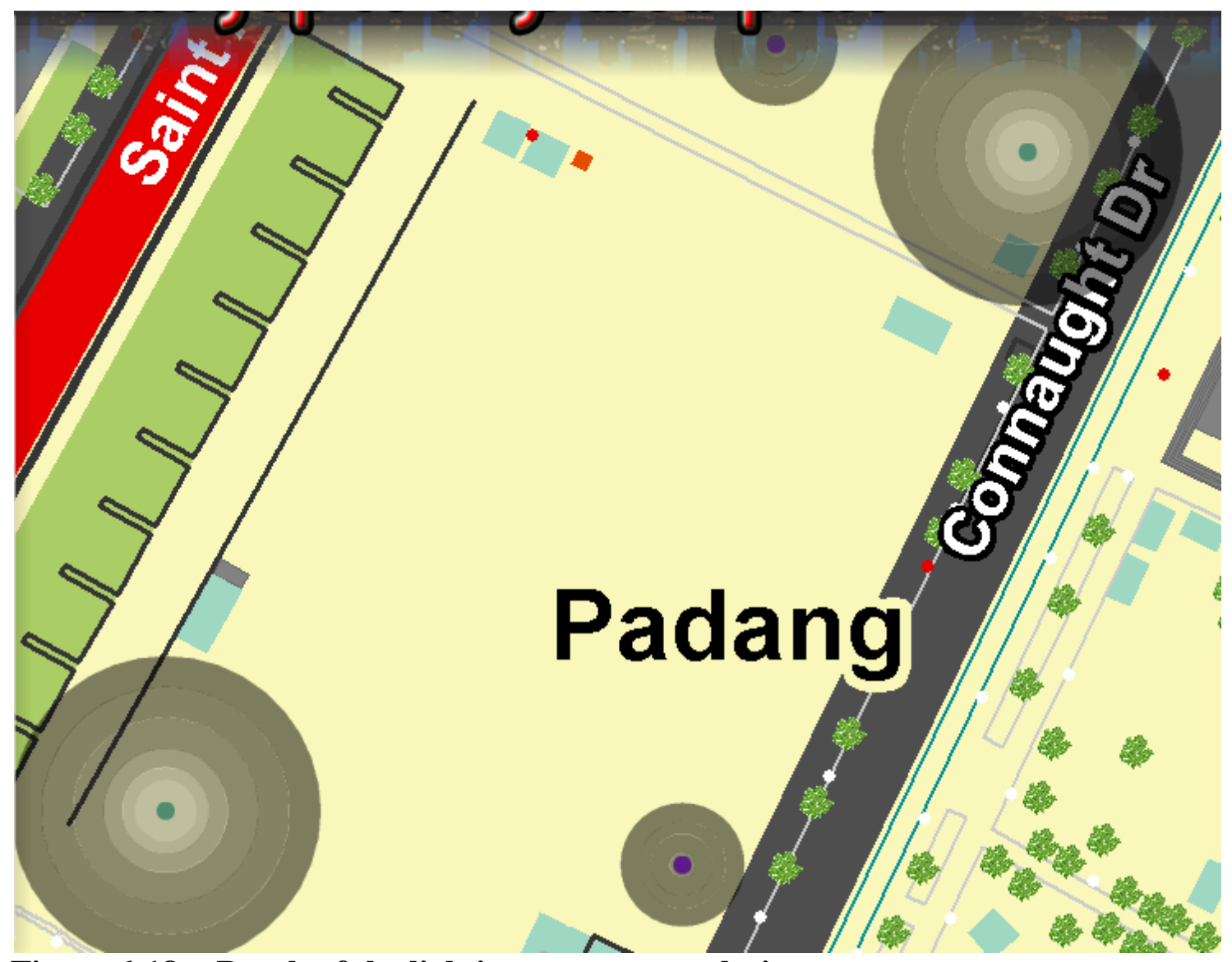

Figure 6-18: Result of the lighting coverage analysis

\subsection{Challenges}

Building the web application was a challenge for the project team as it was the first major project undertaken to build it on Flex platform. The first challenge was to create the widgets that held the key functions of the entire web application. The team was able to overcome it with tutorials and examples from online research and reading. The second challenge was to re-design the interface of default tools in Flex. After learning that the approach to re-designing a tool was to replicate and edit the initial design code, the trial and error method was used to understand the design coding and eventually to create a custom design for the web application. The final challenge also proved to be the most crucial and complicating. It was related to the second analysis for calculating the lighting coverage. The analysis created for ArcGIS desktop used the feature set data type as an input. In the desktop interface, the default feature set input allows the user to change the attributes of the input features based on an inherited schema. However, there was no simple method of assigning attribute changes within the Flex environment while using the ArcGIS 9.3.1 Server. The editing component for Flex recently implemented with the release of ArcGIS 10 only worked with the ArcGIS 10 server. This caused the project team to contemplate upgrading to ArcGIS 10 server to enable this analysis. After much consideration, research, and brainstorming, the project team came up with an alternative solution that applied the same script onto the Flex platform. The Python script was split 
among the ten key lighting balloon types and published each sub script as a geoprocessing tool. At the end, the project team took the last part of the original script apart to enable a sum of all the lux raster created. Each geoprocessing was then called in the web application separately as described in the previous section to enable the analysis of the lighting coverage.

\subsection{Summary}

At the end of creating the web application, the project team successfully implemented the intended design articulated in Chapter 3. The web application design reflected the nature of the project, which was mainly night and light themed. The project team first set out to design the layout of the web application to achieve a simple interface to hold the required tools and functionalities. Next, the project team went on to code simple yet essential tools in the web application for Partex's use: the table of contents, legend, full extent, measure, lighting zone analysis, and lighting coverage analysis tools. Each tool's functionality was captured in each of the graphics shown in the web application's tool bar. Building this web application brought about many challenges that helped the project team learn and improve skills on the Flex application. At the completion of this web application, the project reached completion in terms of delivery required as articulated in Chapter 3. The project team went on to identify potential future work to add more functionality to the project or factors to the analysis tools. The next chapter summarizes all the work done and suggests potential extensions to the project. 


\section{Chapter 7 - Conclusions and Future Work}

\subsection{Summary of Project}

The project started out with two key purposes: to provide Partex with a better situational knowledge of the SGP circuit park, and to provide a suitability analysis for lighting balloon placement within two key study areas: Padang and Esplanade. Partex needed to provide optimal lighting coverage of the SGP circuit park for three purposes: safety, aesthetics, and directional signage, which includes first aid, information booths, and gates. The event coordinators did not provide detailed information of the circuit park to Partex, on site reconnaissance was required of the staff.

Once the purpose of the project was settled, the project team moved on to define the project requirements and design. Based on the requirements analysis, the functional requirement for this project was to build up knowledge on working with CAD data, followed by producing the circuit park map, then creating analyses that provided lighting recommendation to Partex and finally to build a web application that consolidated the previous three functional requirements. The non-functional requirements were split into three categories. The technical requirement was for Partex to acquire a copy of ArcGIS server (Advanced edition) or utilize ArcGIS server services on cloud architecture. This component served to support the functionality required in the web application. The operational requirements for this project included data updates, archiving, and back-up needed to continually sustain the project and analyses. The final non-functional requirement was the transitional requirements that took place during the handing over of the project to Partex at the end of the year. The transitional requirements included the project documentation from the project team, GIS training for Partex staff, consideration for future data conversions, and a user acceptance test submitted by Partex.

Among the four highlighted requirements analyses, the most challenging was requirement to implement was the transitional requirement. It was crucial that Partex be well equipped to carry on with the application and even make improvements after the end of the project. Among the list of transitional requirements, the project team felt that the most important was staff training. Identifying adequate and appropriate training and monitoring the learning progress to ensure that the staff were able to grasp the technology and concepts behind the application were key to sustainability of the project in the long term. The next component that ensured success was the acquisition of essential software, and possibly hardware. Based on the recommended GIS server infrastructure, the domain server and ArcGIS server are on separate servers. At the same time, Partex needed to consider purchasing GIS software that fit their budget and functional requirements.

With the requirements listed out, the project team started to build the database, followed by the spatial analyses. First, the team took on a study to learn more about the native form that the data came in, and worked on converting them to GIS format and creating a functional geodatabase. This fulfilled the first functional requirement of the project. Next, the project team worked on two separate analyses that contributed to providing lighting recommendations to Partex. The first analysis calculated the zones of lighting required based on priority levels assigned. Partex provided the priority assignment levels when they indicated the places to avoid lighting, or needed lighting. Using this information, the project team created an analysis that took in all related 
features. The output of the analysis was a raster layer that highlighted areas that required lighting, that did not require lighting, and the neutral areas. The neutral areas in the project referred to areas where lighting balloons should be placed, as they did not conflict with features with lighting requirement specifications. The second analysis allowed users to indicate locations and models of lighting balloons, and to calculate the total amount of light emitted. The user is able to use the output raster to decide if the locations provided the lighting coverage required by clients and to re-analyze if the locations did not. The analysis worked with data provided by Partex discussed in Chapter 4 . Both the analyses fulfilled the requirements to provide Partex with suitability analysis for the lighting balloon placement.

After completing the analyses, the project team worked on the final component of the project: the web application. The web application was designed to follow as closely as possible to a night theme and, had simple tools that helped the user utilize the web application. The tools available were created using buttons components styled and coded to work like widgets in the web application. The tools in the web application included a table of contents, a legend, a zoom to full extent function, measure tools, and the two analyses. The availability of the web application also acted as a demonstration tool for potential and current clients. This provided a better client experience when Partex's clients are able to visualize the impact of the lighting balloons on their events. If Partex decides to take this technology further, they can consider including more variables that influence placement of each lighting balloons, and apply it into other projects.

In the process of bringing this project to completion, the project team learned a lot about project management for GIS and the importance of planning. In the midst of the learning process, the team also came up with several recommendations for Partex that could push the project to a higher level. First, the lighting charts provided by Airstar to Partex. Due to the inconsistency in some of the lux labeling and other information on the lighting chart, the team had to run through all charts with Partex to clarify it. At the same time, the lighting charts for the crystal lighting balloons were not detailed enough to provide an accurate representation of lighting coverage. The project used an inversesquare law designed for point source light to derive and estimated lux value at each distance. The project team would like to recommend Partex, through to Airstar, to have a consistent set of lighting charts for all lighting balloon models. It would also provide an easy reference for staff working on the lighting balloons. The second recommendation is for Partex to acquire the ability to access an ArcGIS server that can hold the data and web application created for them.

\subsection{Future Work}

In terms of future works, the first additional analysis that could go into the project is the viewshed analysis. An analysis could be created that calculates a buffer of five meters from each first aid and information booth, and create point feature classes on the buffer edges. Following that, the analysis could utilize the observer point tool in spatial analyst extension to calculate the best locations around each booth to place a lighting balloon. The second possible future work includes working on the second analysis to enhance its capability. There are two components to the add-on in the second analysis. First, the second analysis hardcoded its extent to the area covered by Padang and Esplanade zones. It would be very helpful if the script took the spatial extent of the zone analyzed in the 
first analysis. This ensures that the first and second analyses are linked and Partex would be able to run these analysis on more zones. The second component involves providing a reverse engineering of the second analysis. Each output provides only a raster layer with values of light coverage from various numbers of lighting balloons. The reverse engineering analysis allows the user to input a lighting coverage raster, use a point-andclick function to indicate any point of interest, and return information on the lighting balloons that are contributing to it. The third and final future work that this project could take on would be to have a way to archive and store the data and analysis results. Every time an analysis executes, or a new event location is compiled, the application would be able to archive these data. Partex can then access this information once accessible to Partex via the web application, as an enhancement. In this way, Partex could track back on work done and use it as a reference for better planning. Having these marked out as future works would see the project brought to another level altogether.

\subsection{Limitations}

Over the process of creating the web application, one limitation stood out due to lack of support on the software version. The entire web application was built on the ArcGIS 9.3.1 server. This version of the ESRI software suit did not provide support for editing attribute tables on web applications built using the flex API. Due to this limitation, the implementation of the second lighting coverage analysis was improvised so that the geoprocessing tasks could be run on the web application. The modification of the desktop script on the web application analysis took up more time as each model of lighting balloon placed had to be analyzed separately.

However, this limitation could be solved if the web application and scripting analyses were built on the ArcGIS 10 server. In ArcGIS 10, a new editing component was added to enable and support editing on attribute tables and even feature class. If the second analysis was built on the ArcGIS 10 server environment, it would take on the same analytical process as the desktop and the analysis will be executed in less steps and less time. It took an average of two minutes to run the lighting coverage analysis on the desktop. On the ArcGIS 9.3.1 server, it took a minimum of five minutes to run the same analysis with the same number of lighting balloons placed on the map. Hence, ArcGIS 10 would have provided a better solution for the lighting coverage analysis as compared to ArcGIS 9.3.1 server. 



\section{Works Cited}

Basanow, J., Neis, P., Neubauer, S., Schilling, A., \& Zipf, A. (2008). Towards 3D Spatial Data Infrastructures (3D-SDI) based on open standards - experiences, results and future issues. In P. J. Maria van Oosterom, Systems, Advances in 3D Geoinformation (pp. 65-86). Berlin, Germany: Springer Berlin Heidelberg.

Birgin, E. G., Martínez, J. M., \& Ronconi, D. P. (2005). Optimizing the packing of cylinders into a rectangular container: A nonlinear approach. European Journal of Operational Research, 160 (1), 19-33.

Brainy Quote. (n.d.). Brainy Quote. Retrieved April 2010, from Steve Jobs Quotes: http://www.brainyquote.com/quotes/authors/s/steve_jobs.html

Church, R., \& Revelle, C. (1974). The Maximal Covering Location Problem. Papers in Regional Science, 32 (1), 101-118.

Collins, C. R., \& Stephenson, K. (2003). A circle packing algorithm. Computational Geometry, 25 (3), 233-256.

Daksin, M. S. (1983). Maximum expected covering location model: Formulation, properties and heuristic solution. Transportation science, 17 (1), 48-71.

Deb, K., Pratap, A., Agarwal, S., \& Meyarivan, T. (2002). A Fast and Elitist Multiobjective Generic Algoritm: NSGA-II. IEEE Transactions on Evolutionary Computation, 6 (2), 182-197.

El-Rayes, K., \& Hyari, K. (2003). Automated DSS for Lighting Design of Nighttime Operations in Highway Construction Projects. NIST Special Publication SP (989), 135-142.

El-Rayes, K., Liu, L. Y., Soibelman, L., Hyari, K., Rebholz, E. F., Al-Kaisy, A., et al. (2003). Nighttime Construction: Evaluation of Lighting for Highway Construction Operations in Illinois. Illinois Department of Transport. Illinois: Illinois Transportation Research Center.

ESRI ArcNews Online. (2009/2010, Dec). GIS Software that gives you the Geographic Advantage. Retrieved February 18, 2010, from ESRI Brings GIS Power to the People with Mapping Web Site: http://www.esri.com/news/arcnews/winter0910articles/esri-brings.html

Fisher, P. F. (1996). Extending the Applicability of Viewsheds in Landscape Planning. PHOTOGRAMMETRIC ENGINEERING AND REMOTE SENSING, 62 (11), 1297-1302.

Formula One Adminstration Ltd. (2010). Formula 1 - The Official F1 Website. Retrieved February 25, 2010, from Formula 1 - 2010 Calender:

http://www.formula1.com/races/calendar.html

Huang, W. Q., Li, Y., Akeb, H., \& Li, C. M. (2005). Greedy Algorithms for Packing Unequal Circles Into a Rectangular Container. The Journal of the Operational Research Society, 56 (5), 539-548.

Kenneth, S. (2009). Introduction to circle packing: The theory of discrete analytic functions. BULLETIN (New Series) OF THE AMERICAN MATHEMATICAL SOCIETY, 46 (3), 511-525.

Knill, D. C., Mamassian, P., \& Kersten, D. (1997). Geometry of Shadows. JournalOptical Society of America A, 14 (12), 3216-3232. 
LLOBERA, M. (2003). Extending GIS-based visual analysis: the concept of visualscapes. International Journal of Geographical Information Science, 17 (1), 24-48.

Microsoft. (2009). Bing Customer Gallery. Retrieved February 20, 2010, from Bing Maps: http://www.microsoft.com/maps/gallery/\#industryManufacturing

Microsoft. (2009, December). Bing Maps. Retrieved February 20, 2010, from Bing Maps: http://www.bing.com/maps/

Tomlinson, R. (2007). Thinking about GIS: GIS Planning for Managers. ESRI Press.

Wang, H., Huang, W., Zhang, Q., \& Xu, D. (2002). An improved algorithm for the packing of unequal circles within a larger containing circle. European Journal of Operational Research, 144 (2), 440-453.

Wikipedia, the free encyclopedia. (2010, October 21). Inverse-square law. Retrieved October 2010, from Wikipedia, the free encyclopedia: http://en.wikipedia.org/wiki/Inverse-square_law

Zlatanova, S., Rahman, A. A., \& Pilouk, M. (2002). Trends in 3D GIS Development. Journal of Geospatial Engineering, 4 (2), 71-80. 


\section{Appendix A. Data Scrubbing documentation}

\begin{tabular}{|c|c|c|c|c|c|c|}
\hline & GIS Layer & Polyline & Polygon & Points & Description & Layer \\
\hline & & 01 Layer & 01 Layer & 01 Layer & & \\
\hline 1 & Building & Bldg Line & Bldg Lines & & Part Of Details & Base \\
\hline 2 & Building & Bldg Lines & Bldg Lines & & Building Outline & Base \\
\hline 3 & Utility & Drain & Drain Cover & Drain & Drainage & Base \\
\hline 4 & Utility & Drain Cover & Drains Lines & & Drainage & Base \\
\hline 5 & Utility & Drains & & & Drainage & Base \\
\hline 6 & Building & Flyer & Flyer & Flyer & SG Flyer & Base \\
\hline 7 & Road & Flyover & & & Road Flyovers & Base \\
\hline 8 & Footpath & Footpath & Footpath & & Footpath & Base \\
\hline 9 & Road Furniture & & & Lamppost & Lamp Post & Base \\
\hline 10 & Building & Ndp 01 & Ndp & Ndp & NDP Site (Point Is Out Of Alignment) & Base \\
\hline 11 & Road & Road Edge & Road Edge & Roadedge & Kerb Line & Base \\
\hline 12 & Road & Roadline & Road Lines & & Same As Road Edge & Base \\
\hline 13 & Road Furniture & & & STH 5901 & Lampost & Base \\
\hline 14 & Utility & Ten & Ten & Ten & $\begin{array}{l}\text { Points At The Tip Of Event Site Looks Like } \\
\text { Drains (Y Are They Not With Drain Layer, } \\
\text { Anything Special About These Layers?) }\end{array}$ & Base \\
\hline 15 & Road Furniture & Twentyone & Twenty One & Twentyone & Looks Like Trees & Base \\
\hline 16 & Road & Two & & & Looks Like Kerb Lines At The Tip Of Event Site & Base \\
\hline 17 & Building & & & Text & $\begin{array}{l}\text { Something At The Open Theatre At The } \\
\text { Esplanade }\end{array}$ & Base \\
\hline 18 & Road Furniture & Tree & & & Trees & Base \\
\hline 19 & Road Furniture & & Tree 2 & Tree Points & Trees & Base \\
\hline 20 & Road Furniture & & Trees & Trees & Trees & Base \\
\hline
\end{tabular}




\begin{tabular}{|c|c|c|c|c|c|c|}
\hline 21 & Utility & F1 topo & & & Drains And Some Lines Near The Pitbuilding & \\
\hline 22 & Road Furniture & Symbols & & Symbols & $\begin{array}{l}\text { Bus Stop, Elect Box, Flag Staff, Gas Indicator, } \\
\text { Gas Valve, Hydrant, Pics, Pmhp, Pmhs, Road } \\
\text { Sign, Signboard, Single Circle, Survey Camera, } \\
\text { Telepole, Traffic Light, Traffic Sign, Water } \\
\text { Valve, Survey Stuff }\end{array}$ & \\
\hline 23 & Utility & Ug Drain & & & Underground Drains & Base \\
\hline 24 & Fence & Ex Fence & & & Fence Lines With Gates & SGP \\
\hline 25 & Misc & Five & & & Unknown Boxes Around The Tip Of Event Site & SGP \\
\hline 26 & Fence & Hoarding & & & Looks Like Gates To Something & SGP \\
\hline 27 & & Range_5091 01 & Circle 5091 & & $\begin{array}{l}\text { Line Of CIRCLE_5901, Boxes, Features That } \\
\text { Look Like Wavelength And Lights }\end{array}$ & SGP \\
\hline 28 & & Temp & Temp & & Temp Stuff & SGP \\
\hline 29 & Road & Temp Kerb & & Tempkerb & Temporary Kerb & SGP \\
\hline 30 & Misc & Twentytwo & & & $\begin{array}{l}\text { Lines At The Tip Of Event Site Looks Like } \\
\text { Wavelength (Not Sure What They Are For) }\end{array}$ & SGP \\
\hline 31 & Fence & Conc Barrier & Conc Barrier & Concbarrier & Concrete Barriers & SGP \\
\hline 32 & Media & Camera & Camera & Camera & TV Cameras & SGP \\
\hline 33 & Race Track & Driveline & Driveline & Driveline & Route That Race Drivers Will Take & SGP \\
\hline 34 & Race Track & F1 Start Lights & F1 Start Lights & & Starting Point Overhead For Race & SGP \\
\hline 35 & $\begin{array}{l}\text { Building And } \\
\text { Fence }\end{array}$ & Fixtures & Fixtures & Fixtures & $\begin{array}{l}1 \text { Pitbuilding, 24 Connectors Between Concrete } \\
\text { Barriers At Specific Turn Points, } 2 \text { Unknown } \\
\text { Items }\end{array}$ & SGP \\
\hline 36 & Misc & F1 Turn Num & F1 Turn Num & F1 Turn Num & $\begin{array}{l}\text { Points Where There Is A Turn Along The Race } \\
\text { Track }\end{array}$ & SGP \\
\hline 37 & Fence & F1 Wall Temp & & F1 Wall Temp & $\begin{array}{l}1 \text { Connecting Wall Between An Opening From } \\
\text { The Concrete Barriers }\end{array}$ & SGP \\
\hline 38 & Fence & Gate & Gate & Gate & Only 1 Gate & SGP \\
\hline 39 & Grandstand & Grandstand & Grandstand & & Grandstand & SGP \\
\hline
\end{tabular}




\begin{tabular}{|c|c|c|c|c|c|c|}
\hline 40 & Road & Kerbing & Kerbing & & $\begin{array}{l}\text { Kerbs Sporadically Placed Around The } \\
\text { Boundaries Of Race Track }\end{array}$ & SGP \\
\hline 41 & Lights & None & None & & Part Of The F1 Start Lights Features & SGP \\
\hline 42 & Fence & Spectator Fence & & & Spectator Fencing & SGP \\
\hline 43 & SGP Road & Overpass & Overpass & Overpass & Overhead Bridges Setup For The Event & SGP \\
\hline 44 & Race Track & $\begin{array}{l}\text { Track } \\
\text { Alignment } \\
\text { Linemarking }\end{array}$ & & $\begin{array}{l}\text { Trackalign } \\
\text { Linemarking }\end{array}$ & $\begin{array}{l}\text { Line Markings Before Start Line (Is That The } \\
\text { Alignment For Each Cars' Starting Position?) }\end{array}$ & SGP \\
\hline 45 & Race Track & Trackcentreline & Track Centreline & & Centre Line Along Track & SGP \\
\hline 46 & Race Track & Trackedge & & & Edge Of The Race Track & SGP \\
\hline 47 & Race Track & $\begin{array}{l}\text { Trackedge } \\
\text { Pitlane Warning }\end{array}$ & & & $\begin{array}{l}\text { Lines Along The Front Of The Pit Building } \\
\text { (What Are They For?) }\end{array}$ & SGP \\
\hline 48 & Misc & Vehicles & & VEHICLES & Race Cars On Display & SGP \\
\hline 49 & Media & Camera & Camera & Camera & Position Of TV Camera & SGP \\
\hline 50 & & Boundary2008 & & & 2008 Event Boundary & SGP \\
\hline 51 & Fence & Decfnce & Decfnce & & Decorative Fence & SGP \\
\hline 52 & Grandstand & $\begin{array}{l}\text { Commentator } \\
\text { Grandstand }\end{array}$ & & $\begin{array}{l}\text { Commentator } \\
\text { Text }\end{array}$ & Commentator's Grandstand & SGP \\
\hline 53 & & Compound 07 & Compound 07 & Compound 07 & A Box Next To The Pit Building & SGP \\
\hline 54 & & & & EMAC & Random Points & SGP \\
\hline 55 & Fence & E Fence & & E Fence & Gates/Fences Around Pitbuilding & SGP \\
\hline 56 & Fence & Gate & Gate & Gate & Gates & SGP \\
\hline 57 & Details & Fnb & Fnb & Fnb & FOA Turnstiles At Pit Building (What Is It For?) & SGP \\
\hline 58 & Fence & Fom & Fom & & $\begin{array}{l}\text { Looks Like A Turnstile At The FOM Supplies } \\
\text { Area (??) }\end{array}$ & SGP \\
\hline 59 & Fence & Fs18wafnce & Fs18wafnce & & $\begin{array}{l}\text { Fences (But What Are The Difference Between } \\
\text { The } 3 \text { Fence Numbering) }\end{array}$ & SGP \\
\hline 60 & Fence & Fs24fnce & Fs24fnce & Fs24fnce & $\begin{array}{l}\text { Fences (But What Are The Difference Between } \\
\text { The } 3 \text { Fence Numbering) }\end{array}$ & SGP \\
\hline
\end{tabular}




\begin{tabular}{|c|c|c|c|c|c|c|}
\hline 61 & Fence & Fs3fnce & & & $\begin{array}{l}\text { Fences (But What Are The Difference Between } \\
\text { The } 3 \text { Fence Numbering) }\end{array}$ & SGP \\
\hline 62 & Grandstand & Grandstand & Grandstand & Grandstand & General Grandstand & SGP \\
\hline 63 & Cars, Utility & & & M STUFF & $\begin{array}{l}\text { Toyota Camry, Pumps And SANI Behind The } \\
\text { Commentators Grandstand }\end{array}$ & SGP \\
\hline 64 & Cars, Utility & M_Dwat & M Dwat & & $\begin{array}{l}\text { Toyota Camry, Pumps And SANI Behind The } \\
\text { Commentators Grandstand }\end{array}$ & SGP \\
\hline 65 & & Magri & Magri & & $\begin{array}{l}\text { Group Of Structure Behind Grandstand That Is } \\
\text { Next To Pitbuilding ( What Are They?) }\end{array}$ & SGP \\
\hline 66 & & Inv Num & & & Lines That Surrond The Event Area & SGP \\
\hline 67 & Building & Medical Centre & Medical Centre & Medical Centre & First Aid Centre & SGP \\
\hline 68 & & Perimeter & Perimeter & & $\begin{array}{l}\text { Perimeter Of Event Along Coast Line And Other } \\
\text { Block Items }\end{array}$ & SGP \\
\hline 69 & Details & Protrak & Protrak & & $\begin{array}{l}3 \text { Items That Look Like Bee Hive Along Coast } \\
\text { Opp Pit Building }\end{array}$ & SGP \\
\hline 70 & Media & Satellites & Satellites & & TV Satellites & SGP \\
\hline 71 & Building & Scdf Spf & Scdf Spf & Scdf Spf & SCDF And SPF Booths & SGP \\
\hline 72 & Details & Screen & Screens & Screens & Live Broadcast Screens & SGP \\
\hline 73 & Signage & Signage & & Signage & $\begin{array}{l}\text { Signages Around The Event Area (What Do } \\
\text { They Show?) }\end{array}$ & SGP \\
\hline 74 & Fence & Sl24fnce & & & $\begin{array}{l}\text { Random Fences Along Event Area ( Is There A } \\
\text { Way To Better Define Them?) }\end{array}$ & SGP \\
\hline 75 & Fence & Sl3fnce & & & Fence Along The Back Of Pitbuilding & SGP \\
\hline 76 & Fence & Spectator Fence & & & Sepctator Fence & SGP \\
\hline 77 & Grandstand & Stairs & & & Stairs To Grandstands At The Padang Area & SGP \\
\hline 78 & Details & Toilets & Toilets Single & Toilets & Toilets & SGP \\
\hline 79 & Media & Tv Compound & Tv Compound & Tv_Compound & Turnstile Entrance Into TV Compounds & SGP \\
\hline 80 & & Base & Base & & $\begin{array}{l}\text { Squre Base (With Circle In Them) At The } \\
\text { Southern Tip Of Sg Flyer (Do You Know What }\end{array}$ & \\
\hline
\end{tabular}




\begin{tabular}{|c|c|c|c|c|c|}
\hline & & & & & They Are?) \\
\hline 81 & Misc & Demo & & & Unknown \\
\hline 82 & Misc & Detail & Details & Details & Details (Need More Clarification) \\
\hline 83 & Misc & Details & Details Lines & Details Points & Details (Need More Clarification) \\
\hline 84 & Race Track & & & Driveway & Points On The Pitbuilding \\
\hline 85 & & Fifteen & & & $\begin{array}{l}\text { Lines At The Tip Of Event Site (Not Sure What } \\
\text { They Are For) }\end{array}$ \\
\hline 86 & Road BL & Four & & & $\begin{array}{l}\text { Lines At The Tip Of Event Site (Not Sure What } \\
\text { They Are For) }\end{array}$ \\
\hline 87 & & Fp Lines & & & $\begin{array}{l}2 \text { Lines Opposite The Esplanade; In Front Of } \\
\text { Marina Sq (Joined With Details 01) }\end{array}$ \\
\hline 88 & & Ground Points & & Ground Points & Not Sure \\
\hline 89 & & Icn 01 & Icn & & Blocks Of Things Around The Flyer Building \\
\hline 90 & Utility & $\operatorname{Ig} 01$ & & Ig Points & $\begin{array}{l}\text { Seems Like Drain Covers Along The Pitbuilding } \\
\text { (Why Labelled Differently?) }\end{array}$ \\
\hline 91 & Utility & None 01 & & & Links To Various Line Features \\
\hline 92 & & Perimeter 01 & Perimeter & Perimeter & Not Sure \\
\hline 93 & Utility & Pipeline Point & Pipeline Pt & Pipeline Point & Pipeline Point \\
\hline 94 & Details & Seventeen & Seventeen & Seventeen & $\begin{array}{l}\text { Points In A Line Above The Race Tracks, But } \\
\text { Not Sure What They Are }\end{array}$ \\
\hline 95 & Road Furniture & Sym Pts & & Symbol Points & $\begin{array}{l}\text { PMHT (??), SIGNPOSTS, LAMPOST, WATER } \\
\text { VAVLE }\end{array}$ \\
\hline 96 & & Thirtythree & Thirtythree & Thirtythree & $\begin{array}{l}\text { Points At The Tip Of Event Site Looks Like } \\
\text { Lights (Are They Lighting Balloons?) }\end{array}$ \\
\hline 97 & & Twenty & Twenty & Twenty & $\begin{array}{l}\text { Points At The Tip Of Event Site (Not Sure What } \\
\text { They Are For) }\end{array}$ \\
\hline 98 & & Vport & Vport & & Circles Along The Tip Of Event Site \\
\hline 99 & Misc & Marshall & Marshall & Marshall & $\begin{array}{l}\text { Not Sure (Positions Where The Marshall } \\
\text { Volunteers Are Located? What Do They Do?) }\end{array}$ \\
\hline
\end{tabular}




\begin{tabular}{|c|c|c|c|c|c|}
\hline 100 & Utility & Mbb & & Mbb Drain & Drain (I Think) \\
\hline 101 & Utility & & & Mbblevel35 & Drain (I Think) \\
\hline 102 & Fence & Rumble Bars & & Rumble Bars & $\begin{array}{l}\text { Something Positioned Outside Each Turns On } \\
\text { The Track }\end{array}$ \\
\hline 103 & Fence & Tec Gry & Tec Gry & Tec Gry & $\begin{array}{l}\text { Some Kind Of Barrier Used On Outer Scope Of } \\
\text { Race Track }\end{array}$ \\
\hline 104 & Fence & Tec Red & Tec Red & Tec Red & $\begin{array}{l}\text { Some Kind Of Barrier Used On Outer Scope Of } \\
\text { Race Track }\end{array}$ \\
\hline 105 & Signage & Barrier Signage & & & Signs For Barriers?? What Does It Have? \\
\hline 106 & Building & Building2 & Building2 & & Building Outline \\
\hline 107 & Car & & CAR & Car & $\begin{array}{l}\text { Cars (For Display Or Parking Of Actual Race } \\
\text { Cars?) }\end{array}$ \\
\hline 108 & Building & Container & Container & Container & $\begin{array}{l}\text { Containers Around The Event Area (Do You } \\
\text { Recall Any Containers During The } 2009 \text { Event?) }\end{array}$ \\
\hline 109 & Grandstand & $\begin{array}{l}\text { Deleted } \\
\text { Grandstand }\end{array}$ & $\begin{array}{l}\text { Deleted } \\
\text { Grandstand }\end{array}$ & $\begin{array}{l}\begin{array}{l}\text { Deleted } \\
\text { grandstand }\end{array} \\
\end{array}$ & $\begin{array}{l}\text { Features Does Not Look Like Grandstands } \\
\text { (Does It Refer To Any Deleted Structure?) }\end{array}$ \\
\hline 110 & Utility & Drains & Drains & & Drains \\
\hline 111 & Cars & Cat & & & $\begin{array}{l}\text { Cars (For Display Or Parking Of Actual Race } \\
\text { Cars?) }\end{array}$ \\
\hline 112 & Details & $\begin{array}{l}\text { Circulation } \\
\text { Arrows }\end{array}$ & $\begin{array}{l}\text { Circulation } \\
\text { Arrows }\end{array}$ & $\begin{array}{l}\text { Circulation } \\
\text { Arrows }\end{array}$ & $\begin{array}{l}\text { Arrows Opposite Pit Building (What Are They } \\
\text { For?) }\end{array}$ \\
\hline 113 & Building & Cold Room & Cold Room & Coldroomtext & ?? \\
\hline 114 & & Dummies & Dummies & Dummies & $\begin{array}{l}\text { Dummy Structures Near SCDF SPF Spot At The } \\
\text { SG Flyer (What Are They Actually?) }\end{array}$ \\
\hline 115 & & Escape Line & & & ?? \\
\hline 116 & Building & Fixtures & Fixtures & & $\begin{array}{l}\text { Some Structure In The Pit Building (What Do } \\
\text { They Represent?) }\end{array}$ \\
\hline 117 & Details & Gen & Gen & Gen & $\begin{array}{l}\text { Rectangular Boxes, } 3 \text { Behind Cars At Flyer, } 2 \\
\text { Next To Pit Building (Are They Generators?) }\end{array}$ \\
\hline
\end{tabular}




\begin{tabular}{|c|c|c|c|c|c|}
\hline 118 & Details & Fom Supplied & Fom Supplied & Fom Supplied & $\begin{array}{l}\text { Some Kind Of Square Supplies At The Pit } \\
\text { Building (Includes } 2 \text { Light Towers) (What Are } \\
\text { They?) }\end{array}$ \\
\hline 119 & & Furn & Furn & Furn & $\begin{array}{l}\text { Round Things That Look Like Lights Spaced } \\
\text { Out Around The Event Area (??) }\end{array}$ \\
\hline 120 & & Marquee & Marquee & Marquee & Any Idea? \\
\hline 121 & Building & New & New & New & New Offices? \\
\hline 122 & Fence & Mshfnce & & & $\begin{array}{l}\text { Decorative Fence Near The Bitbuidling, Padang } \\
\text { And Raffles City (Do You Know The Diff } \\
\text { Between This And Other Fences?) }\end{array}$ \\
\hline 123 & Media & Nbc Container & & Nbc Container & Container For NBC Channel Broadcast? \\
\hline 124 & Roads & New Roads & New Roads & Newroads & $\begin{array}{l}\text { New Roads (As In Newly Paved Or Newly } \\
\text { Built?) }\end{array}$ \\
\hline 125 & & None & None & & Randoms Items To Be Identified Later \\
\hline 126 & Building & Office & Office & Office & Office For ?? \\
\hline 127 & & Symbol Points & & Symbol Points & Water Value/Lampost \\
\hline 128 & Fence & Seat & & & Suspect Is Concret Slabs Used For Seating \\
\hline 129 & Utility & Sewip & Sewip & & Sewages \\
\hline 130 & Details & Structure & Structure & Structure & Structures But Not Sure What They Represent \\
\hline 131 & & Survey & Survey & & 3 Points \\
\hline 132 & Details & $\mathrm{T} 25$ & $\mathrm{~T} 25$ & & $\begin{array}{l}\text { Polygons Always Found Next To 'Structure' } \\
\text { Layer Features }\end{array}$ \\
\hline 133 & Grandstand & $\begin{array}{l}\text { Vomitory } \\
\text { Assembley }\end{array}$ & & & Looks Like Stairs To Commentator Grandstand \\
\hline 134 & Roads/Footpath & Walkway & & & $\begin{array}{l}\text { Along } 3 \text { Newroads Layer (But } 2 \text { Pairs Of } \\
\text { Walkway Are Not On Roads... Weird?) }\end{array}$ \\
\hline 135 & Roads & Temp Roads & & & $\begin{array}{l}\text { Temp Roads End Of Pit Building And End Of } \\
\text { Event Area }\end{array}$ \\
\hline 136 & Buildings & Xref & Xref & Xref & Buildings Near The Pit Building \\
\hline
\end{tabular}




\section{Appendix B. Lighting Priority Analysis Model Builder}

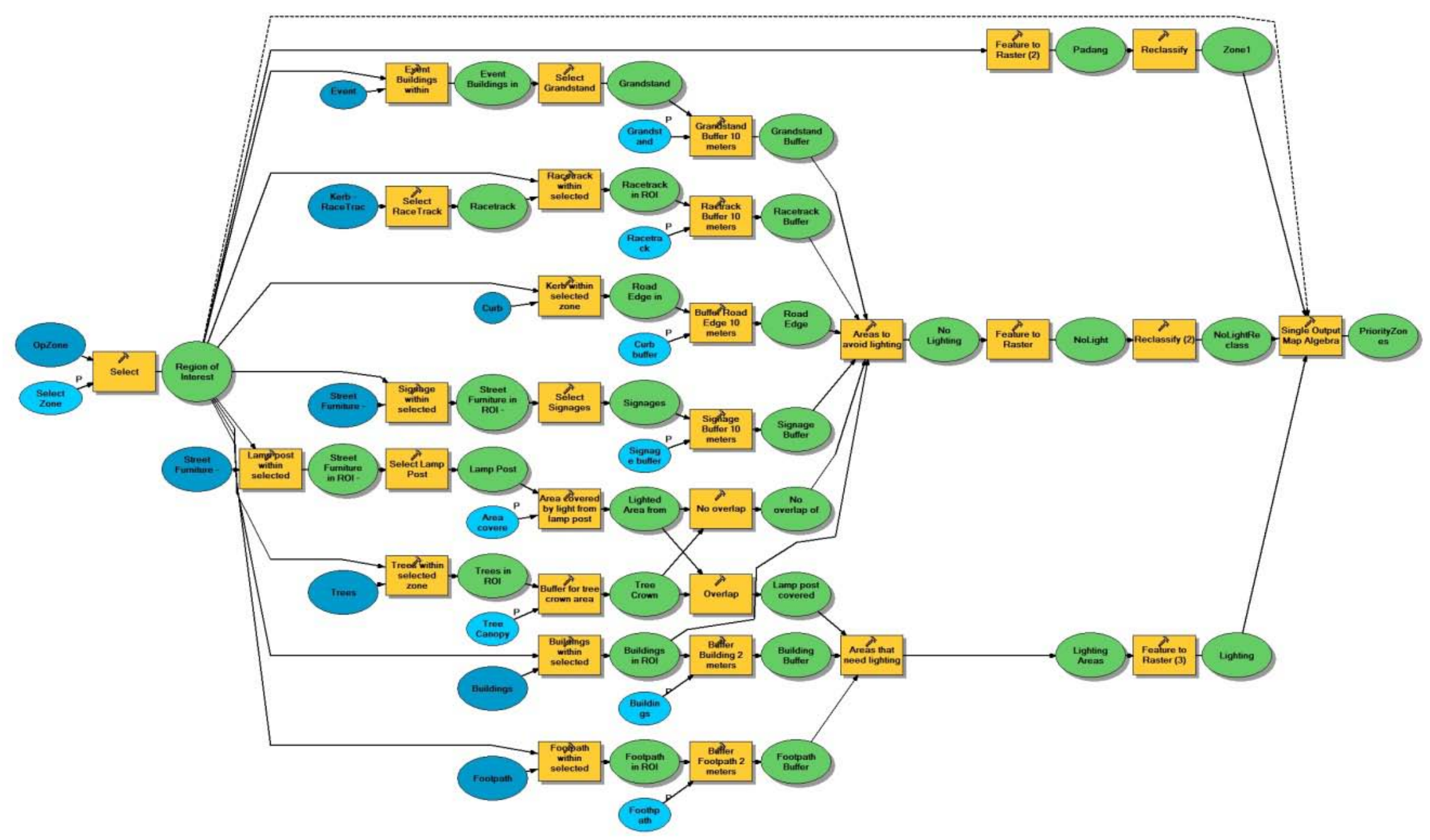

